\title{
Naturally Fractured
}

\section{Tight Gas Reservoir}

\section{Detection Optimization}

Prepared for

Advanced Resources International

by:

Subcontractor:

Laboratory for Computational Geochemistry

Indiana University

Principal Investigator:

Peter J. Ortoleva

Co-Principal Investigator:

John B. Comer 


\section{DISCLAIMER}

This report was prepared as an account of work sponsored by an agency of the United States Government. Neither the United States Government nor any agency thereof, nor any of their employees, make any warranty, express or implied, or assumes any legal liability or responsibility for the accuracy, completeness, or usefulness of any information, apparatus, product, or process disclosed, or represents that its use would not infringe privately owned rights. Reference herein to any specific commercial product, process, or service by trade name, trademark, manufacturer, or otherwise does not necessarily constitute or imply its endorsement, recommendation, or favoring by the United States Government or any agency thereof. The views and opinions of authors expressed herein do not necessarily state or reflect those of the United States Government or any agency thereof. 


\section{DISCLAIMER}

Portions of this document may be illegible in electronic image products. Images are produced from the best available original document. 


\section{Report Prepared By}

John B. Comer

J. Miles Maxwell

Peter Ortoleva

Anthony Park

Dorothy Payne

Walid Sibo 


\section{Contents}

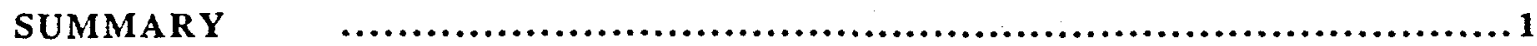

WORK PLAN FOR LAST SIX MONTHS OF PROJECT..........................5

\section{APPENDIX A GEOLOGICAL HISTORY DATA FOR SIMULATING THE PICEANCE BASIN AND ITS NATURALLY FRACTURED RESERVOIRS}

I GEOLOGICAL OVERVIEW. 1

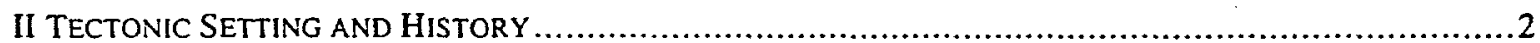

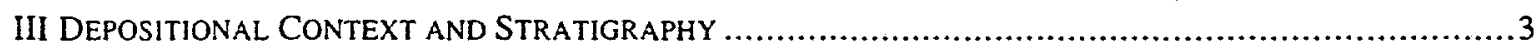

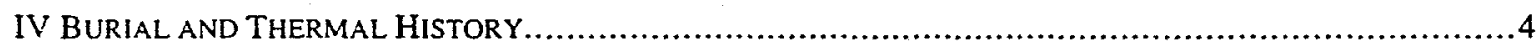

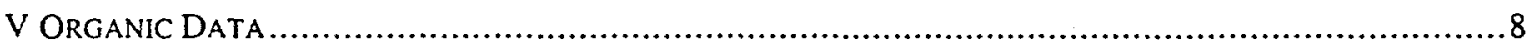

APPENDIX B AUTOMATED THREE DIMENSIONAL RECONSTRUCTION OF SEDIMENT GEOMETRY AND HISTORY

ABSTRACT. 1

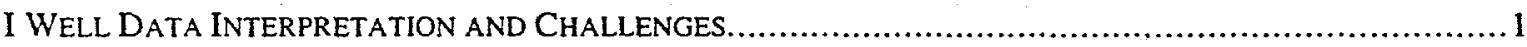

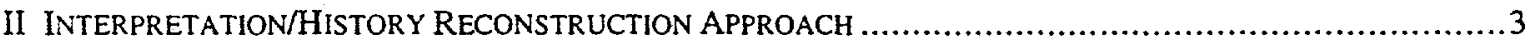

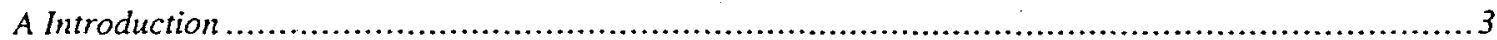

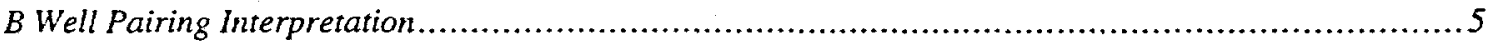

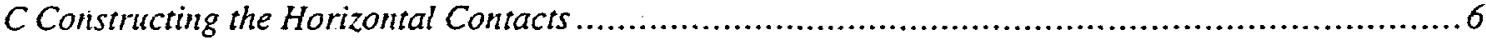

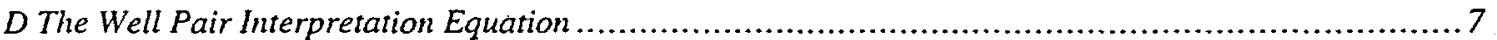

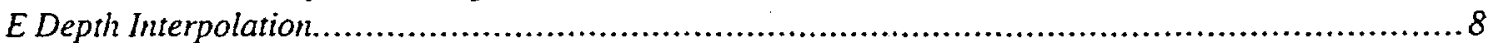

F Upward and Downward Extensin of Individual Well File .....................................................9

1 Upward/Downward Neighbor, Corrlated Extrapolation............................................................. 10

2 Earliest Time Surface Smoothing and Well Readjustment............................................... 10

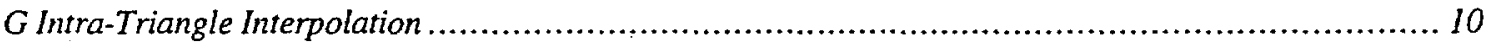

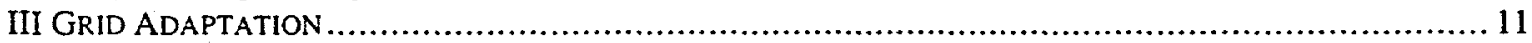

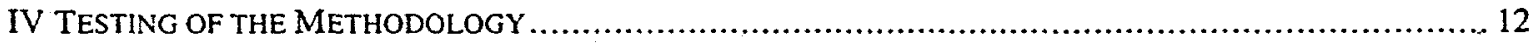

APPENDIX C EXTENDED MODELING DOMAIN FOR FRACTURE PREDICTION IN THE PICEANCE BASIN

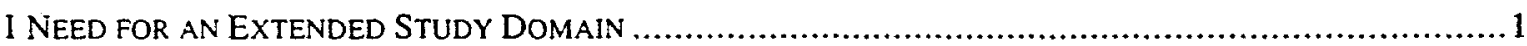

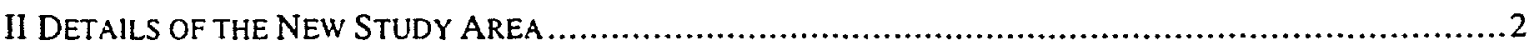

APPENDIX D FLUID PRESSURE DATA AND COMPARTMENTATION

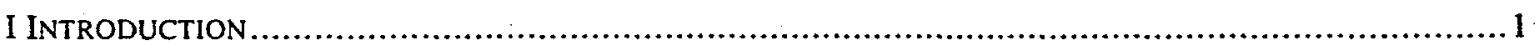

II REANALYSiS of Limited DATA SET: PRESSURE COMPARTMENT IN THE SOUTHERN HALF OF THE BASIN. 1 III PRESSURE COMPARTMENTATION ACCORDING TO THE TBEG DATA SET: MOSAIC

COMPARTMENTATION.

\section{APPENDIX E PRELIMINARY PICEANCE BASIN SIMULATION}

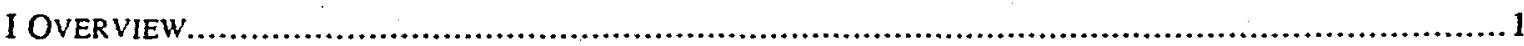

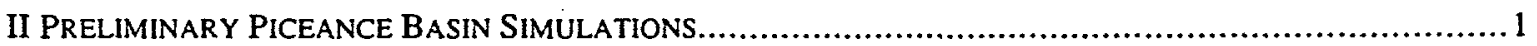

III EFFECT OF LITHOLOGIC VARIATION ON COMPARTMENTATION. .............................................

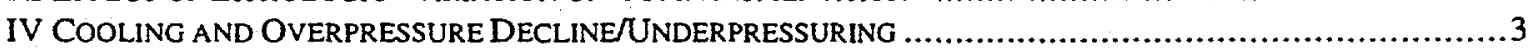

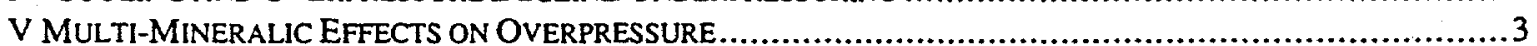




\section{Summary}

The focus of this year was on preparing data and modules for Piceance Basin-wide fracture prediction. A review of the geological data input and automated history reconstruction approach was made. Fluid pressure data analysis and preliminary basin simulations were carried out. These activities are summarized briefly below and reviewed in more detail in Appendices A-E. Appendix D is a review of the fluid pressure data and its implications for compartmentation. Preliminary fracture prediction computations on generic basins are presented in Appendix E; these were carried out as part of our code testing activities. The results of these two Appendices are the beginning of what will be the basis of the model testing; fluid pressures are directly comparable with the model predictions and are a key element of fracture nucleation and preservation.

We summarize the tectonic and sedimentary history of the Piceance Basin based on our automated history reconstruction and published interpretations. The narrative and figures provide the basic material we have quantified for our CIRF.B basin simulator input. This data supplements our existing well data interpretation approach (see below). It provides an independent check of the automated sedimentary/subsidence history reconstruction module.

Fluid pressure data was gathered and analyzed. This data serves two functions. Fluid pressure distribution across the basin provides a quantitative test as it is a direct prediction of CIRF.B. Furthermore, fluid pressure modifies effective stress. It thereby enters fracture nucleation criteria and fracture extension rate and aperture laws. The pressure data is presented in Appendix $D$ in terms of overpressure maps and isosurfaces.

The overpressure analysis shows an interesting mosaic character of under- and overpressured zones in the basin. The mosaic of abnormally pressured zones suggests a corresponding pattern of compartments and seals. These results, based on data screened by the TBEG, are in contrast to larger, more continuous zones of over- and under-pressure 
predicted from a more limited data set. This points out the dangers in using limited data sets or data sets which contain unreliable pressures in defining the compartmentation or fracture sweet spot characteristics of a basin.

Sedimentary history is a key element of our CIRF.B basin modeling approach. It provides the history of overburden and thereby affects the history of the distribution of stress within the basin. Sedimentary history also provides the history of the input of sediment mineralogy and texture. These affect the later distribution of rock rheologic properties and rock strength/fracture criteria. This history also affects the history of the distribution of rock properties as the latter depend not only on the stress, pressure and temperature history but also on initial sediment porosity, mineralogy, grain size and other textural information.

The importance of a good sedimentary history data set and the typical sparseness of the sedimentation data requires that we take great care to develop an algorithm and computer module to create this history. Our efforts have, we believe, led to the development of an important advance in three dimensional sedimentary history reconstruction and interpretation. As described in Appendix B, our sediment history reconstruction module takes well data, such as lithologies and ages, and interpolates, extrapolates and interprets the rate and character of sediment input at all points in map view for all times from the inception of the basin to the present. Wells may be at any location (not necessarily regularly spaced) and may have data of a range of completeness that varies from well to well. The approach is completely automated so that as new wells become available, the history reconstruction becomes more accurately resolved spatially. The approach preserves sharply defined contacts and gradual textural changes within a given unit, and incorporates various aspects of sedimentological principles by looking forward and backward in age as part of the interpolation in space. Many of the details of our approach are presented in Appendix B. 
The benefits of extending our simulation domain to the whole Piceance Basin are noted in Appendix C. Earlier in this project, limited well data availability required that the simulation domain be restricted to the southern half of the basin However, the strong stress interaction between the northern and southern halves of the basin makes such an approach likely to be vulnerable to great uncertainty. New pressure, tectonic, well log and other data have made a full basin simulation feasible. The general philosophy of choosing the best simulation domain is discussed in Appendix C. It is seen that the choice of the domain is a compromise between the accuracy improvement upon taking a larger domain size and the practical limitations of data availability.

Code development and calibration (verification) for the mechanical and multi-phase modules should be completed by next quarter. Delays have been due to the unforeseen difficulties caused by the budget reduction from that originally proposed.

Several technology transfer activities were performed:

- a paper and booth presentation were given at the 1996 Annual AAPG meeting;

- two papers on this project were accepted for presentation at the 1997 Annual AAPG meeting;

- a booth will be set up at the 1997 Annual AAPG meeting to illustrate the results of this project and to begin our planned Basin Insight consortium wherein we will offer our basin fracture simulation capabilities to member companies who contribute to a publicly accessible U.S. on-shore basin data bank specially formatted for our CIRF.B simulator;

- creation and revision of the manuscript "Predicting fractured reservoir location and characteristics: A basin modeling approach" by P. Ortoleva, J.M. Maxwell, D. Payne, W. Sibo and J. Comer, to appear in Fractured Reservoirs: Identification, Characterization and Prediction, Rocky Mountain Association of Geologists; 
- three chapters of the book Basin Compartments (Ortoleva, 1996) were written on fracture sweet spots, seal dynamics and compartments; and

- a preliminary CIRF.B user's manual was written.

These activities will continue into the last six months of this project.

Several CIRF.B simulations are presented in Appendix E. They illustrate the genesis of overpressure and fracturing arising from compaction and fluid thermal expansion. The fracturing is shown to lead to compartmentation wherein a zone of fractured, high permeability rock is surrounded by low permeability (sealing) rock. The relation between fracture sweet spots and compartments was also developed in a paper (Ortoleva et al., 1996) and three chapters of the book Basin Compartments (Ortoleva, 1996). The preliminary CIRF.B simulations also show the role of sedimentary features and their interplay with the coupled dynamics of fluid flow, diagenesis and fracturing to produce complex patterns of fracturing and overpressuring. 


\section{Work Plan for Last Six Months of Project}

\section{October 1996}

a. Complete sedimentary history reconstruction module improvements based on new triangulation approach.

D. Complete testing of stress solver.

c. Review pressure data and 3-D distribution for model calibration and testing.

d. Make Piceance Basin simulations.

e. Debug and optimize multi-phase reaction-transport module.

f. Complete yearly report.

g. Present results in two lectures at AAPG special workshop on basin compartments.

\section{November 1996}

a. Carry out Piceance Basin simulations for one aqueous phase..

Preliminary Piceance Basin simulations with multi-fluid phase dynamics (including methane genesis).

c. Develop data on deposited organics in the Piceance Basin

d. Present lecture at Gas Research Institute conference on compartments, contrasting examples from the Piceance Basin as compared to the Anadarko Basin.

\section{December 1996}

a. Simulations of Piceance Basin to predict fractured reservoir locations and characteristics and identify factors on basin history affecting them.

b. Host Advanced Resources International/Department of Energy Site visit. (Jarexe)

c. Quarterly report preparation.

d. Edit manuscripts on fractured reservoir predictions for Piceance Basin. 
4. January 1997

a. Further Piceance simulations

b. Comparison of modeling predictions with observations (in close collaboration with Advanced Resources International personnel).

5. February 1997

a. Complete manuscript on fractured reservoir predictive modeling approach.

b. Complete manuscript on detailed comparison of modeling and observations (in collaboration with Advanced Resources International personnel).

c. Start final report.

6. March 1997

a. Complete final report.

b. Prepare materials for presentations and commercial booth at 1997 Annual AAPG.

c. Formulate plans for commercialization and future applications and model development.

d. Miscellaneous issues of project completion. 
Naturally Fractured

Tight Gas Reservoir

Detection Optimization

Appendix A

Geological History Data for Simulating the Piceance Basin and its Naturally Fractured Reservoirs

P. Ortoleva, J. Comer, D. Payne and W. Sibo Laboratory for Computational Geodynamics

Department of Chemistry

Indiana University

Bloomington IN 47405 


\section{Geological Overview}

The data reviewed herein was collected from the literature and industry sources to serve as input into the three dimensional, basin reaction-transport-mechanical simulator CIRF.B. The output of CIRF.B is the predicted present-day configuration of fractures and other characteristics of reservoirs across the basin. In our project this output is then to be used to enhance the interpretation of seismic and other remote and downhole probes used for naturally fractured reservoir exploration.

The study area is the Piceance Basin. This basin is rich in natural gas generally believed to be sourced from coal beds. The reservoirs are typically of low matrix permeability so that natural fractures are key to producibility.

The basin simulator to be used in this project (CIRF.B) is a fully coupled, three dimensional reaction-transport-mechanical simulator. As such, it requires a knowledge of mass and energy influx at the basin boundaries and the deformation. In particular, the inputs are:

- tectonic data in terms of the overall compressional/extensional history at the basin lateral borders and the subsidence/uplift history at the basin periphery;

- the heat flux into the basin bottom and the temperature (ocean bottom or climate) at the top of the sediment pile;

- history of sediment input and erosional removal at the top of the basin;

- influx of fluids at the top, bottom and sides of the basin.

The particular assumptions required for the present implementation of CIRF.B are as suggested in Fig. A1.

The Piceance Basin in northwestern Colorado is a structural basin of Late Cretaceous to early Tertiary age. The basin is bounded by the Axial Basin Anticline on the north, White River Uplift on the east, Wasatch Uplift on the southeast, Uncompahgre Uplift on the southwest, and Douglas Creek Arch on the west (Fig. A2). The basin is elongated in a 
northwest-southeast orientation and occupies an area of approximately $18,720 \mathrm{~km}^{2}$, with dimensions of roughly $240 \mathrm{~km} \times 78 \mathrm{~km}$ (Tyler et al., 1995). Dips in the basin are steep $\left(>60^{\circ}\right.$ to overturned) in the east and gentle $\left(5^{\circ}\right.$ to $\left.10^{\circ}\right)$ in the west and southwest, and the structural axis trends northwestward near the eastern margin (Fig. A3). The principal tight gas sandstone reservoirs are in the Upper Cretaceous Mesaverde Group (Iles and Williams Fork Formations) (Fig. A4) and were deposited between approximately 77 and $66 \mathrm{Ma}$. Mesaverde strata outcrop along the basin margins and are at depths approaching 5,000 meters along the basin axis.

\section{Tectonic Setting and History}

Since the beginning of the Late Cretaceous (97 Ma), two orogenic episodes have influenced sedimentation and structures in the Piceance Basin. The Sevier orogeny (160$72 \mathrm{Ma}$ ) produced a fold and thrust belt from Alaska to Mexico, the nearest eastern margin of which lay in western Utah. Stresses from this thrust belt were transmitted eastward, causing regional east-west compression and producing low amplitude flexures in the areas of the Douglas Creek Arch, Uncompahgre Uplift, and White River Uplift. During the later stages of the Sevier orogeny, beginning in the Late Cretaceous, the Piceance Basin commenced to subside rapidly.

The Laramide orogeny (72-40 Ma) is characterized by regional uplift and differential basin subsidence. During this time the uplifts bounding the Piceance Basin formed and a widespread erosional unconformity developed at the top of the Mesaverde Group. The dominant stress regime was east-west horizontal compression and there was chronological overlap of Sevier and Laramide deformation styles as thrusting in the Sevier orogenic belt gradually became inactive. In the Piceance Basin, Mesaverde Group sediments reached 
their maximum burial depth at the end of the Laramide near the end of the Eocene (around $37 \mathrm{Ma})$.

A change in the tectonic style occurred after the Laramide (40 Ma to present) that is marked by the onset of volcanism and igneous intrusion and by regional basin and range extension. Several episodes of uplift and igneous activity occurred during this time period but there remains controversy as to whether these episodes occurred in compressional or extensional stress regimes. Lorenz (1985) concluded that present-day in situ stresses represent remnant strains from the Sevier and Laramide east-west compressional stress fields, whereas Hoak (1995, personal communication) suggested that some structures in the Piceance Basin represent contemporaneous west or west-northwest compression.

\section{Depositional Context and Stratigraphy}

Throughout the Cretaceous Period, the region now occupied by the Piceance Basin lay along the western margin of the Western Interior Seaway. During the Late Cretaceous Epoch, as much as 2,000 meters of marine and nonmarine sediments were deposited in this region. The stratigraphic sequence that contains the principal tight gas reservoirs consists of the two genetically linked systems that comprise the Mesaverde Group; the older lles Formation is dominantly marine and the younger Williams Fork Formation is dominantly nonmarine. The Iles Formation consists of several progradational shallow marine and shoreface sandstones (Sego, Corcoran, Cozzette; Rollins) separated by tongues of the marine Mancos Shale. The Williams Fork Formation consists of coal-bearing sequences and nonmarine sandstones and shales that are interpreted as fluvial-deltaic (Collins, 1976) or as wave-dominated clastic shoreline deposits (Young, 1966). Fig. A5 shows the progression through time of three progradational periods and the intervening marine flooding periods, constructed using our automated sedimentary history recreation module. 
Each picture shows the distribution of different lithologies (the lighter shades represent near-shore sands and associated landward deposits, and the darker shade represents marine shale) in the southern Piceance study area, at specific ages; and together, the series of pictures shows how the location of the coastline changed through time.

Following the period of uplift and erosion at the end of the Cretaceous, the Piceance Basin became exclusively the site of nonmarine sedimentation. Tertiary rocks of the Wasatch Formation and Green River Formation, the youngest in the basin, include a wide variety of sandstones, siltstones, nonmarine carbonates, and continental evaporites that represent fluvial, alluvial, and lacustrine sediments deposited well above sea level in a continental intermontane basin setting. While these rocks include beds with significant petroleum resource potential, they do not include the tight gas reservoirs that are the focus of this research. However, information about their areal extent and thickness as well as their depositional, erosional, burial, and stress histories are important in modeling the continuum of reaction-transport-mechanical processes that operated during basin evolution and that led to the formation of fractured reservoirs in the Mesaverde Group.

Fig. A6(a) shows a three dimensional diagram of the present-day distribution in space of the Iles Formation units as defined for this modeling project, constructed using the automated sedimentary history recreation module. Figs. $A 6(b, c)$ were derived similarly and illustrate the present-day geometry of the Rollins and Paludal Interval units.

\section{Burial and Thermal History}

Burial and thermal histories were developed for selected sites in the Piceance Basin (Fig. A7). The burial history data and geothermal gradients for the various locations were assembled from published reports (Lorenz, 1985; Johnson and Nuccio, 1986; Nuccio and Johnson, 1989; Johnson and Nuccio, 1993) and the present-day elevations were verified 
using geophysical logs. Geothermal gradients were chosen to agree, as closely as possible, with the modern-day gradients mapped by Johnson and Nuccio $(1986,1989)$. these authors assumed that the modern gradients had persisted in the basin back through the time of Mesaverde deposition ( $74 \mathrm{Ma})$.

The appropriateness of the chosen gradients was verified by comparing the measured values of vitrinite reflectance $\left(R_{0}\right)$ from each well site with those calculated using the parallel reaction kinetic model EASY\% $\left(\mathrm{R}_{\mathrm{o}}\right)$ (Sweeney and Burnhan, 1990). The measured $\left(\mathrm{R}_{\mathrm{o}}\right)$ values record the maximum temperature experienced by the organic maceral vitrinite and are generally accepted as valid indicators of the thermal maturity of organic matter in sedimentary rocks. Geothermal gradients were adjusted from the modern-day values only if necessary until the calculated and measured $\left(R_{0}\right)$ agreed. Paleodepths of burial at some sites were modified slightly ( $\mathrm{a}$ few hundred feet) from the published curves in order to bring the measured and calculated $\left(R_{0}\right)$ values into agreement while retaining a geologically reasonable value for the paleogeothermal gradient. Adjustments to the thermal gradients were made by either increasing or decreasing the paleogradient prior to $30 \mathrm{Ma}$ (Table A1), the approximate time at which significant changes occurred in the magmatic and tectonic styles of the basin (Lorenz, 1985). The gradients at all sites for the time period from $30 \mathrm{Ma}$ to the present (Table A1) are in general agreement with the modern gradients mapped by Johnson and Nuccio (1986) and Nuccio and Johnson (1989).

Extensive coal deposits are found in the marine and near-shore units of the Mesaverde Group (see Fig. A8). These coals are believed to be sources for much of the basin's methane reserves (Tyler and McMurry, 1995). These coals tend to overlie marine sandstones in the progradational sequences (Tyler and McMurry, 1995), and are interpreted as swamp deposits directly behind the shoreline. The thickest coal units are in the lower part of the Williams Fork Formation, overlying the Rollins sandstone of the Iles Formation. Because of the repeated transgressive-regressive sequences, and the general 
Table A1 Thermal gradients at 18 sites in the Piceance Basin.

\begin{tabular}{|c|c|c|c|}
\hline Map Symbol & Location & Before $30 \mathrm{Ma}$ & After $30 \mathrm{Ma}$ \\
\hline & $(\mathrm{T}, \mathrm{R})$ & $\left({ }^{\circ} \mathrm{C} / \mathrm{km}\right)$ & $\left({ }^{\circ} \mathrm{C} / \mathrm{km}\right)$ \\
\hline MWX & $6 S-94 W$ & 25.0 & 45.6 \\
\hline 1 & $2 \mathrm{~N}-97 \mathrm{~W}$ & 29.0 & 29.0 \\
\hline 2 & $3 N-96 W$ & 25.0 & 29.0 \\
\hline 3 & $4 N-97 W$ & 29.0 & 29.0 \\
\hline 4 & $2 N-96 W$ & 29.0 & 29.0 \\
\hline 5 & $3 S-97 W$ & 36.5 & 36.5 \\
\hline 6 & $3 S-97 \mathrm{~W}$ & 36.5 & 36.5 \\
\hline 7 & $2 S-96 W$ & 36.5 & 36.5 \\
\hline 8 & $10 S-90 W$ & 45.6 & 45.6 \\
\hline 9 & $9 S-92 W$ & 45.6 & 45.6 \\
\hline 11 & $1 \mathrm{~N}-100 \mathrm{~W}$ & 40.0 & 32.8 \\
\hline 12 & $6 \mathrm{~S}-90 \mathrm{~W}$ & 31.0 & 36.5 \\
\hline 13 & $5 S-100 W$ & 32.8 & 43.7 \\
\hline 14 & $1 S-100 W$ & 32.8 & 32.8 \\
\hline 15 & $7 S-99 W$ & 29.0 & 43.7 \\
\hline 16 & $2 S-98 W$ & 36.5 & 36.5 \\
\hline 17 & $11 S-93 W$ & 36.5 & 36.5 \\
\hline 18 & $9 S-95 W$ & 47.4 & 47.4 \\
\hline
\end{tabular}

movement of the shoreline toward the east, the net thickness of coal beds increases toward the east in the Piceance Basin (Fig. A8; Tyler and McMurry, 1995).

The distribution of gas fields (Fig. A9) does not correlate well with the distribution of coal (Fig. A8) in the basin. Gas fields are distributed across the basin from east to west, 
and do not show a greater density eastward. Prolific gas fields are more concentrated toward the southern part of the basin, except in the southernmost part, where diabase dykes are abundant. Gas fields do tend to correlate with local structures in the basin, particularly anticlines (Fig. A10), although this may reflect drilling strategy as much as occurrence. In addition, gas fields in the southern half of the basin correlate with the overall basin shape in that fields located toward the basin axis tend to be sourced from the younger Williams Fork Formation, whereas fields toward the basin margin are sourced from the older Iles Formation. Thus, it can be speculated that as younger coals of the Williams Fork Formation get buried deeper, they can produce more gas; and if the low permeability of the sediments limits gas transport, much of this gas could be trapped in the Williams Fork Formation and cause overpressuring. Conversely, toward the basin margin only goals in the older Iles Formation may have been buried deep enough to generate methane, and with limited transport, gas would be trapped only in the Iles Formation.

A fluid pressure gradient map for the southern part of the Piceance Basin shows the greatest pressure gradients to be in the axis of the basin, while lower gradients tend to be located toward the basin flanks (Fig. A11). This pressure gradient distribution correlates neither with the distribution of net coal thickness (Fig. A8), nor with the distribution of structures within the basin (Fig. A10). It does correlate with the general basin shape (Figs. A2.8) and therefore gas fields sourced by the Williams Fork Formation tend to be in areas of higher pressure gradient, whereas those sourced by the Iles Formation tend to be in areas of lower pressure gradient. One possible reason for this pressure gradient distribution is that where more coal is buried to depths great enough to generate methane (in the basin axis), more methane has been generated. If trapped by low permeability sediments, the greater volume of methane generated toward the basin axis would result in greater pressure gradients there than on the flanks, where less methane was generated. 


\section{Organic Data}

An important part of fracture-promoting fluid overpressuring in the Piceance Basin is believed to be the generation of methane from coal beds. Thus we are in the process of obtaining data on depositional organic molecules in the coal-forming organic sediment components. This data, along with a network of organic reactions and accompanying rate data will be used by the multi-phase reaction-transport module within CIRF.B to calculate aqueous and gas phase saturations, compositions and pressures.

Specific data on Mesaverde Group coal composition and volume may be found in Reinecke et al. (1991), Rightmire and Choate (1986), Tyler and McMurry (1995), and USGS (1994). Our first simulations will be carried out assuming that the molecular starting point for the thermally induced methane production is lignin, which is the major contributor to terrigenously sourced kerogen and coal (DeLeeuw and Largeau, 1993). Available kinetic and thermodynamic organic data will be used in the Piceance Basin simulations to assess the role of methanogenic overpressuring in fracture generation, the persistence and window of existence in time of the fractures, as well as their distribution within the basin. 
(a)

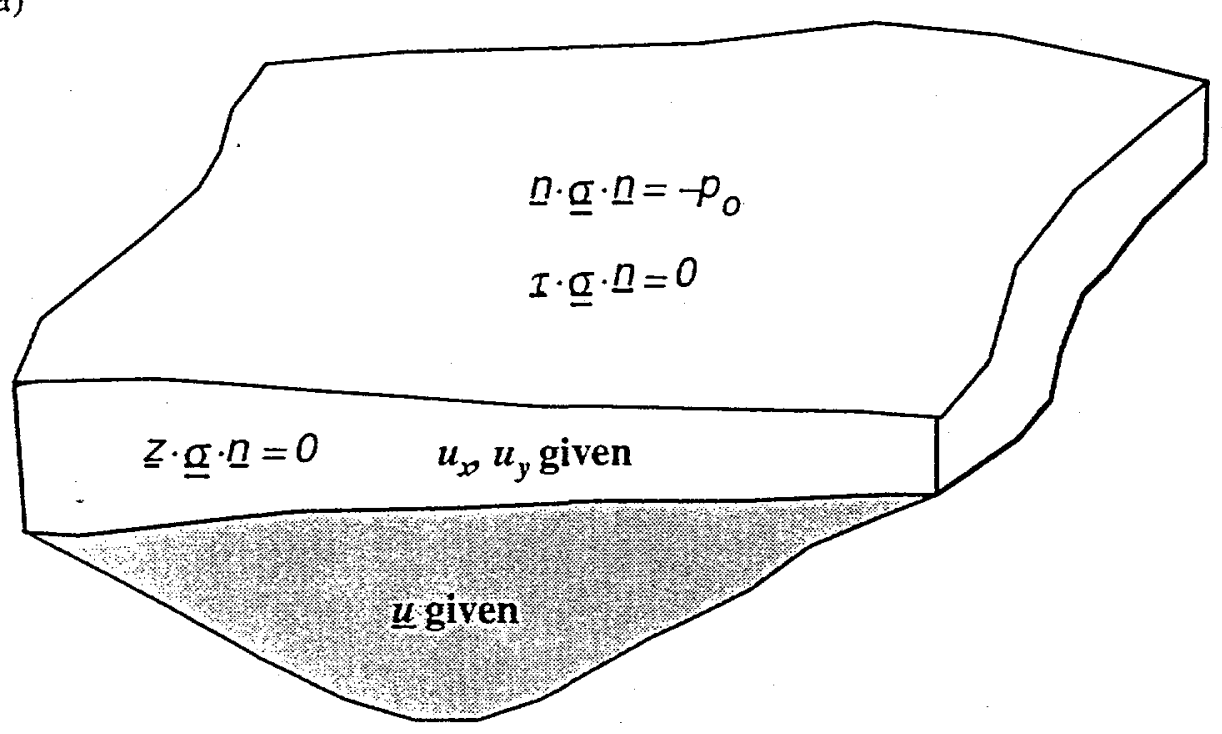

(b)

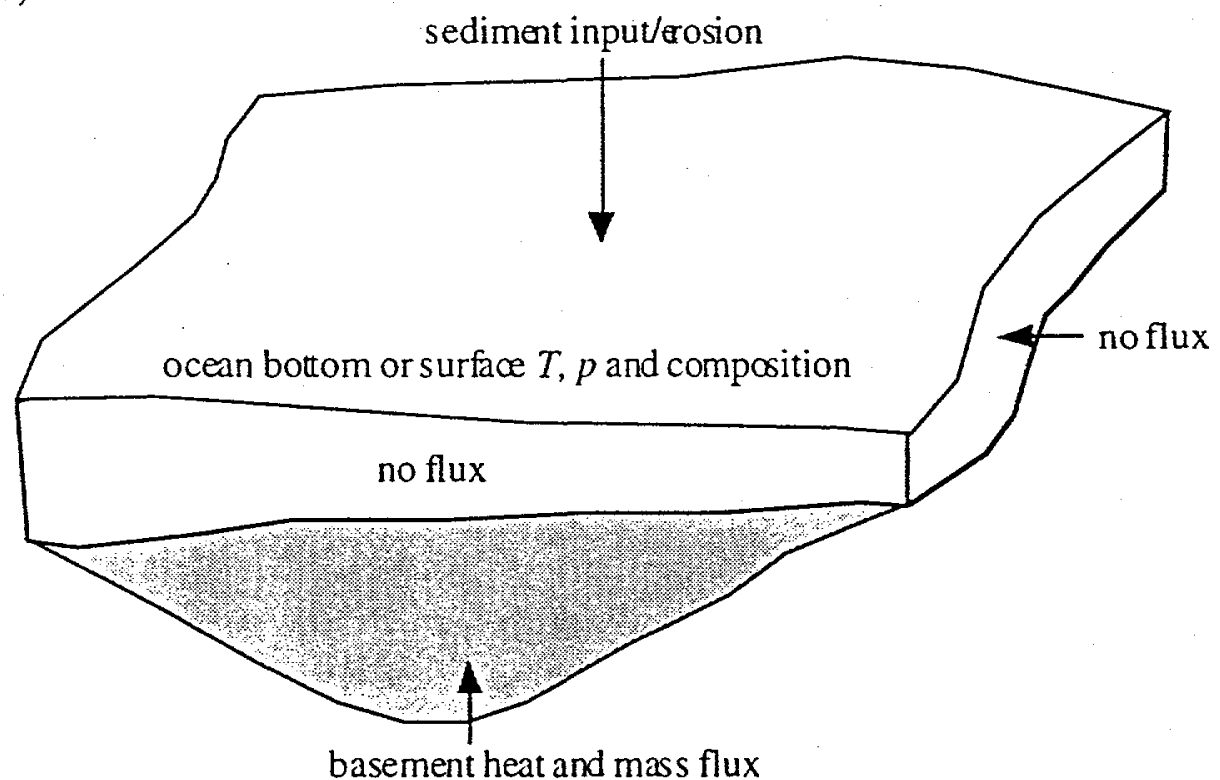

Fig. A1 Summary of boundary input data required for predictive modeling using the three dimensional reaction-transport-mechanical simulator CIRF.B. (a) For the stress solver normal stress $\underline{n} \cdot \underline{\underline{\sigma}} \cdot \underline{n}$ is minus ocean bottom or atmospheric pressure $p_{o}$; the velocity $\underline{u}$ of deformation is imposed at the bottom while its horizontal components $u_{x}, u_{y}$ (compression/extension history) are imposed at the sides; vertical shear at the sides, $z \cdot \underline{\underline{\sigma}} \cdot \underline{n}$ is zero to avoid artificial boundary stress and allow for natural compaction; tangential shear $\underline{\tau} \cdot \underline{\underline{\sigma}} \cdot \underline{n}$ at the top is assumed negligible. (b) At the top of the sediment pile ocean (or surface) $p, T$ and sediment/erosion history is imposed; heat and mass flux are zero at the sides and must be given at the bottom of the simulation domain. 


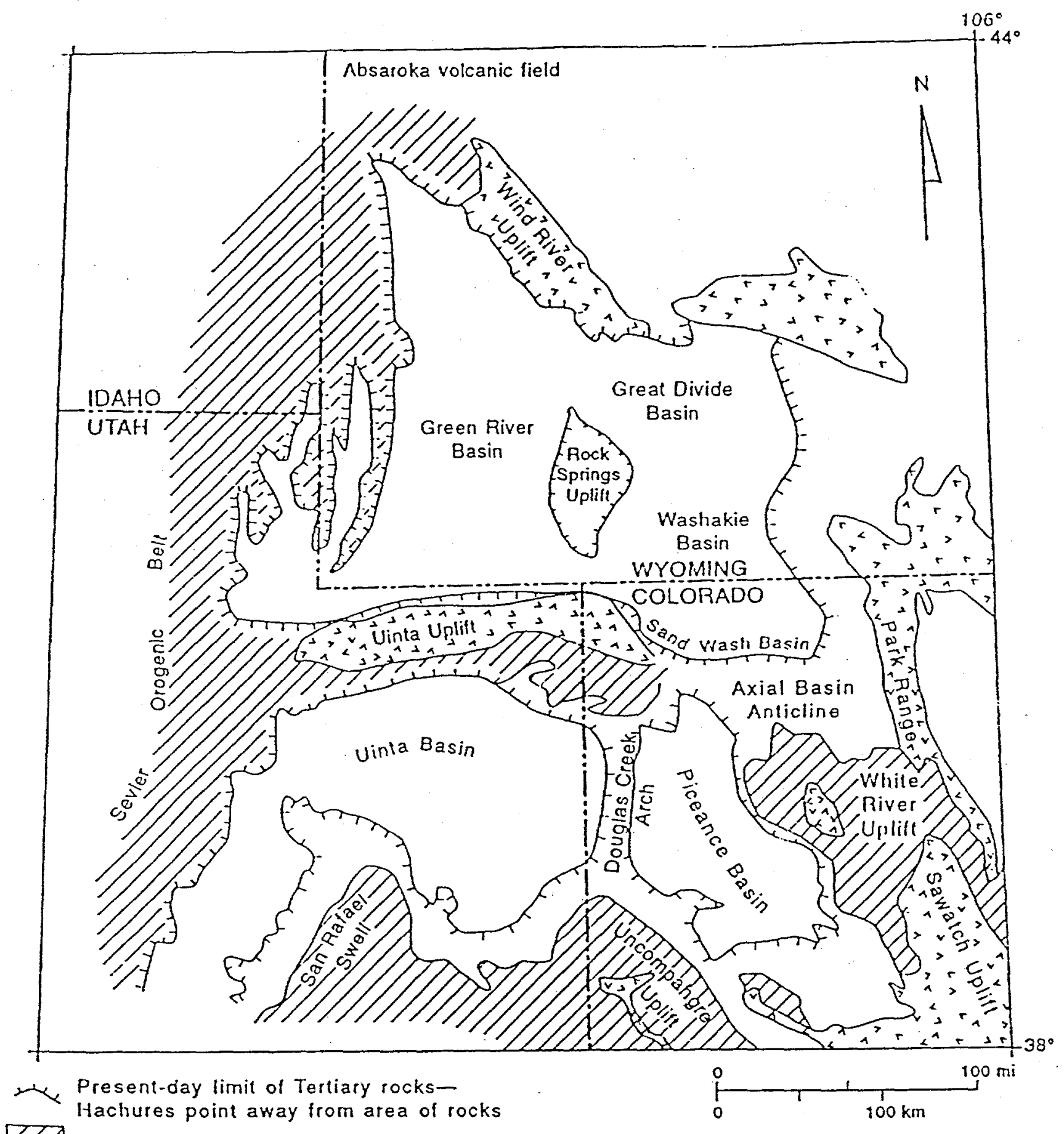

Present-day outcrop of Cambrian through Lower Cretaceous rocks

S Present-day outcrop of Precambrian rocks

Fig. A2 Map showing the location of the Piceance Basin in northwestern Colorado. Also shown are the basins and uplifts created during the Laramide orogeny in adjacent areas of Colorado, Utah, and Wyoming. From Tyler et al. (1995). 


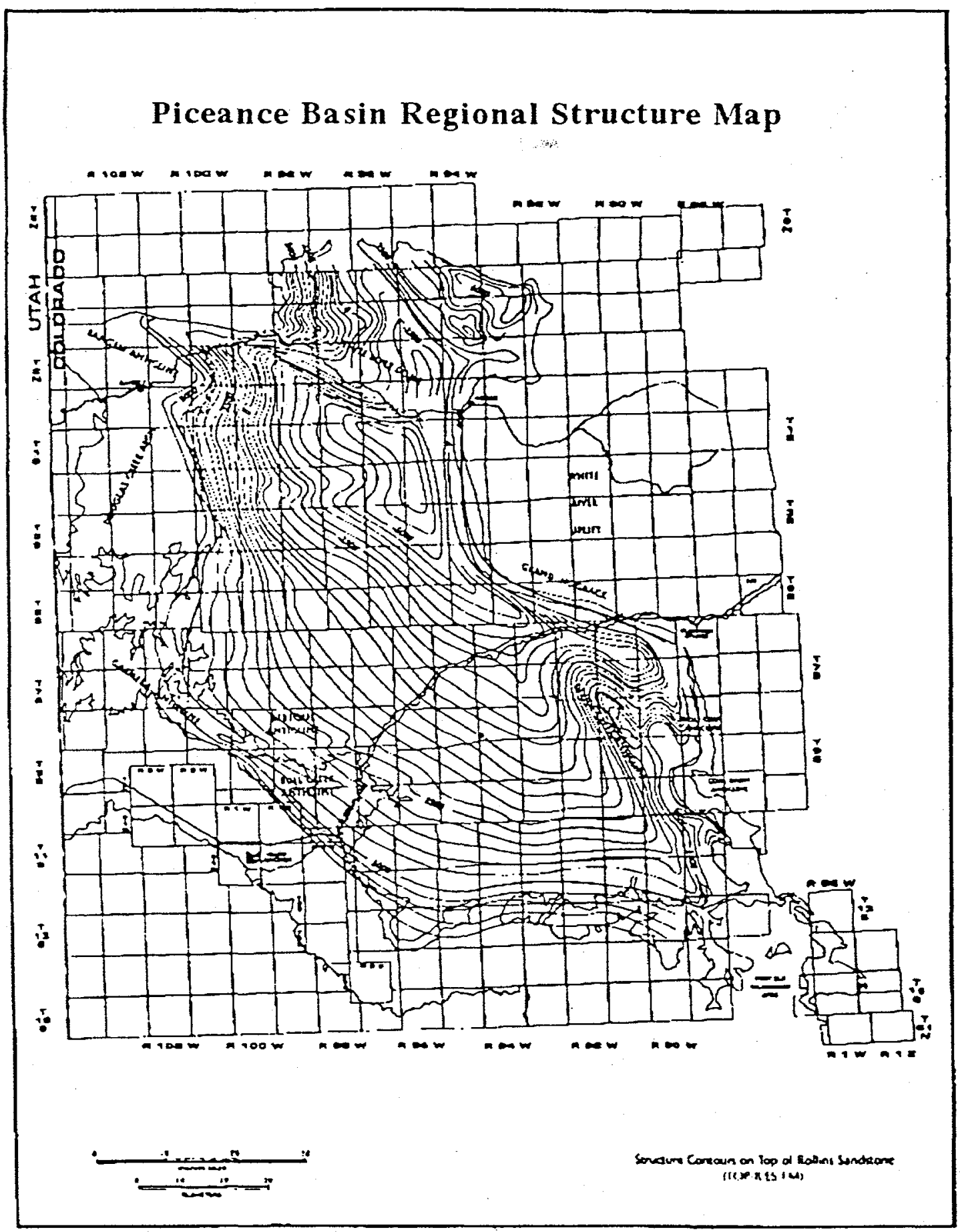

Fig. A3 Piceance Basin in western Colorado. Contour lines show depth to top of Rollins sandstone of the Iles Formation, Mesaverde Group. This figure shows the symmetry of the basin, with the steep flank on the northeast side of the NW-SE-oriented basin axis. 


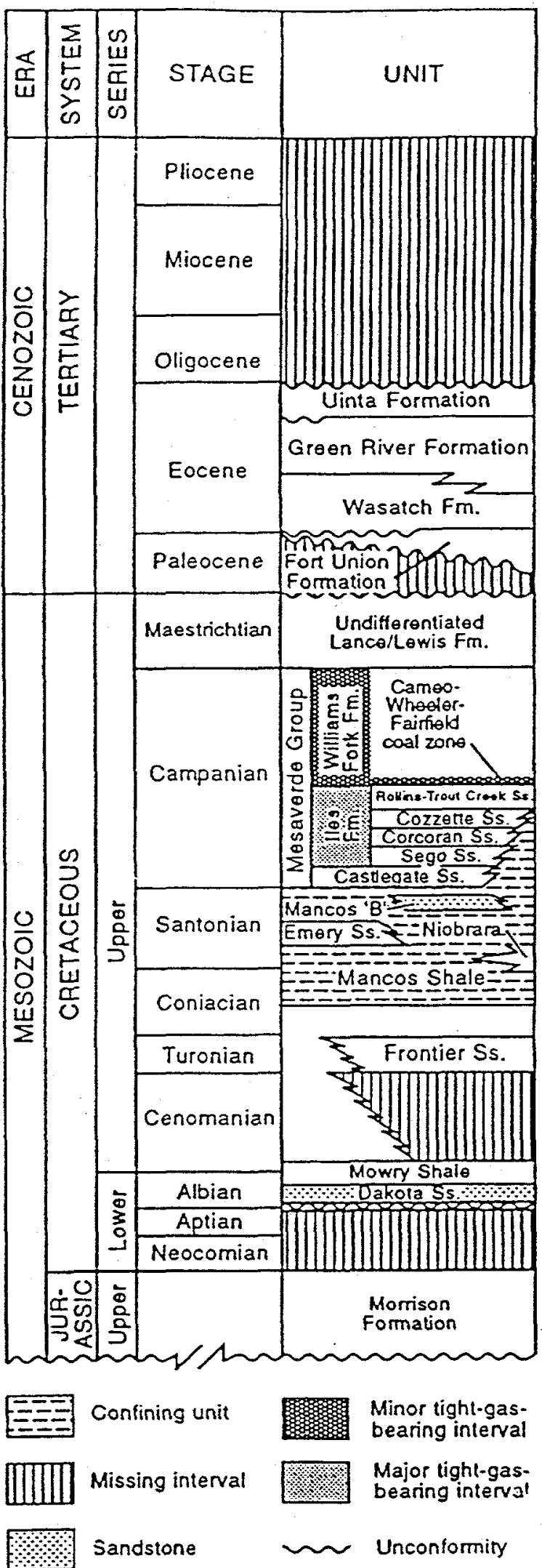

Fig. A4 Cretaceous and Tertiary stratigraphy in the Piceance Basin. From Tyteret at:$(1995)$. 
(a1)

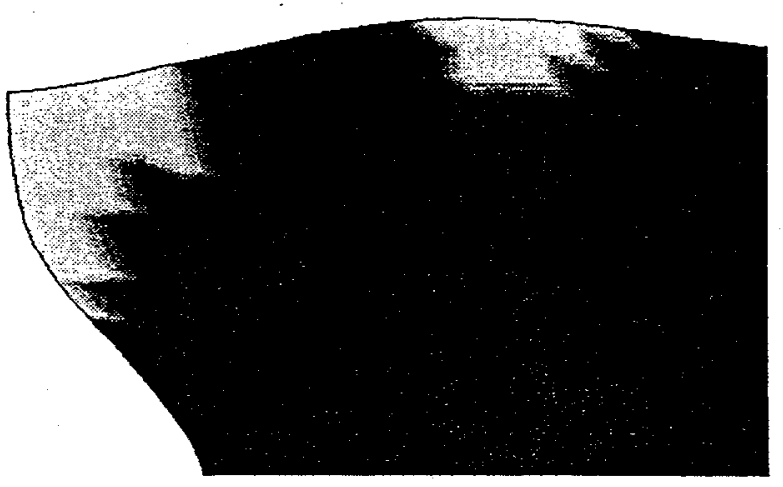

(a2)

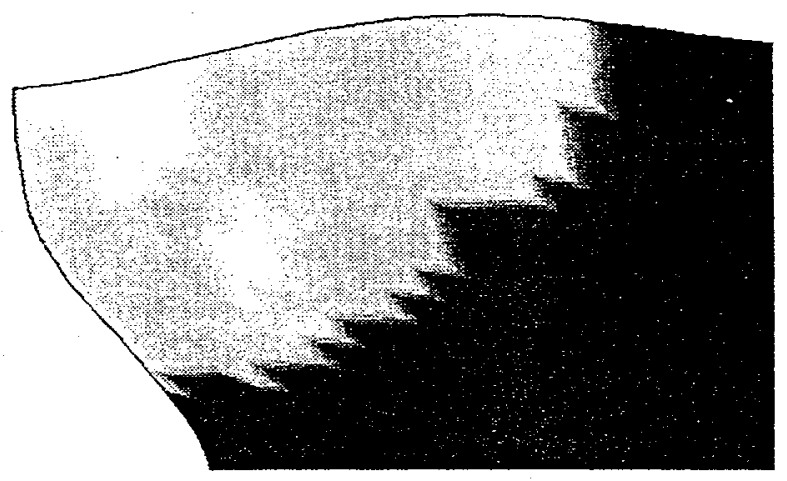

(a3)

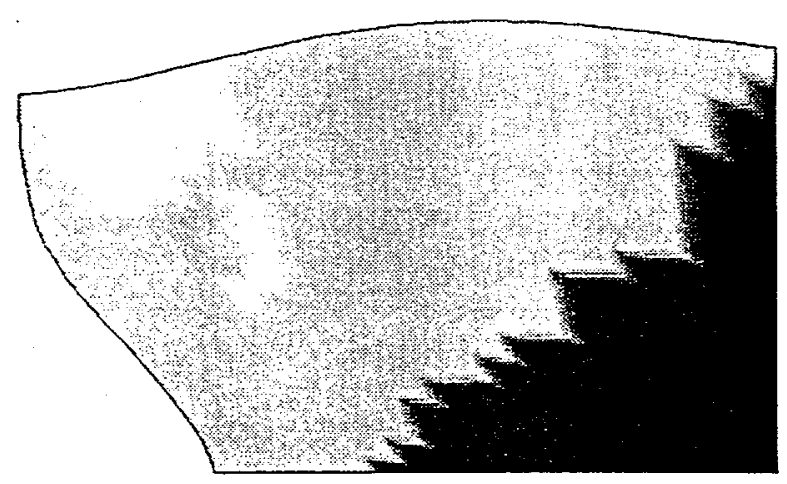

Fig. A5 Time-slice isochron maps showing deposition of regressive marine units. Dark is Mancos shale, medium gray and white are shoreline sand units, and light gray is area of nondeposition or erosion. (a) Corcoran, (b) Cozzette and (c) Rollins. Jagged contacts are only a graphical artifact. 
(b1)

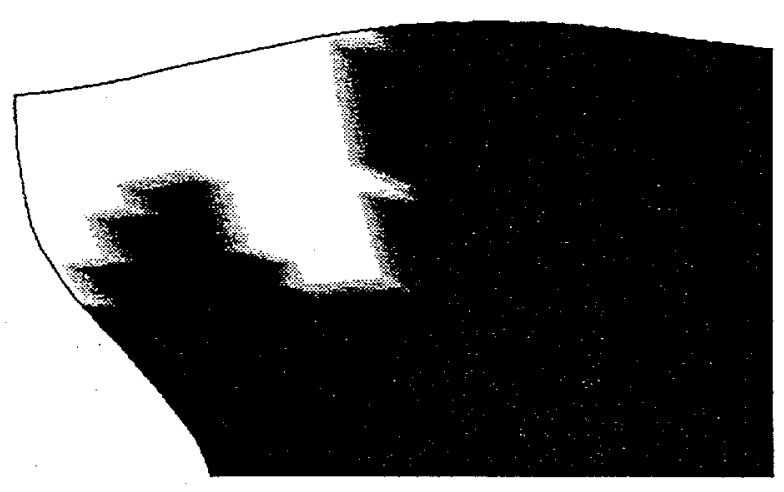

(b2)

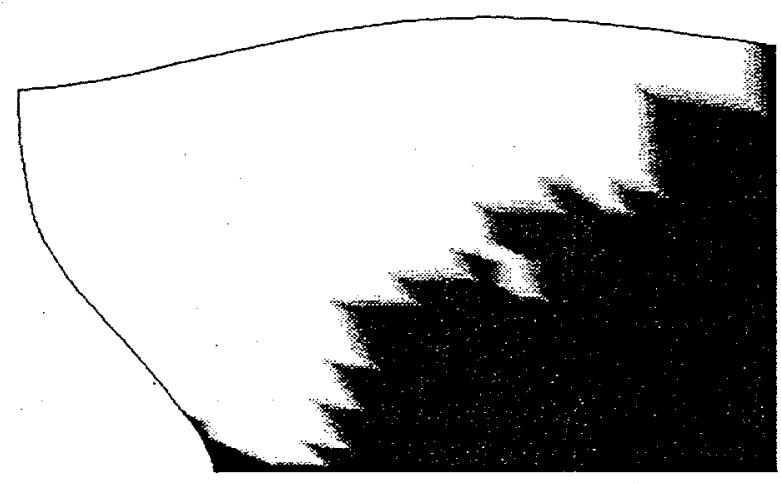

(b3)

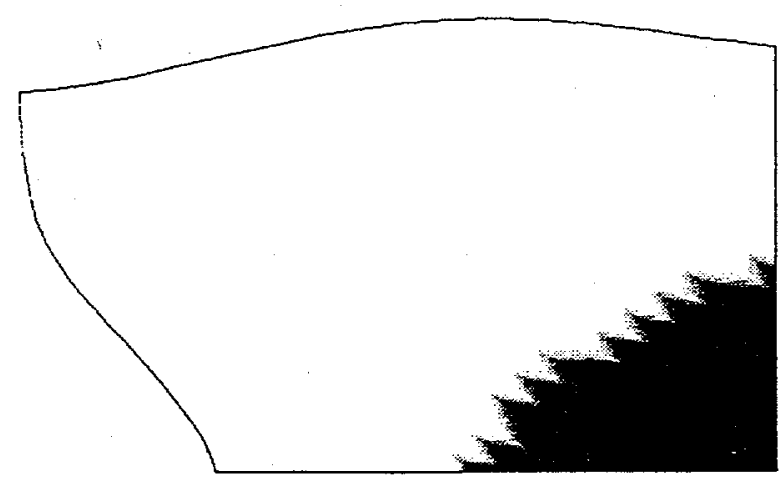


(c1)

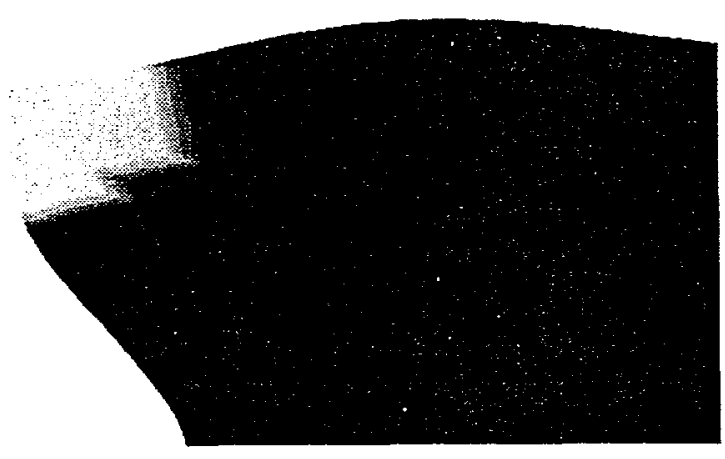

(c3)

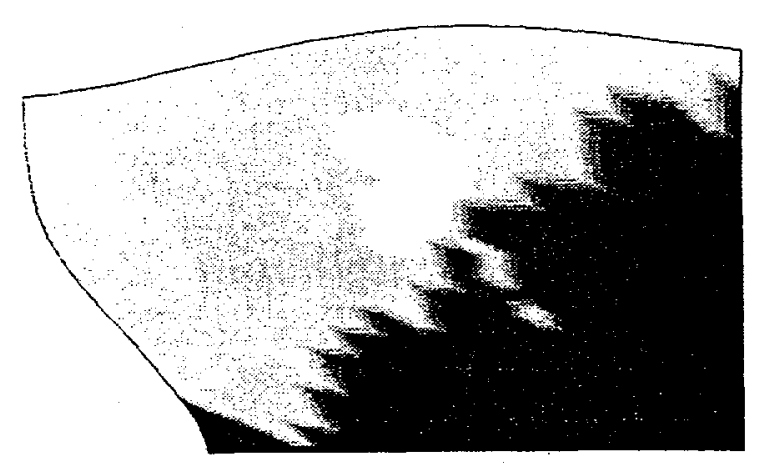

(c2)

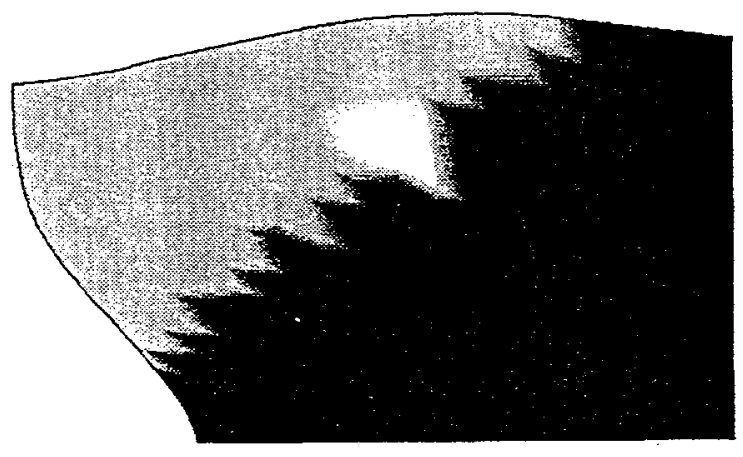

(c4)

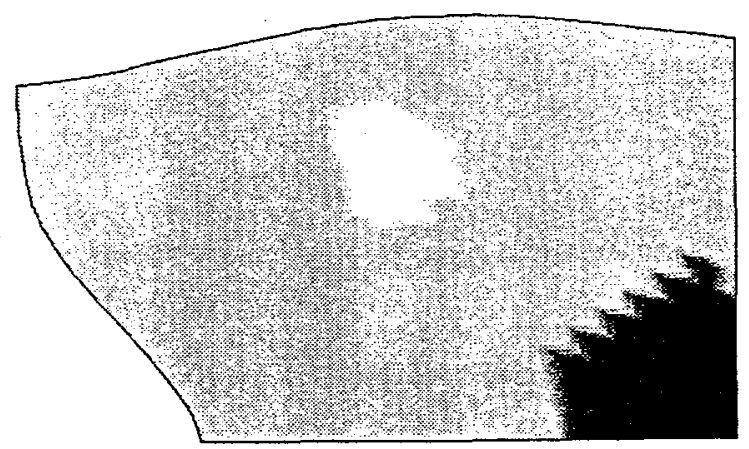




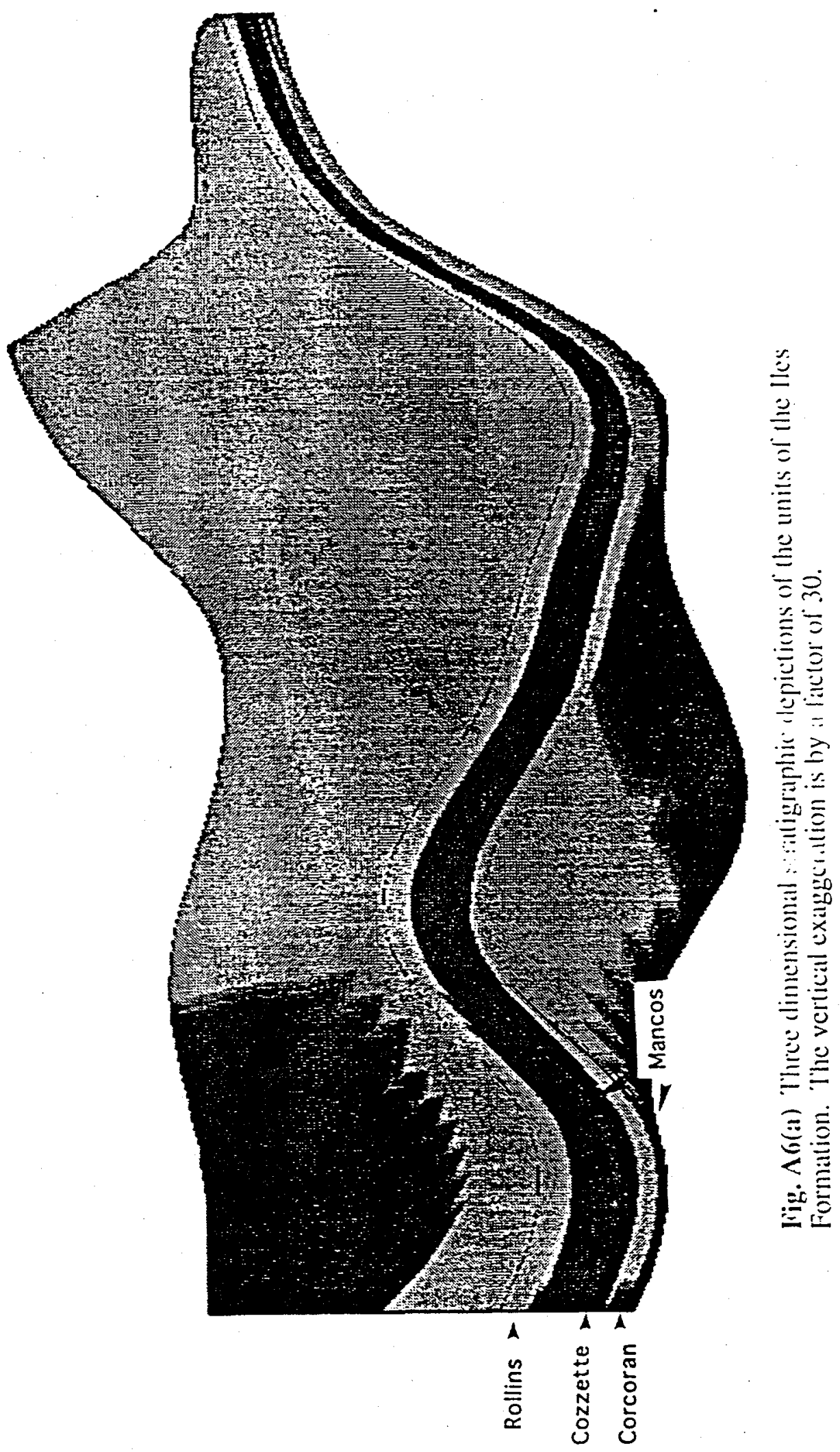




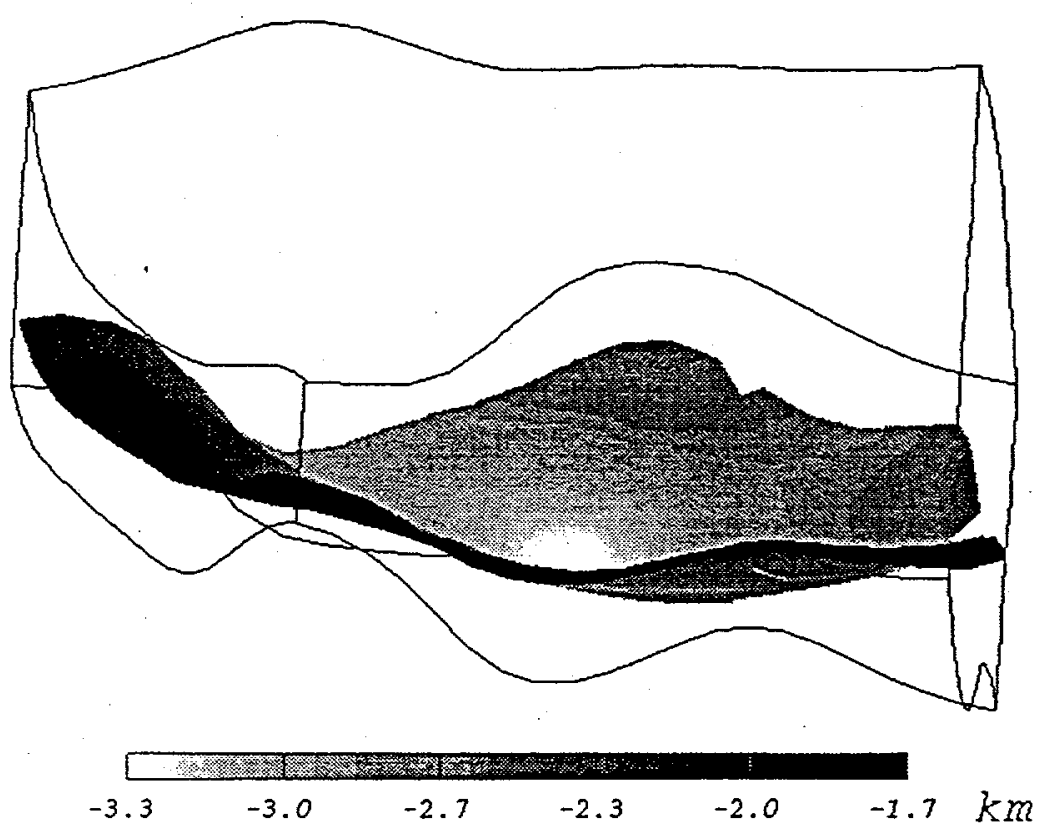

Fig. A6(b) Three dimensional stratigraphic depiction of the Rollins sandstone of the Iles Formation. The vertical exaggeration is $25 \mathrm{X}$.

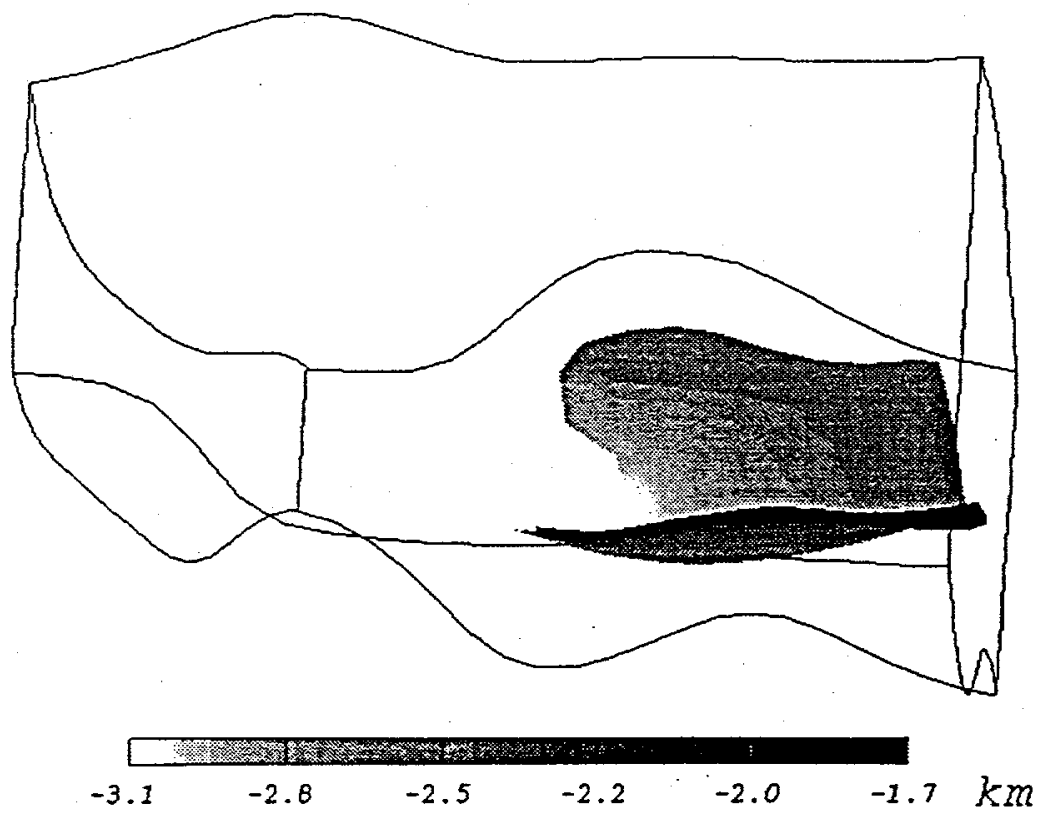

Fig. A6(c) Three dimensional stratigraphic depiction of the Paludal Interval of the Williams Fork Formation. The vertical exaggeration is $25 \mathrm{X}$. 


\section{BURIAL HISTORY}

MWX SITTE

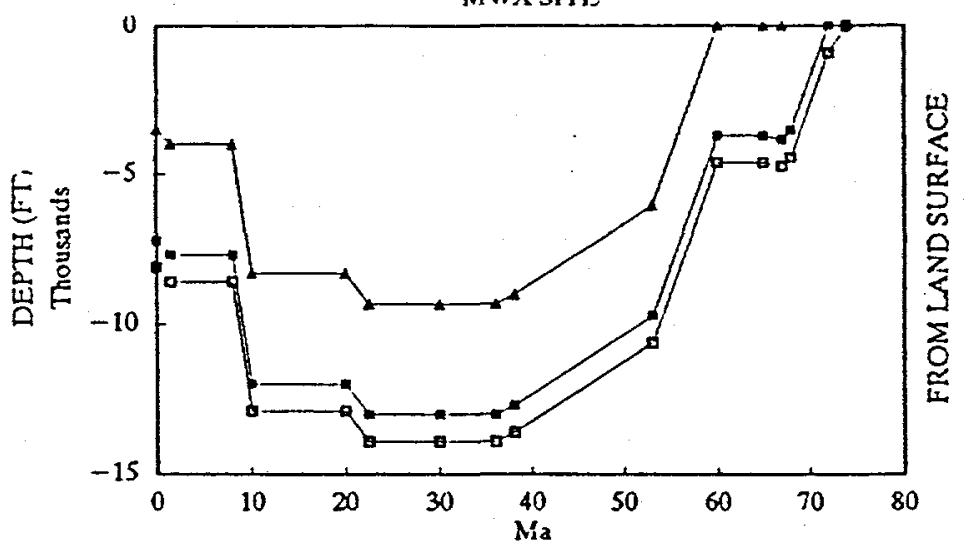

-- ROLLINS TOP
$\rightarrow$ MESAVERDE BASE - MESAVERDE TOP

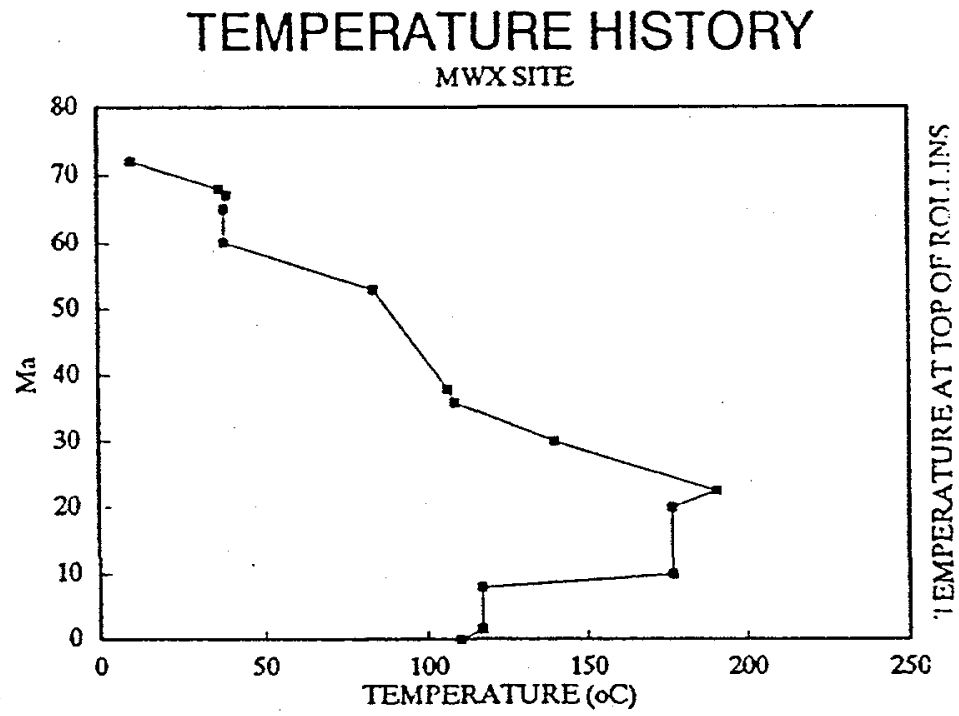

VITRINITE MATURATION

MWX Site

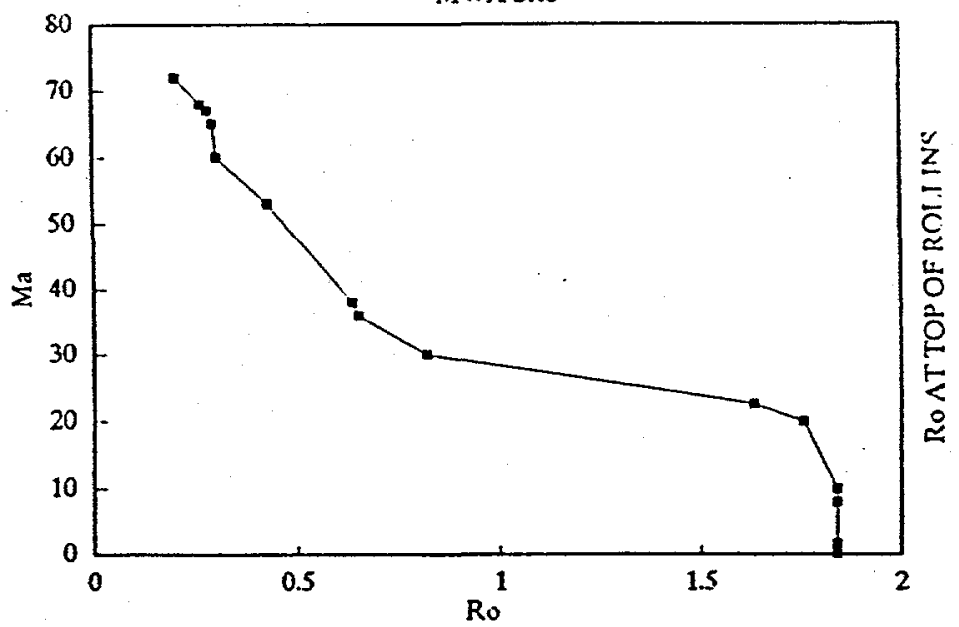

Fig. A7 Graphs illustrating the (a) burial, (b) temperature and (c) maturation history of the Mesaverde Group at the MWX site. 


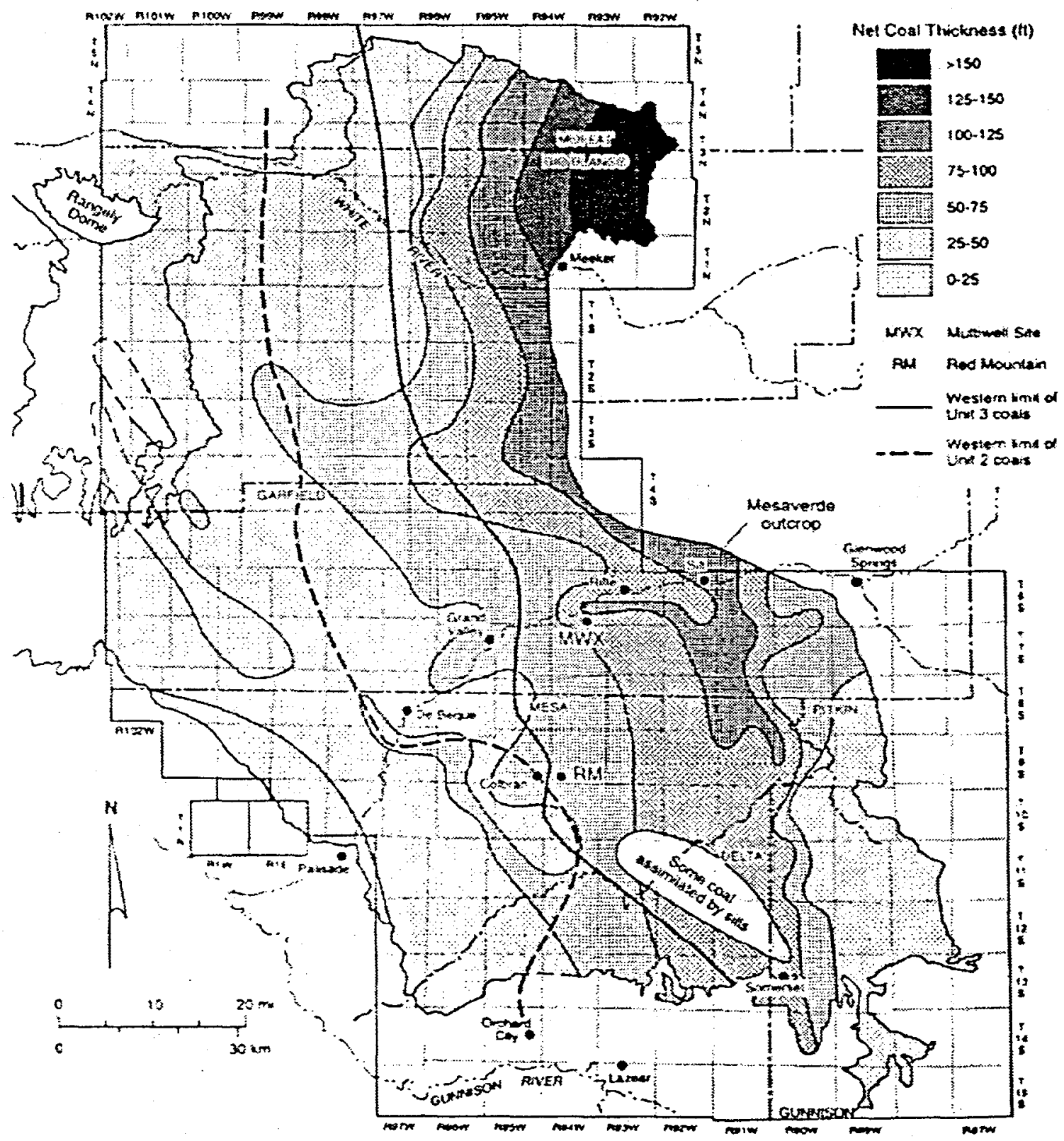

Fig. A8 Distribution of net coal thickness in the Piceance Basin. Note the increasing net thickness toward the cast, due to the repeated transgressiveregressive sequences as the shoreline generally moved toward the east. (The distribution of net coal thickness does not correlate with the distribution of major producing gas fields in the Piceance Basin.) 


\section{SELECTED CHETACEDUS GAS FIELDS AND BASIN LOCATION MAP}

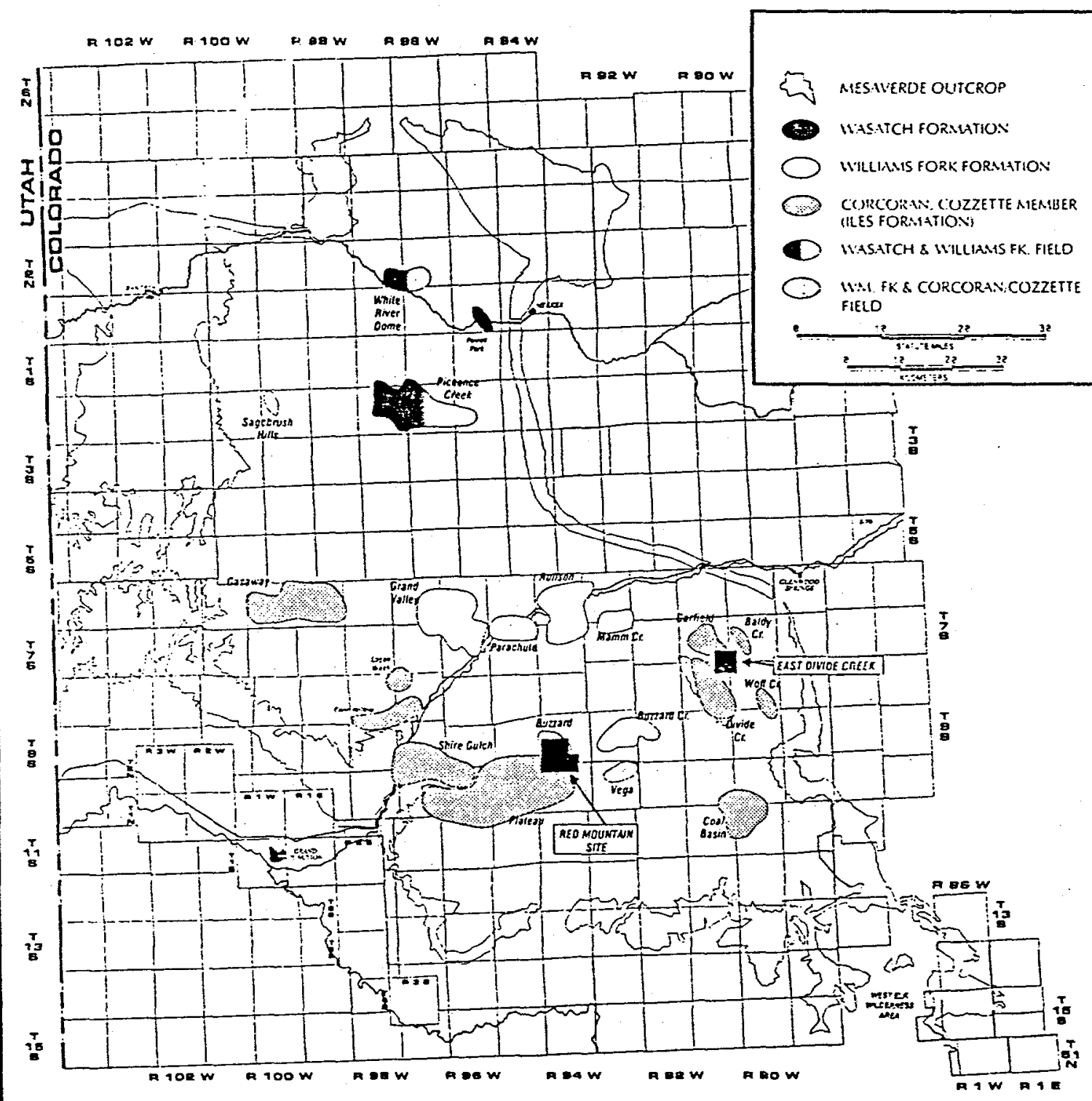

Fig. A9 Major producing gas fields in the Piceance Basin. The lightest gray shaded fields are sourced from the Williams Fork Formation; the medium gray shaded fields are sourced from the Iles Formation; and the darkest gray fields are sourced from the Wasatch Formation, which overlies the Mesaverde Group. 


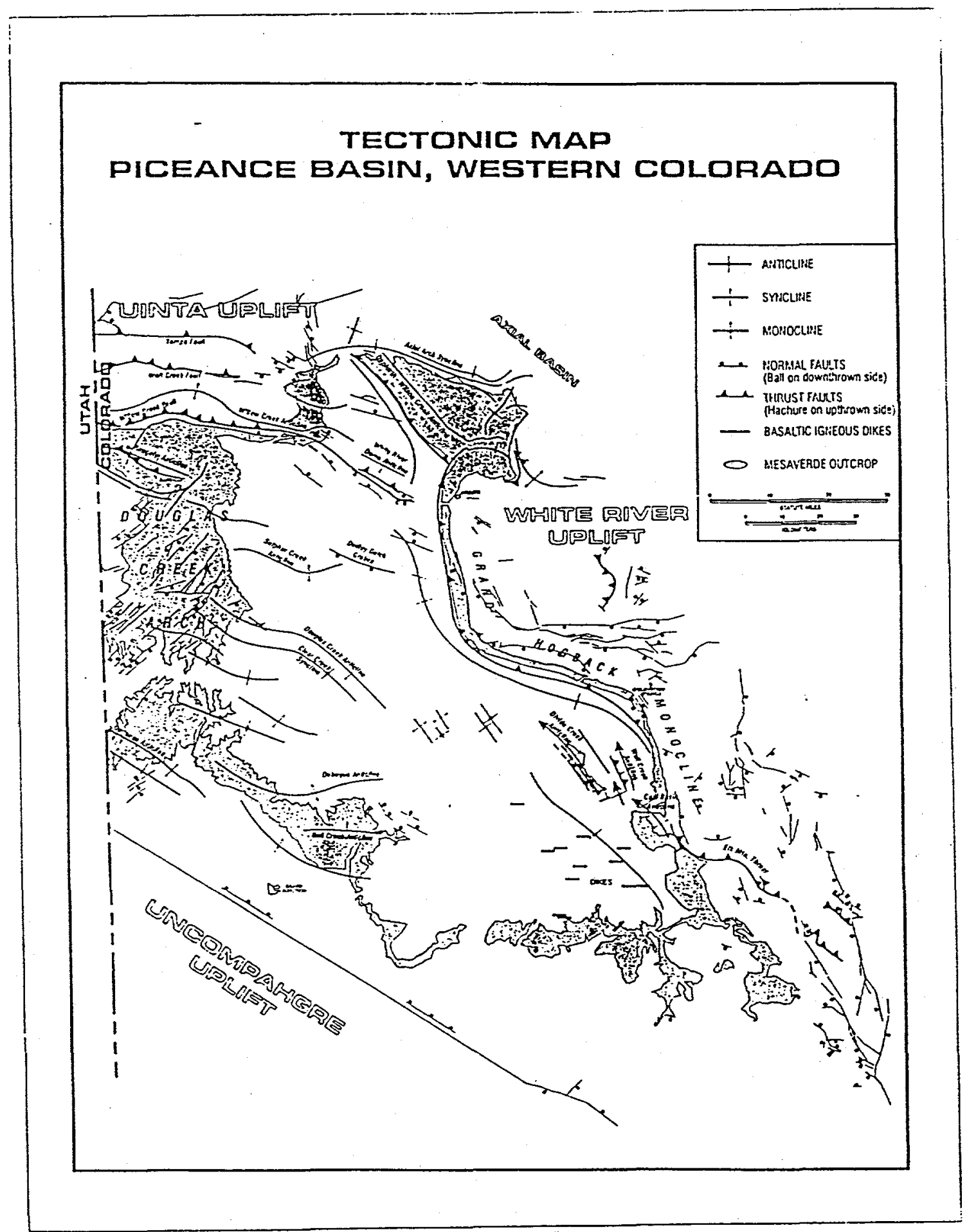

Fig. A10 Major structures in the Piceance Basin area. Note the correlation between distribution of major producing gas fields and some of their structural features, particularly anticlines. 


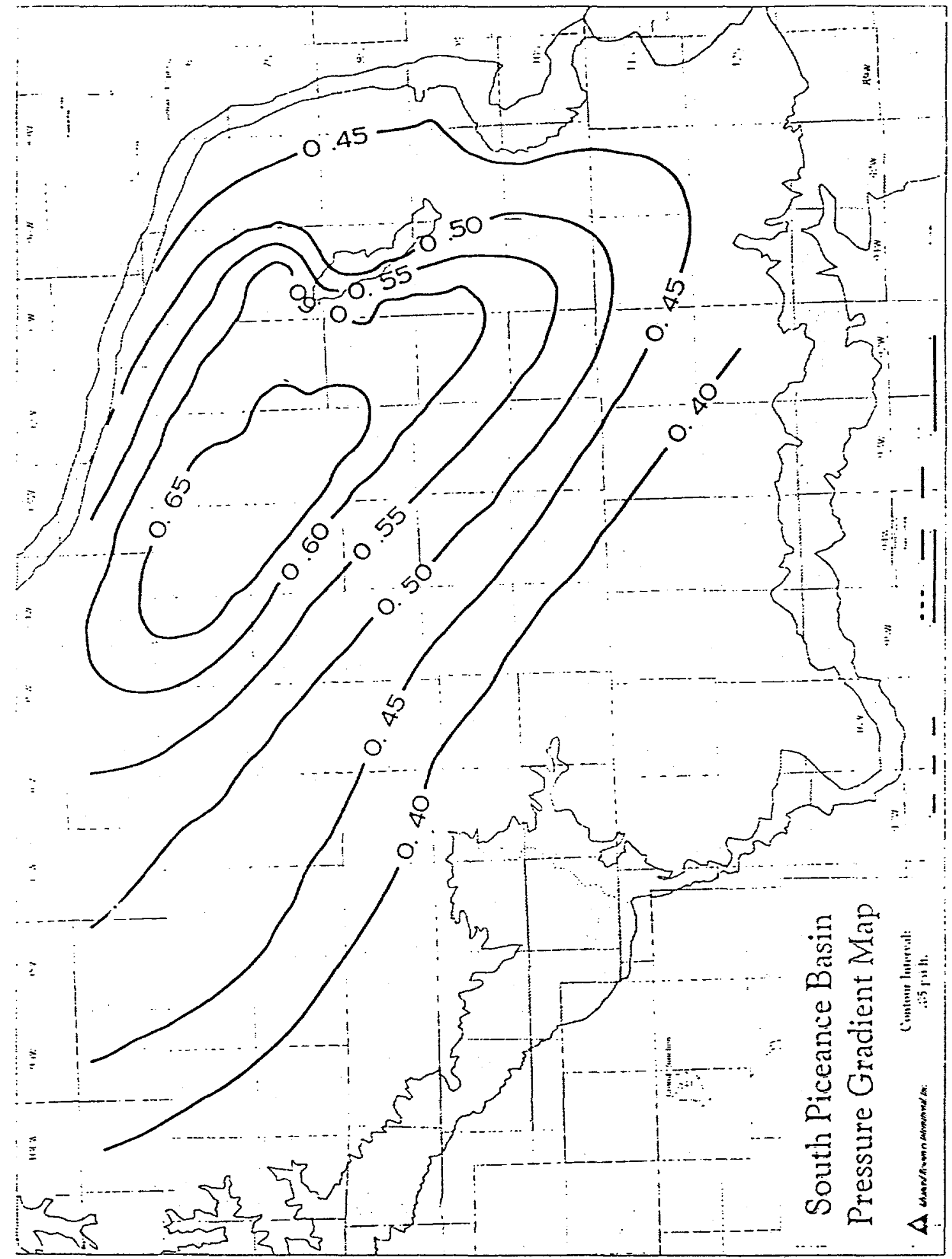

Fig. A11 Pressure gradient (producing formation pressure/depth to producing zone) as a contour map in the southern part of the Piceance Basin. 


\section{Naturally Fractured}

\section{Tight Gas Reservoir}

\section{Detection Optimization}

\section{Appendix B}

\section{Automated Three Dimensional Reconstruction of Sediment Geometry and History}

D. Payne, W. Sibo and P. Ortoleva Laboratory for Computational Geodynamics Department of Chemistry

Indiana University Bloomington IN 47405 


\section{Abstract}

The geometry of sedimentary bodies and the history of sediment input across a basin are reconstructed from well data. The spatial and space-time interpolation approaches introduced here respect the sharpness of property changes across a contact and the possible smooth variations within a sedimentary body. The shape of sedimentary bodies in three dimensions is constructed by our algorithm to be consistent with forms generally expected from observations of well-studied basins and sedimentary environments.

The algorithm we have developed has the generality to accept wells of irregular spacing. Data from each well need only cover a limited interval of depth and time. The technique admits even very sparse well coverage by incorporating a correlated interwell interpolation approach.

The procedure is implemented as a computer code. As new well data becomes available the spatial and historical reconstruction becomes improved in precision. Input to the simulator is a set of well files. Each well contains the sequence of lithologies for a given well including information on the thickness, age, mineralogy, grain size, and surface elevation. The output is the rate and characteristics of sediment being deposited at any time in the geological past for any location within the basin. Our program yields the present-day three dimensional configuration of all sedimentary bodies and the variations of lithologic characteristics within each of them. Built-in three dimensional graphical tools make the software package a valuable research and E\&P tool.

\section{Well Data Interpolation Concepts and Challenges}

For practical reasons, basin research usually is based on sparse and irregularly 
configured data. Nonetheless one is often interested in reconstructing the spatial geometry of sedimentary bodies in three dimensions or the detailed history of sediment input and erosion across the basin. Such information is invaluable in unraveling the history of the basin and for applications such as exploration through basin simulation, reservoir characterization and simulation, and resource assessment.

To be effective such a reconstruction must have a number of key attributes:

- automation so that new data can continuously be added for constant reevaluation;

- automatic output of cross-sections and three dimensional graphical representations;

- respect of general knowledge of sedimentary body geometry, sharpness of property changes across contacts and smooth variations within a lithologic unit; and

- respect of irregularity of well location and depth/time interval of available lithologic information.

Thus an effective approach must transfer sparse, irregular data into a basin-covering picture that respects notions of sedimentology and can be continuously and automatically updated. Clearly a computational approach is called for.

Our approach is based on a set of mathematical formulae and algorithms which can be implemented as a computer program. The input is chronostratigraphic data for a set of irregularly located wells. The output is the three dimensional data characterizing the present-day configuration and characteristics of all sedimentary bodies. The data is output on a hexahedral grid adapted to the bodies for accurate and efficient graphical characterization and reservoir simulation. Historical data is developed such that the rate and character of sediment at any point across the basin at the time of deposition (excepting diagenetic changes), at any time in the past history of the basin, can be recalled. The 
history recreation is formatted as a subroutine for use in three dimensional basin history simulation. Our concepts, formulae and procedures are outlined in the next section.

It should be emphasized that our procedure is far from a simplistic, interwell interpolation scheme. Rather, it might more accurately be characterized as an interpretation algorithm. The discrete (i.e., well) data is extended and infilled by procedures which carefully adhere to special constraints arising out of commonly held sedimentological concepts. Furthermore, the flexibility of our approach will allow for later improvements that directly integrate seismic and other data.

\section{Interpolation/History Reconstruction Approach}

\section{A. Introduction}

A new triangulation sedimentary history reconstruction module has been developed and has been implemented. The data input is in the form of well files. These files contain petrologic and age data at a set of well locations. The output of this module is the rate and texture of sediments laid down at any point in the basin at any specified time during the evolution of the basin.

In our earlier approach, the interwell interpolation formulae had the problem that contacts between lithologies were often artificially jagged, although the approach did preserve sharp changes of texture across contacts. In the new approach, the contact irregularity problem is alleviated by dividing the map into a set of triangles whose vertices lie at the well sites. Then the shape of a contact can be constructed geometrically within each triangle so as to be continuous across the basin. 
A key to our practical implementation of this approach is to automatically create the triangular subdivision of the map by a computational algorithm. An example of such a computer generated subdivision of our Piceance Basin simulation domain is seen in Fig. B1.

There are several special cases for the sedimentary history reconstruction at a point in map view of the basin:

- the point lies outside the triangulated region (see Fig. B1); or

- the point lies within a triangle with three vertices such that

(a) all vertices (wells) have the same lithology;

(b) one vertex is a different lithology from the other two; or

(c) all three vertices are different lithologies.

We believe that the result is the only sedimentary history reconstruction module that

- preserves sharp contrasts of texture across lithologic boundaries, and

- integrates space and time data to predict the morphologies of sedimentary bodies in three dimensions.

Next quarter, we shall include a detailed examination of the key formations in the Piceance Basin and of the entire sediment package using our new reconstruction algorithm. This shall be invaluable in exploration and development projects in general, and for naturally fractured reservoir prediction in particular. In the latter context, the mechanical properties of various lithologies enter into the computation of stress. Hence, an accurate characterization of the geometry and texture of these lithologies is a central issue.

Simple least square or other interpolation approaches do not meet the demanding requirements of space and space-time reconstruction of the present problem. Our specific procedures were developed in a step-by-step effort to integrate all the above-cited attributes into our methodology. Here we describe the major procedures and the special reasons for developing each of them. 


\section{B . Well Pairing Interpolation}

The goal of the interpolation is to know the state of the system (lithologic and chronostratigraphic characteristics) at any given point $\bar{r}$ in the horizontal plane for specific depth $(z)$ and time $(t)$, given the status at each of a finite number of wells where lithologic and chronostratigraphic information is known. Fig. B1 suggests the typical sparseness and irregularity of well coverage in a basin. As sedimentation tends to be a local phenomenon, the interpolation approach adopted is based on the selection of an appropriate pair of wells near the point $\vec{r}$ of interest. If the pair is strategically chosen then the states of the sediments at $\bar{r}$ in map view can be interpolated from data at these wells. The complexities that arise, however, are that a simple geometric criterion such as "the nearest two wells" may fail as one or both may lack the required depth/time data and that the point $\bar{r}$ may not reside in the general region between such a pair.

For each point $\vec{r}=(x, y)$ an interpretation pair of wells is chosen according to the following strategy. The map view of the interpolation well (pair denoted by indices) $i$ and $j$ and the point $\bar{r}$ are seen in Fig. B2(a).

The nearest well to the point $\bar{r}$ is identified and called $i$. Then one would like to find the next nearest well (called $j$ ) such that $\vec{r}$ lies in the region between the $(i, j)$ pair. This is insured as long as

$$
\vec{r}_{i} \cdot \vec{r}_{j}<0
$$

where $\bar{r}_{i}$ is vector displacement in the horizontal plane from $\bar{r}$ to well $i$ (and similarly for well $j$ ). If the above search yields no such $(i, j)$ pair, our procedure is to choose $j$ to be the next-nearest well to $\vec{r}$. The well pair $(i, j)$ is used in the interpolation for the point $\vec{r}$.

With this pairing algorithm the basin becomes divided into domains, each of which is dictated by a given well pair. Fig. B2 (b) illustrates how our algorithm does this for a three well data set. 


\section{Constructing the Horizontal Contacts}

For sedimentary history reconstruction, the value of the rate and character of sedimentation is required at any time $t$ of interest in the past for each point $\vec{r}(=x, y)$ in map view. At a given $t$, the contact between two formations is a curve in the $x, y$ plane. In our approach we determine how this curve passes through the interpolation region controlled by the $(i, j)$ pair. In our procedure the contact in this region is considered to be a straight line passing between $(i j)$ normal to the line joining the location of wells $i$ and $j$, passing through a particular point on this line. Several rules were established to make the choice of intersection point reflect the time course of the sedimentation as suggested by the well data. As a result the contact curve is piecewise linear.

The rules for picking the intersection point reflect the formation at wells $i$ and $j$ at the time of interest as follows.

1. If the formations in $i$ and $j$ at $t$ are the same, obviously there is no contact curve passing through the $(i, j)$-dominated zone.

2. Consider the case illustrated in Fig. B3 that shows a view of two wells where at the specific time $t$, well- $i$ has formation A and well- $j$ has formation B with the preceding and following formations and their corresponding times as illustrated in Fig. B3. Using the distance between the two wells and the time differences $t_{3}-t_{1}$ and $t-t_{l}$, we can specify the contact point $p$ by the linear method as suggested in Fig. B3.

3. In another case, at the time $t$ of interest the well $i$ has formation A and well $j$ has formation $B$ and no formation $A$ above or below; the entire period of deposition of $A$ is included within the period of deposition of $B$, as is illustrated in Fig. B4. Then the point of intersection $p$ is found by using the times $t_{2}$ and the median time $\frac{1}{2}\left(t_{2}-t_{1}\right)$ and the midpoint on the line joining the two wells, as suggested in Fig. B4. 
Many other cases can arise. More than 12 different cases are actually considered in our procedure so as to account for the many possible situations that may occur geologically.

\section{The Well Pair Interpolation Equation}

After determining the intersection of the horizontal contact curve at time $t$ and the line joining the interpretation well pair $(i, j)$, the following is assumed. Within the domain in the $(x, y)$ plane dominated by the $(i, j)$ pair, the horizontal contact is a straight line perpendicular to and passing through the contact point on that connecting line determined as in Subsection E. Therefore the region dominated by the two wells is divided into two portions by the perpendicular line contact. Thus any point on the $j$-well side will have the same formation as that of the $j$-well at that time (and similarly for the $i$-well).

Having established the horizontal contact in the $(i, j)$-dominated region, we adopt an interpolation scheme that reflects potential sharp changes in sediment characteristics across it. Let $U(\bar{r})$ be a variable quantifying the rate of deposition or the texture of the deposited material. The formula is adopted:

$$
U(\bar{r})=U_{i}(1-\Phi)+U_{j} \Phi
$$

where

$$
\begin{gathered}
\Phi=\left\{1+\exp \left[\gamma\left(d_{j}-d_{p}\right)\right]\right\} \\
\gamma=\left(1 / d_{i}+1 / d_{j}+1 / d\right) / \alpha \\
\alpha=\alpha_{1}+q\left(\alpha_{2}-\alpha_{1}\right)
\end{gathered}
$$

The symbols used are as follows.

$U \quad$ the variable of interest

$\bar{r} \quad$ location at which sedimentation information is sought

d a constant fixing the minimum distance on which properties change when traversing the contact 
$q, \alpha_{2}>\alpha_{1} \quad$ constants that control the degree of smoothness of the transition of, for example, across a contact (deposition rate or textural characteristics - i.e., $U(\bar{r})$ ); note $0<q<1$ and thus the two $\alpha$-parameters characterize sharp (small $\alpha=\alpha_{1}$ ) and smooth (large $\alpha=\alpha_{2}$ extremes, thus $q$ measures the "quality" of the preservation of the resolution imposed local interwell spacings

$d_{i}, d_{j}$. the distance from the point of interest to the line perpendicular to the line joining the pair of wells $(i, j)$ at the point of wells $i$ and $j$ respectively

$d_{p} \quad$ the distance between the point $\bar{r}$ and the locally linear contact in the $(i, j)$-dominated region (that is perpendicular to the interpolation well pair $(i, j))$

Thus the horizontal contact takes the form of a set of joined line segments and the sedimentation variables $(U)$ vary smoothly across the contact via formulae whose sharp or gradational character is controlled by the quality factor $q$ and the resolution imposed by the local interwell spacing.

\section{E. Depth Interpolation}

The above history reconstruction was also found to be most effective in developing a three dimensional $(x, y, z)$ interpolation of the distribution of texture and the geometry of lithologic units within the basin. The formulation we propose is to constrain the presentday configuration by determining the depth of sedimentary isochrons. This formulation allows the development of an automatically adapted three dimensional grid that resolves and preserves contacts as noted in later sections.

To determine the depth of each point of the basin at certain times, first we find the corresponding depth at each well then the depth of the point is calculated by using a 
modified Gaussian interpolation formula as follows. Let $Z(\vec{r}, t)$ be the present-day depth of the material deposited at time $t$ in the geological past at point $\bar{r}$ in the horizontal plane. Then $Z(\bar{r}, t)$ is expressed as an interpolation from the depths $Z_{w}(t)$ at well $w$ :

$$
Z(\vec{r})=\sum_{w} \omega_{w} Z_{w} / \sum \omega_{w}
$$

where

$$
\omega_{w}=\exp \left(-L q\left|\bar{r}-\bar{r}_{w}\right|^{q}\right)
$$

$\vec{r} \quad$ the location in the horizontal plane $(x, y)$ of the point of interest

$\bar{r}_{w} \quad$ well $w$ location

$L \quad$ length characterizing the smoothness interval of the interpolations

$q$ exponent which controls the smoothness of the transition of properties across a contact.

In our formulation, $L$ and $q$ are

$$
\begin{aligned}
& L=\text { the average distance between all pairs of wells } \\
& \qquad q=2
\end{aligned}
$$

\section{F. Upward and Downward Extension of Individual Well File}

Typical well data is only available for a given depth and time interval and does not necessarily start from the surface or end at the same depth and age in all wells. This data irregularity has been surmounted by automatic upward and downward extension of all individual well data via a correlation procedure using the wells near a given well to "fill in" missing data. This correlation incorporates two factors. Well data intervals are extended upward to the surface and downward to a common time originated by a direct nearest neighbor well correlation. Then a smooth isochron surface $Z\left(\bar{r}, t_{o}\right)$ for the earliest time is 
constructed, the downward extrapolations are then extended or compressed to terminate on the smoothed origin isochron surface. These two procedures are as follows.

\section{Upward/Downward Neighbor Correlated Extrapolation}

Each well is checked for its oldest age. If it is younger in age than the oldest data in the total well set, the data from the nearest well originating at an older age is used to add older data according to the sediment rate and the difference in time interval and to copy the lithologic characteristics to the younger-terminating neighbor. If the nearest well does not contain old enough data to extend the well of interest to the original time the next nearest well is checked and, if it contains old enough data, is used, and so on. This process is repeated until all wells are extended back in time to $t_{o}$. A similar procedure is used to extend wells up to the surface of the sediment pile (i.e., to the present time).

\section{Earliest Time Surface Smoothing and Well Readjustment}

The above procedure makes all wells end at the same (original) time $t_{o}$ but tends to yield an original isochron surface $Z\left(\bar{r}, t_{0}\right)$ which is artificially rough due to the underlying scarcity of data. Some of the added depths have exaggeration or underestimation of what one might expect the real depth to be. We attempt to find a smoother surface $Z\left(\vec{r}, t_{o}\right)$ that passes as close as possible to all the extended bottoms of the wells by using a least square method. After the least square surface is constructed, the wells with added earlier age data are compressed or extended so that they meet the least square surface $Z^{L S}\left(\bar{r}, t_{o}\right)$.

\section{G. Intra-Triangle Interpolation}

The interpolation within a triangle is determined by considering three cases separately:

- wells at all vertices have the same lithologic unit $(\mathrm{A}, \mathrm{A}, \mathrm{A})$ 
- wells at two vertices have the same lithologic unit and have one vertex with a different unit $(A, B, B)$

- wells at all vertices have different lithologic units $(A, B, C)$.

The contact for the (A,B,C) case is established as suggested in Fig. B5. The other nontrivial case $(\mathrm{A}, \mathrm{B}, \mathrm{B})$ is determined similarly. Interpolation of properties within the triangle in the domain dominated by each vertex is by formulae analogous to the pair formulae. Details will appear in the final report.

\section{Grid Adaptation}

Sedimentary history reconstruction and present-day state interwell interpolation are both used in a computational approach to basin evolution or reservoir simulation. These two applications are implemented on discrete computational grids. Some optimal characteristics of these grids are as follows:

- grid lines should conform to the overall shape of the domain;

- within grid layers there should be adaptation to capture horizontal contacts; and

- subhorizontal grid layers should conform and adapt to top and bottom lithologic contacts.

These features are built into our formulation. Proceeding by a set of appropriately chosen times, the subhorizontal grid layers are added one by one to construct an adapted spatial grid. Also, grid nodes within each subhorizontal layer are adjusted to adapt with high node density to horizontal contacts. More details on our adaptive schemes are given in Sibo and Ortoleva (1996). 


\section{Testing of the Methodology}

Our approach was tested with Piceance basin data. With the output of the code and the integrated graphical interface we were able to obtain a three dimensional image of the basin stratigraphy, associated cross-sections, map views of the distribution of sediment being deposited at the earth's surface at specific times, and the possibility of using the probing modules to show the depth dependence of a user-specified variable at a specific map location.

Fig. B1 shows the map view of the well locations in the whole Piceance Basin. Examples of the output of our sedimentary recreation module are seen in Appendix C, Figure C5. 
Y

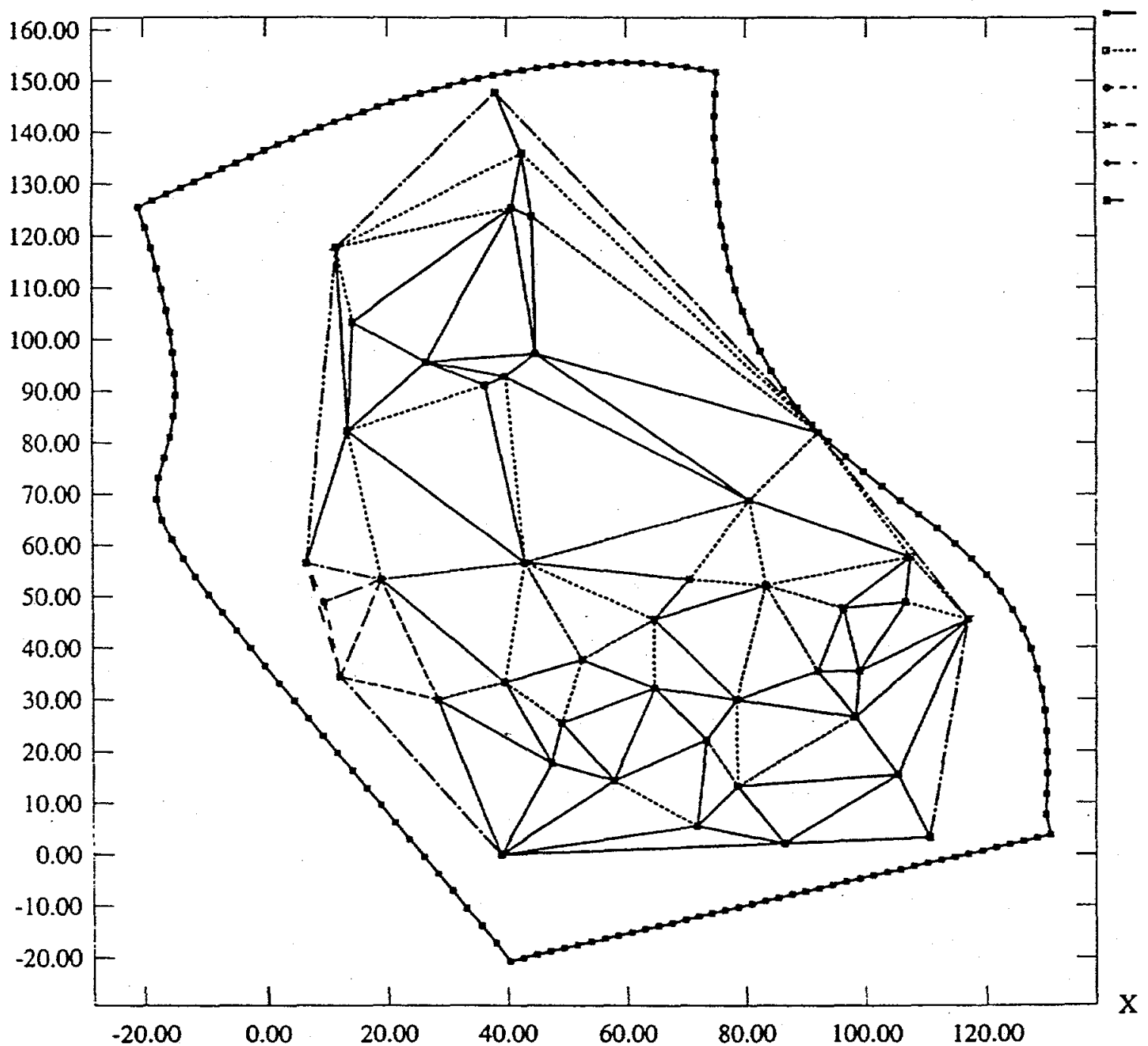

Fig. B1 Triangulation automatically created by our interpolation module that is part of our sedimentary history recreation module. By design, vertices of the triangles coincide with data well locations. 


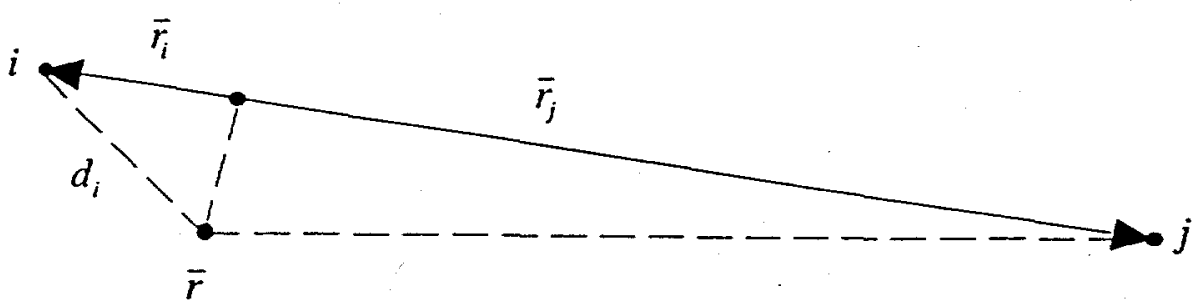

Fig. B2(a) Map view of two wells and one point.

Y

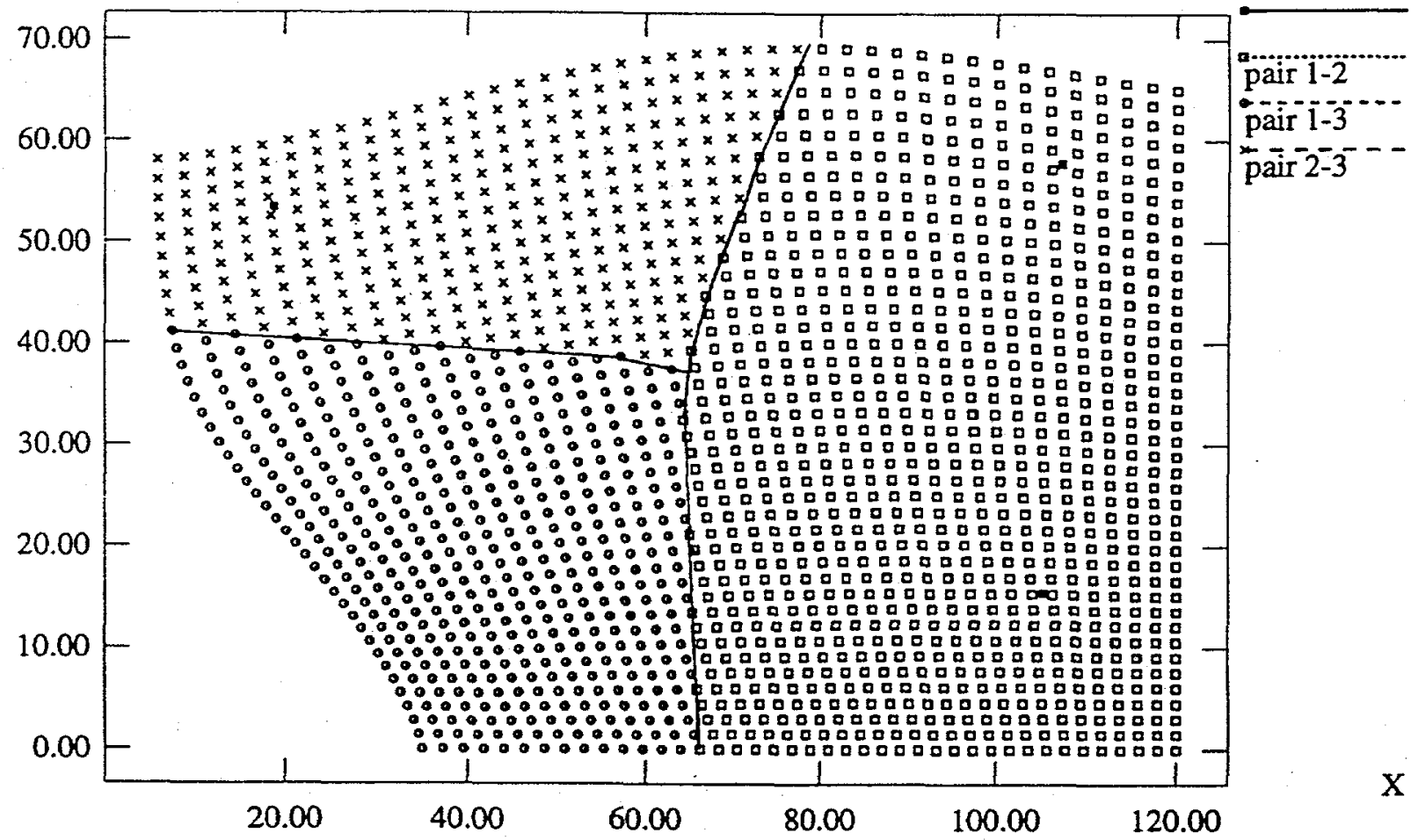

Fig. B2(b) Map view of a domain showing the dominance regions for the three wells. 


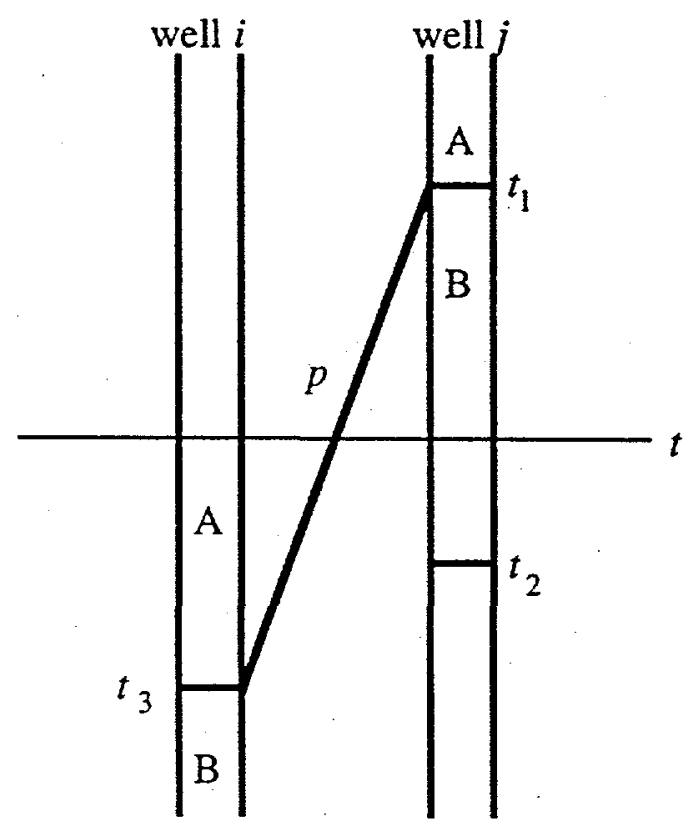

Fig. B3 Time view of two wells with matching formations $A$ and $B$ and the contact point $p$ for case 2 .

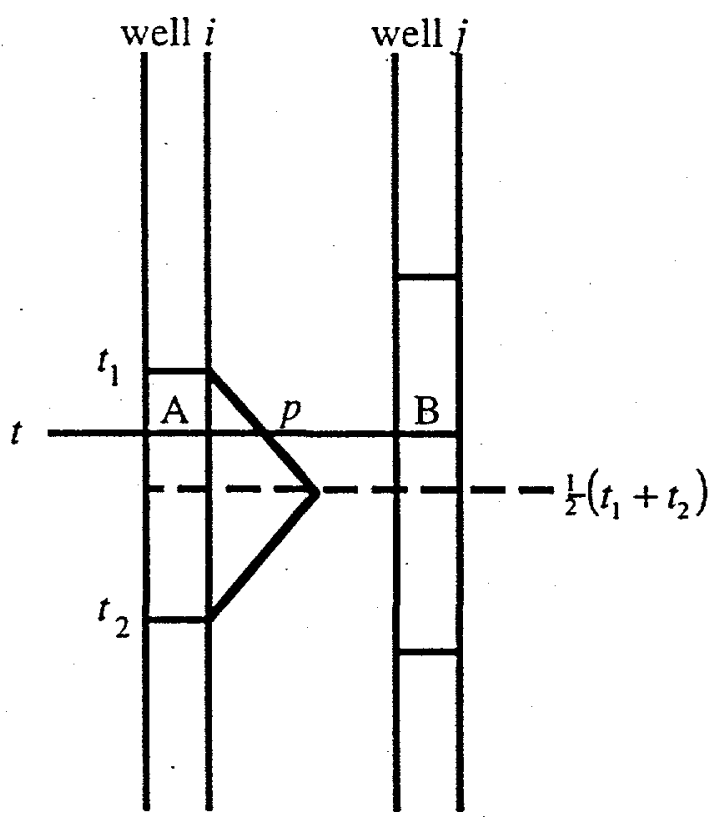

Fig. B4 Time view of two wells with formations A and B and the contact point $p$ dictated by the linear pinchout assumed to be at the midpoint between the wells $(i, j)$ at time $\frac{1}{2}\left(t_{1}+t_{2}\right)$. 


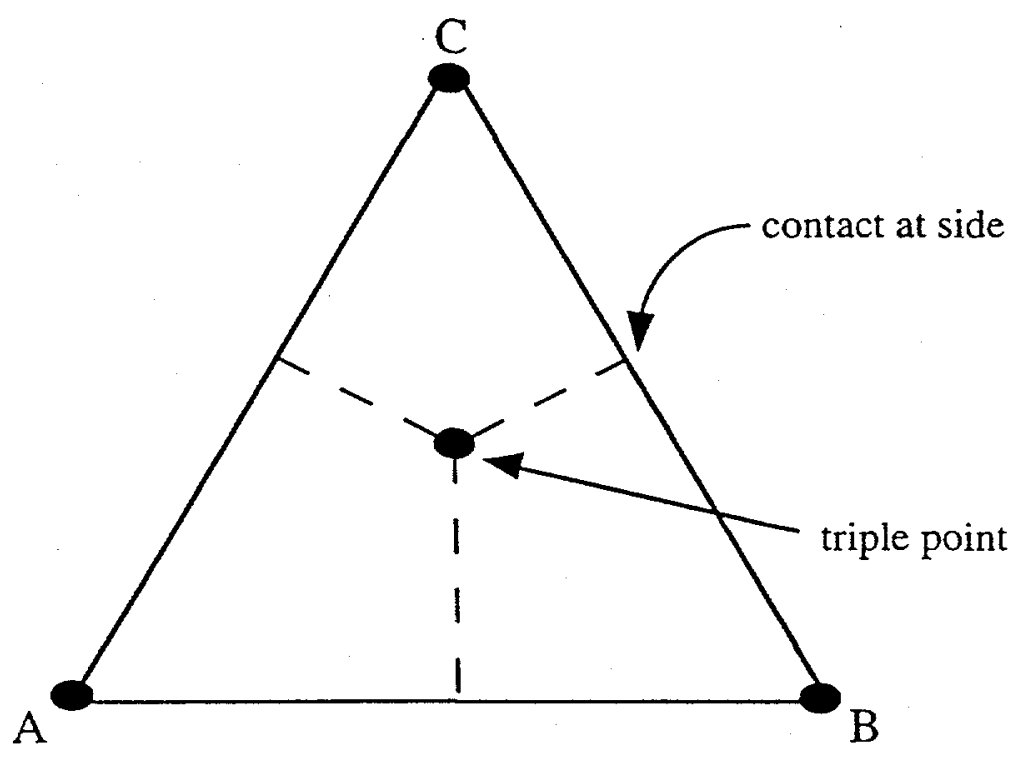

Fig. B5 Three wells (at triangle vertices) have different lithologic units $(A, B, C)$. Contacts on triangle sides are determined by well pair approach. The contact within the triangle is determined by assuming the triple junction is at the "center of mass" of the three side contacts. 


\section{Naturally Fractured}

\section{Tight Gas Reservoir}

\section{Detection Optimization}

\section{Appendix $\mathrm{C}$}

\section{Extended Modeling Domain for Fracture Prediction in the Piceance Basin}

D. Payne, W. Sibo and P. Ortoleva Laboratory for Computational Geodynamics Department of Chemistry Indiana University Bloomington IN 47405 


\section{Need for an Extended Study Domain}

The goal of this project is to develop modeling tools to predict the distribution of fractures in a sedimentary basin. This requires the computation of stress and fluid and rock properties within the basin and their evolution over the geologic past until the present. If the boundaries we choose to define the limits of the part of a basin of interest impose artifactual stresses or other properties then accuracy will be compromised. For practical reasons, however, one must limit the size of the domain even though a very large domain would eliminate boundary artifacts from that part of the system of interest. Clearly some compromise between accuracy, data availability and practicality is required.

In the past two years of this project we have limited our study area to the southern half of the Piceance Basin. This was done because of the paucity of well data on the northern part of the basin available to us in this earlier phase.

The earlier choice has several important shortcomings as follows. These shortcomings illustrate the considerations needed in choosing the simulation domain.

1. The northerm boundary of the original study area eliminated the deepest part of the basin. The deeper part of a basin is commonly an important source of fluid overpressuring from compaction and fluid thermal expansion. As such it likely sourced the southern half of the basin with thermal energy carried by centrifugal fluid flow.

2. Stresses in the deepest part of the basin are transmitted to the periphery and, conversely, stresses imposed by the periphery affect the deep center. Thus imposing an internal boundary can only be done reliably if the deformation history at this boundary are well known from the geological record. This type of data is not generally available. Extending the boundary of our simulation domain tends to overcome these difficulties.

The perspective of the future applicability of our projects also speaks for the northward extension of the simulation domain. In a practical context one would like our methodology to be able to extend information gathered in one well-characterized part of a basin into a prospective region with much sparser data. Thus the extended area study would, we believe, make our project much more interesting from the practical standpoint. 


\section{Details of the New Study Area}

Our choice of the new study area was guided by available geologic data and basement structure. Fig. $\mathrm{C} 1$ shows the major structures believed present in the Piceance Basin and Fig. C2 shows an observed pressure gradient map. In Fig. C3 we show the new and former (south-localized) simulation domains. For the new domain we show in Fig. C4 the map view of the original time basin-conforming grid to be used in our simulations.

The periphery of the domain was chosen for the most part to follow the outcropping of the oldest present unit of the Iles formation. This eliminated the need to specify details of the erosion history of these key units. It also placed the boundaries far from the deeper parts of the basin and included all known producing and likely perspective areas, including all coals and other units that might have served as petroleum sources.

At this time we have a low well coverage for the northern region. However, our automated sedimentary history recreation module allows our modeling to incorporate data from new wells as they become available. As we are formatting such new northern data and expect to have more made available to us, our new data set should meet the rigorous requirements of basin-wide modeling.

Using the interpolation package as described in Appendix B, Fig. C5 shows isochron mpas for the extended basin modeling domain. These are the full basin analogs of isochron maps for half of the basin as in Fig. A5(c). 
Piceance Basin Regional Structure Map
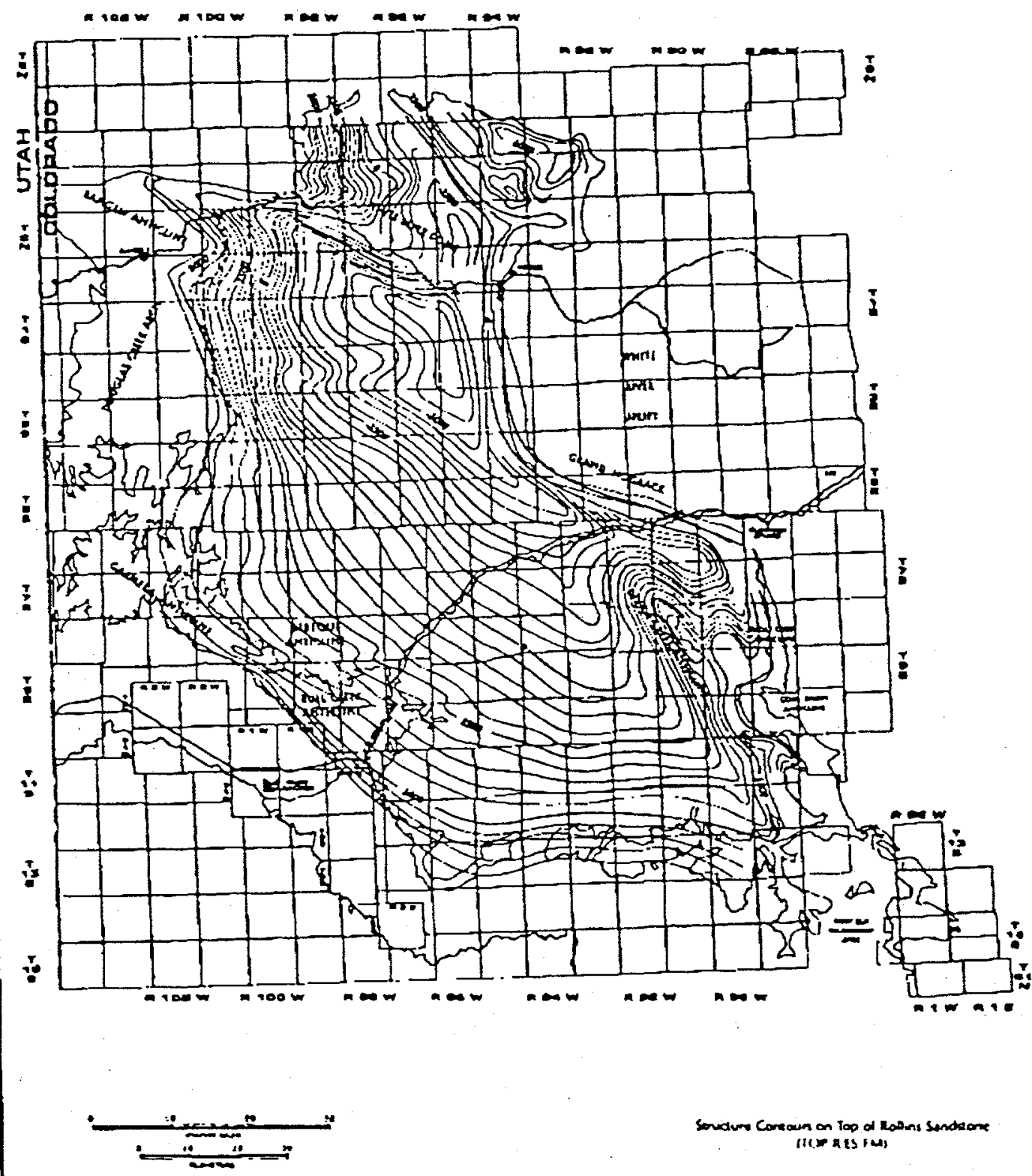

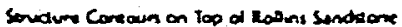
III) nes ins

Fig. C1 Piceance Basin in western Colorado. Contour lines show depth to top of Rollins sandstone of the Iles Formation, Mesaverde Group. This figure shows the symmetry of the basin, with the steep flank on the northeast side of the NW-SE-oriented basin axis. 


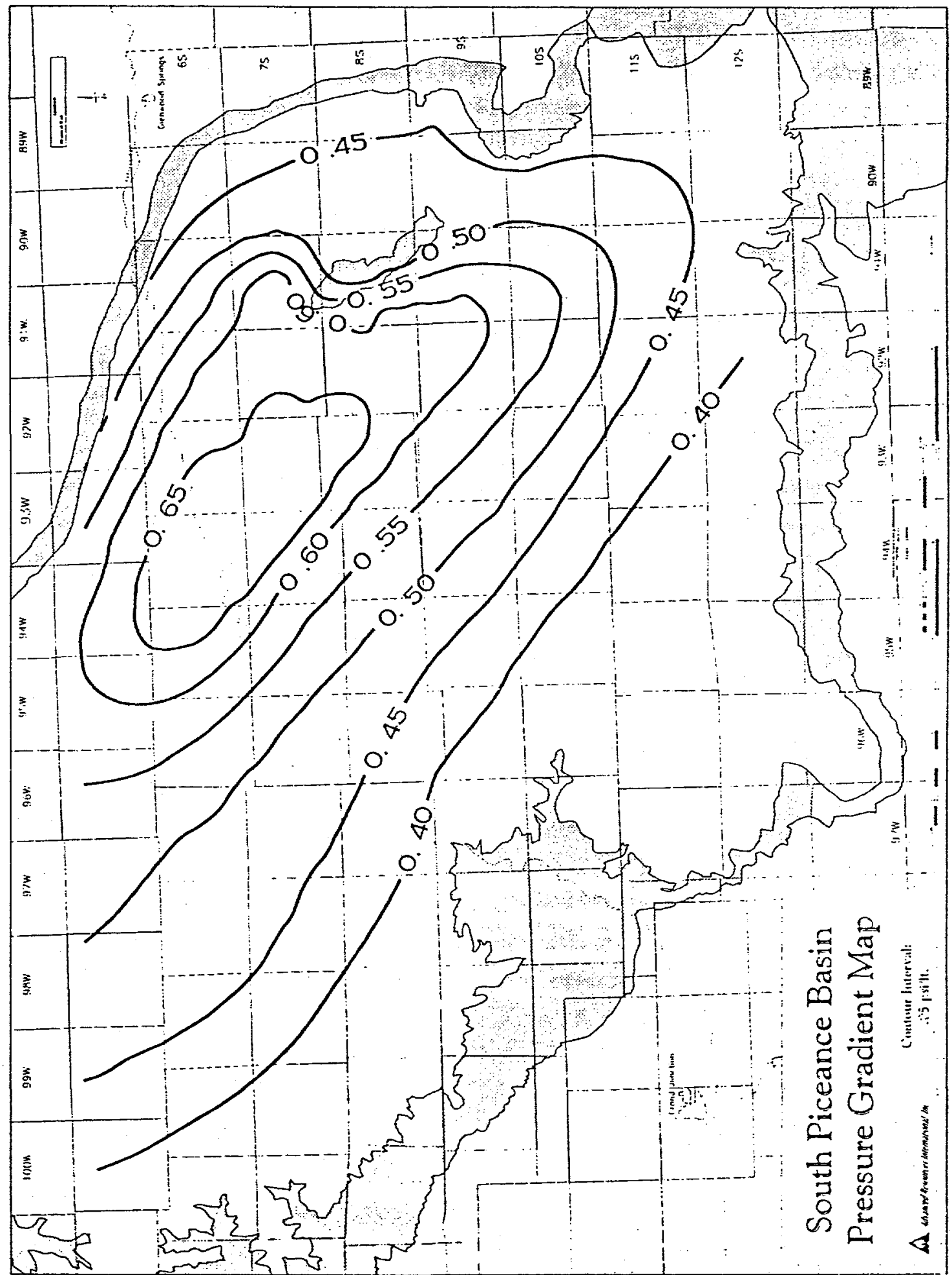

Fig. C2 Pressure gradient (producing formation pressure/depth to producing zone) as a contour map in the southern part of the Piceance Basin. See, however, Appendix D for a new look at the pressure data. 


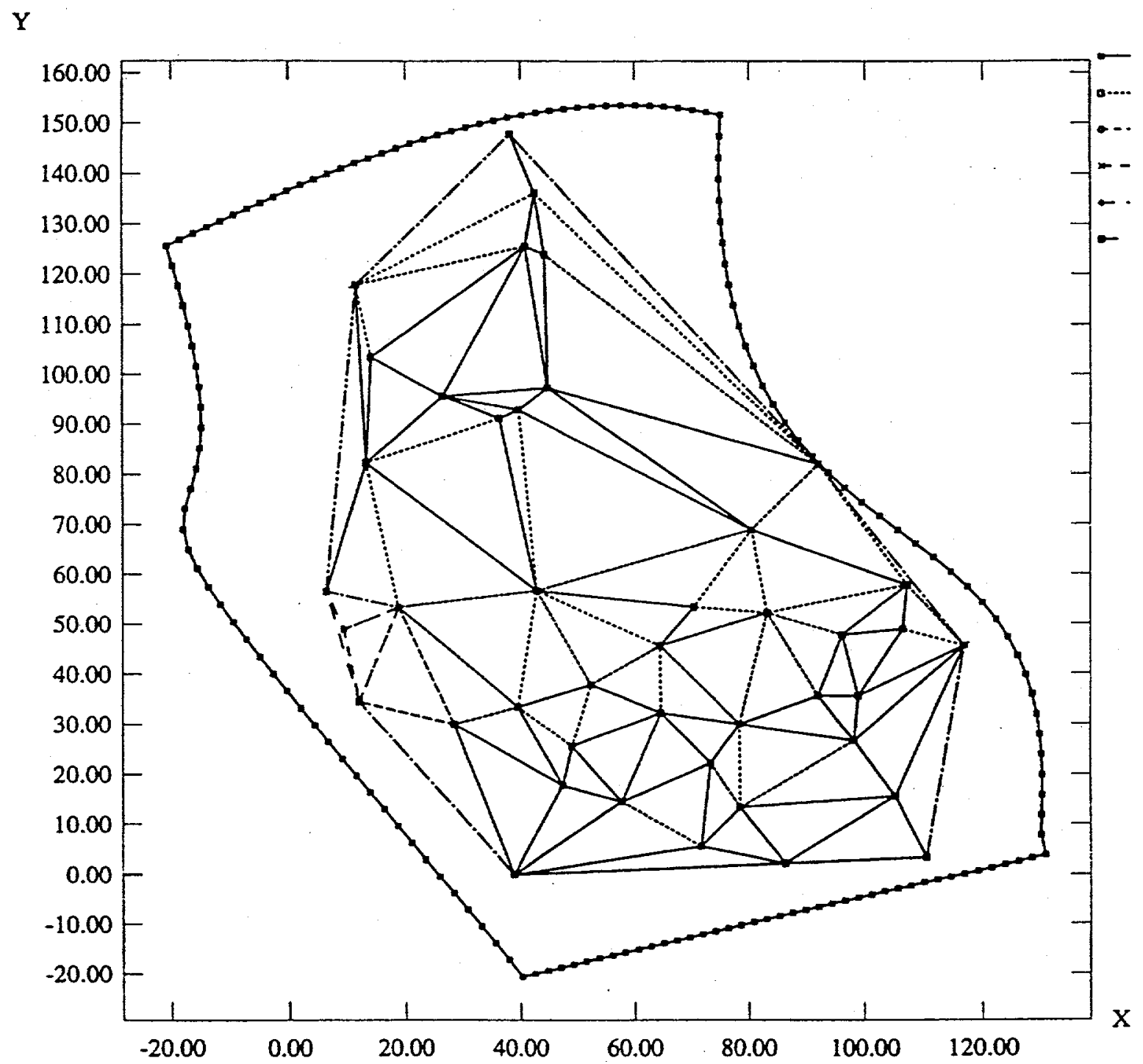

Fig. C3 Location of wells (shown as the vertices of the triangles) in data set for the southern part of the Piceance Basin, with overlain latitude/longitude grid. More wells in the northern part of the basin are being analyzed for basin simulation. 
$\mathrm{Y}$

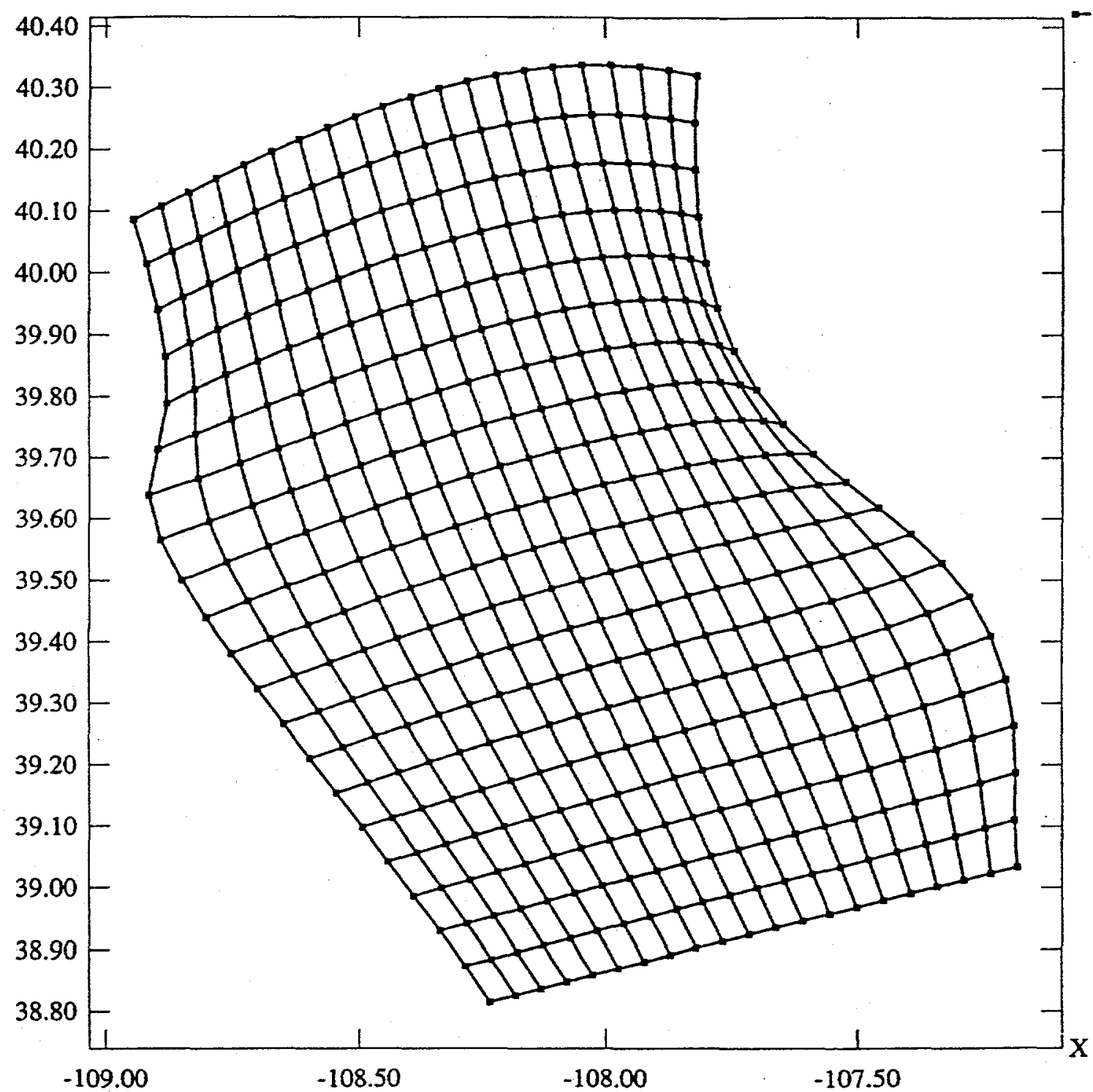

Fig. C4 Layer of computational grid, used to simulate the Piceance Basin; X and $\mathrm{Y}$ values in longitude and latitude. 
(a)

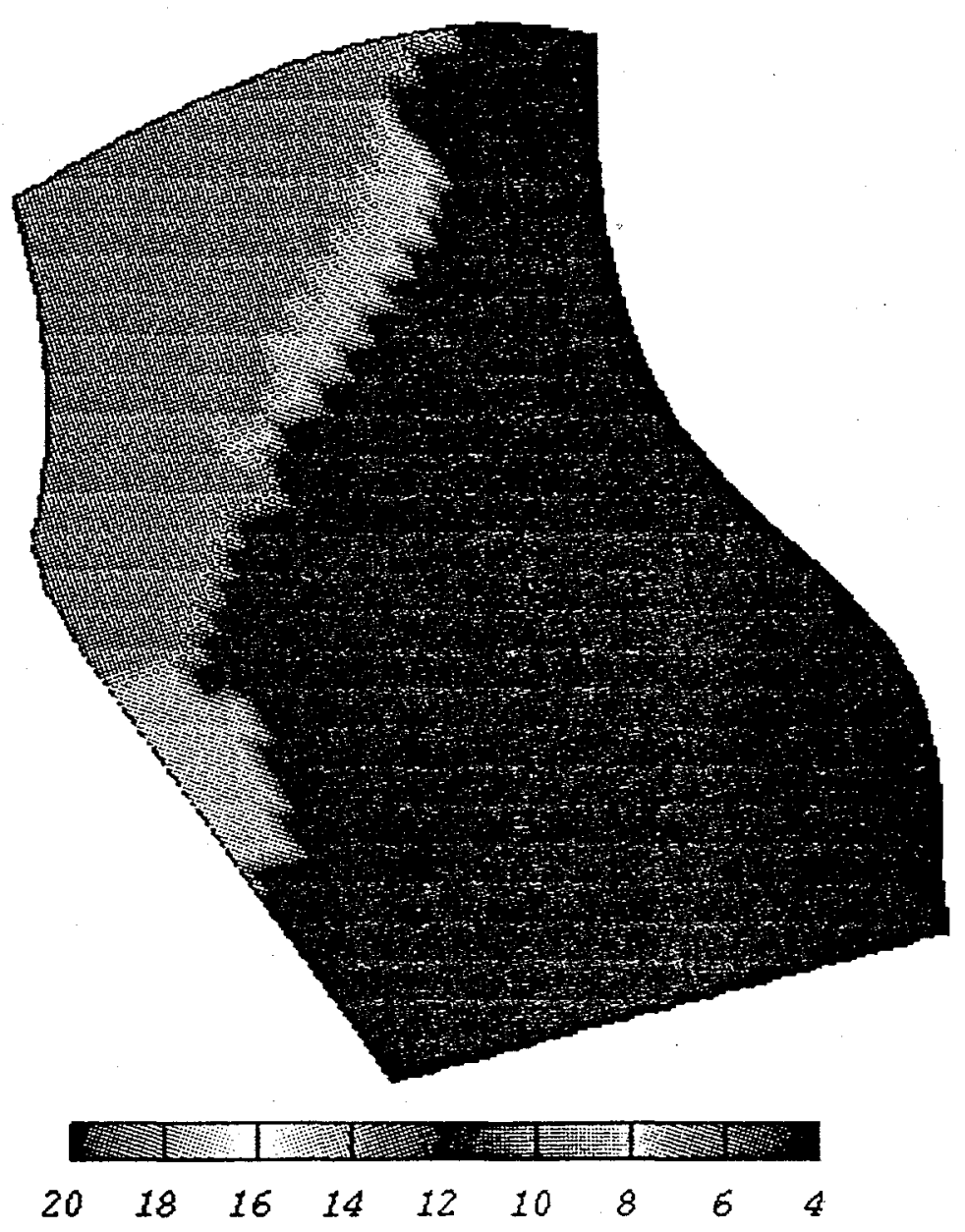

Fig. C5 Time-slice isochron maps showing distribution of formations at specific times, and the progradations of Rollins sandstone toward the southeast during marine regression. Red represents the Mancos marine shale; yellow represents the Rollins marine sandstone; green represents the terrestrial Paludal interval; and blue represents the terrestrial Fluvial interval. (a) 73.32 mya; (b) 73.13 mya; (c) 72.71 mya; and (d) 72.47 mya. 
(b)

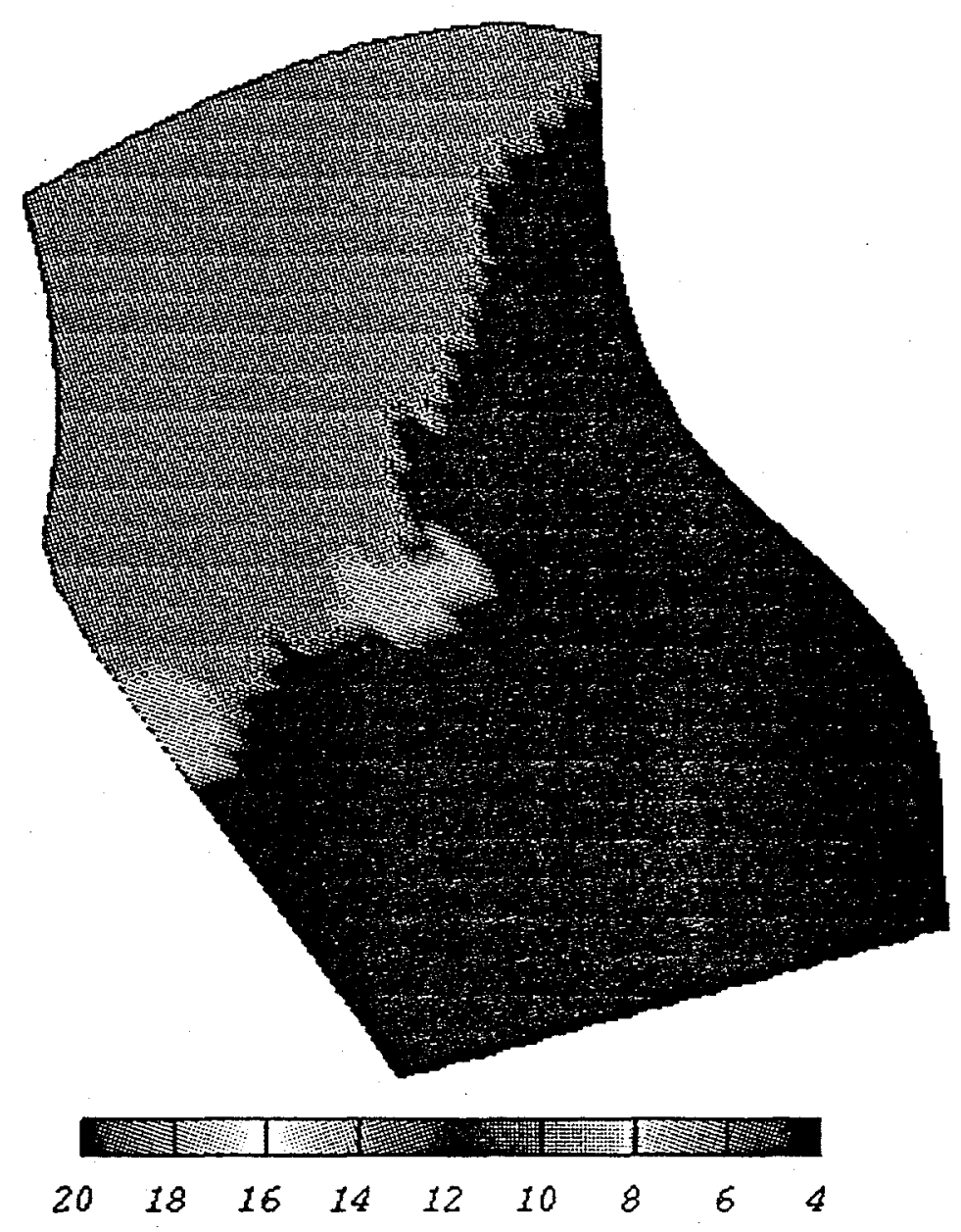


(c)

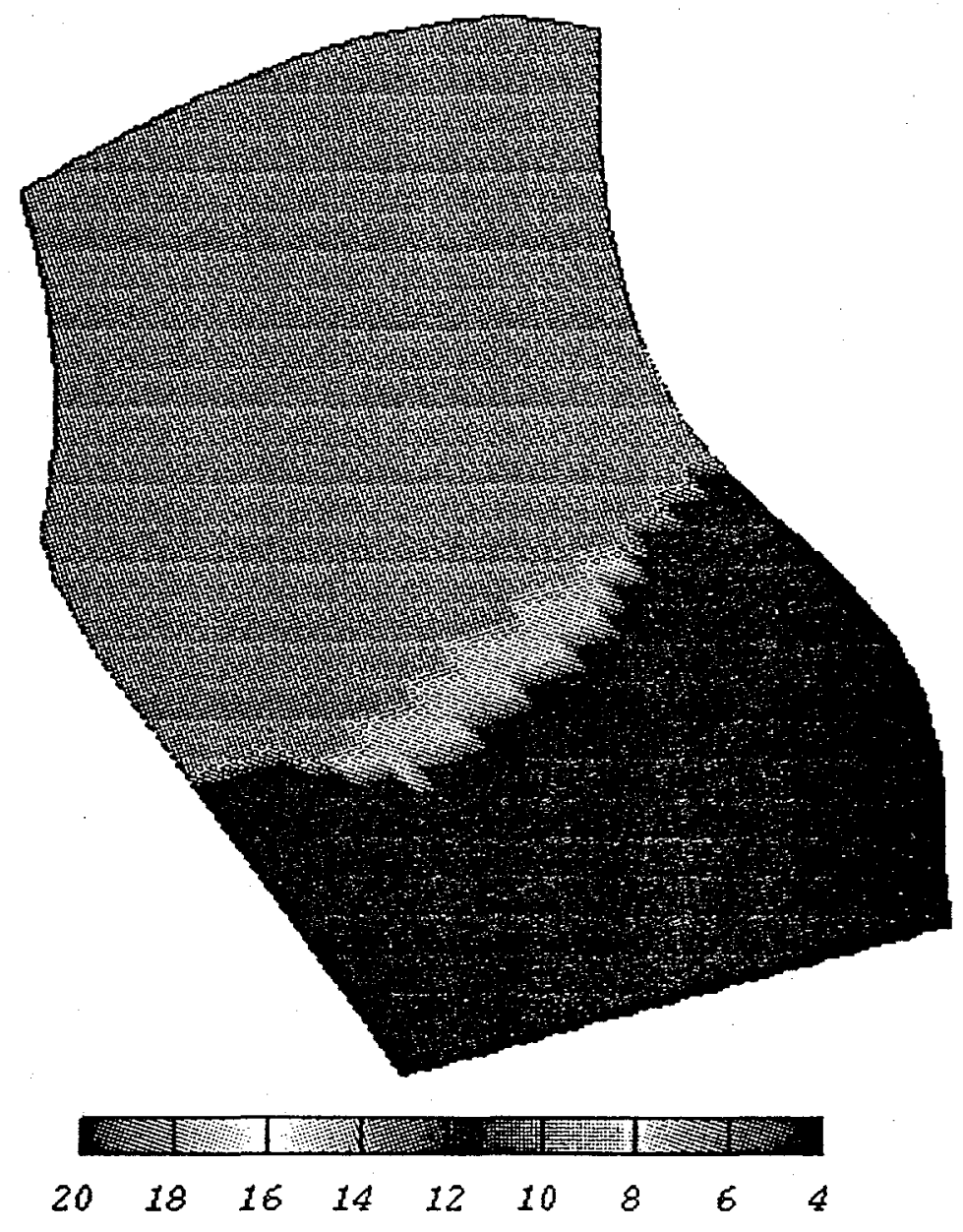


(d)

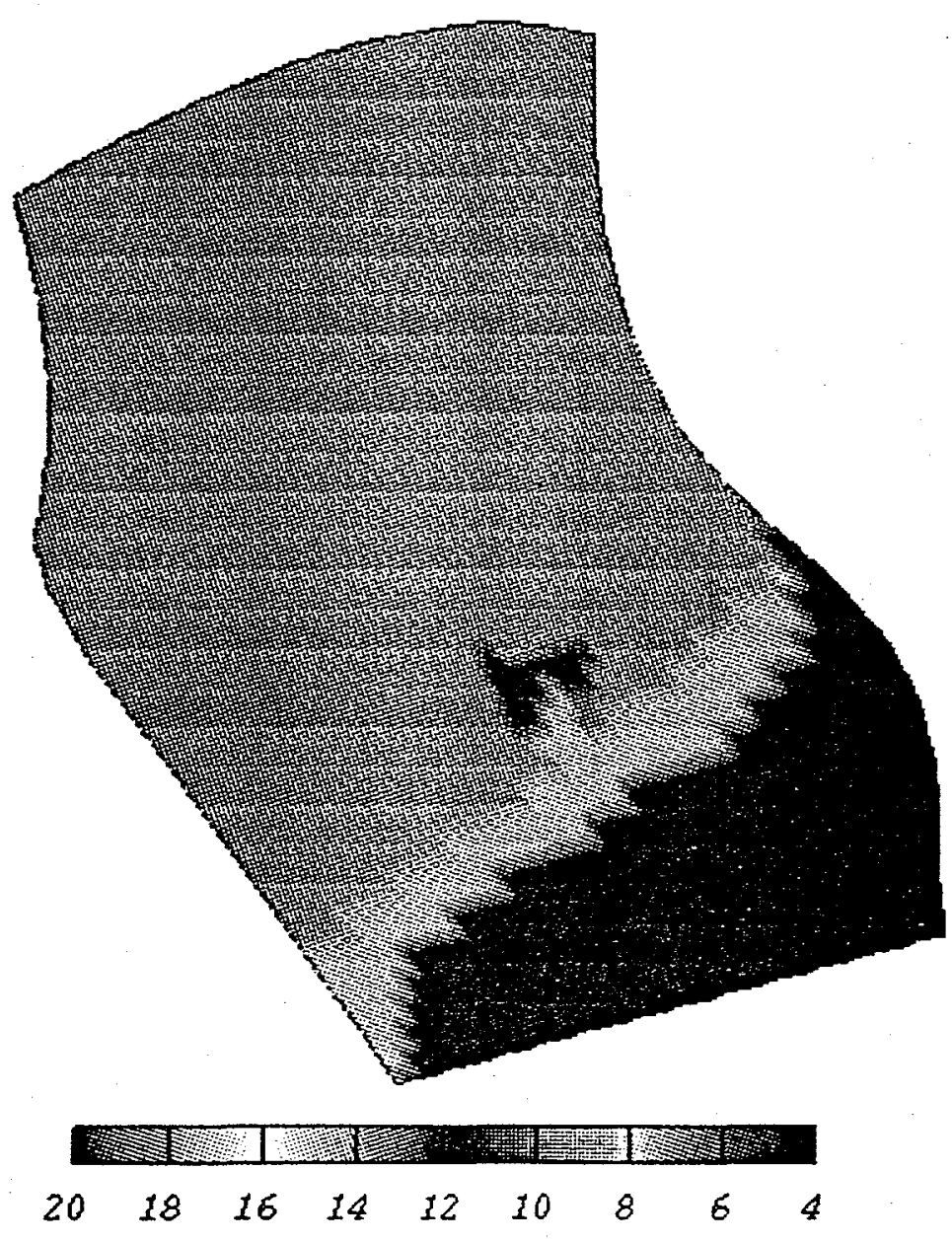


Naturally Fractured

Tight Gas Reservoir

\section{Detection Optimization}

\section{Appendix D}

Fluid Pressure Data and Compartmentation

D. Payne and P. Ortoleva

Laboratory for Computational Geodynamics Department of Chemistry Indiana University Bloomington IN 47405 


\section{Introduction}

Hydrofracturing occurs when pore fluid pressure exceeds least compressive stress plus rock strength. Thus pore fluid pressure is an important variable to be predicted by our CIRF.B model. Furthermore, good basin coverage of fluid pressure data makes fluid pressure an important quantity for calibrating and testing CIRF.B by comparing presentday observed and CIRF.B predicted fluid pressures.

\section{Reanalysis of Limited Data Set: Pressure Compartment in the Southern Half of the Basin}

The observed Piceance Basin pressure gradient map of Fig. D1 suggests that the Piceance Basin contains an abnormally pressured, basin-scale compartment. Here the data used to generate this picture of basin pressure is used to investigate the three dimensional structure of basin overpressured zones. Our objective is to contrast the results with those obtained using larger data sets. The results are dramatically different and appear to point out a very complex pressure (hydrologic) regime in the Piceance Basin. Our results also suggest the need for a more extensive examination of this complexity in the context of pressure data quality.

Compartments are zones of a basin that consist of a very low permeability surrounding seal and an interior of preserved porosity and permeability (Powley, 1990; Bradley and Powley, 1994; Ortoleva, 1994a,b,1996). They have been found of great importance in exploration and production applications. The configuration of compartments in a basin affects its overpressure distribution and hence the location of fractures. 
An attempt was made to delineate pressure compartmentation in the Piceance Basin using pressure data and some general notions of basin hydrology conjectured to hold in the Piceance Basin. The following procedure was used to develop a basin-wide pressure data set. A modified Gaussian formula was used to interpolate data given as a set of shut-in pressure values at 8 selected points $(x, y, z)$ in the southern half of the basin and the known pressure ( $1 \mathrm{~atm})$ along the top surface of the basin. Figs. D2(a,b) show isosurfaces of overpressure and underpressure, indicating that overpressuring tends to occur in the central part of the domain, and underpressuring occurs in the southeastern region of the domain. Note there is both an overpressured domain and underpressured one that lie in juxtaposition. This suggests that a seal lies between these two zones. Fig. D2(c) shows a map view of the overpressure zone on a latitude/longitude grid. Assuming pressures are normal below the abnormally pressured zone (as in many on-shore U.S. basins - see Powley 1990), it was conjectured that below the Mancos Shale normal pressures prevail. Thus, the Mancos Shale (Fig. D3) appears to play the role of the bottom seal of a basinscale abnormally pressured compartmented zone in analogy to that of the Woodford Shale of the Anadarko Basin (see Al-Shaieb et al., 1994a,b). Through this approach, the pressure data interpolation was constrained to keep fluid pressure below the Mancos Shale at its hydrostatic level. The latter was defined relative to the elevation of the surface at the mapview point of interest. This assumption is subject to criticism in that communication to the normally pressured zone might not be vertical. For example, this conjectured communication could be with the basin periphery, thereby having a strong horizontal pathway. This issue, as well as the general assumption of normal sub-Mancos pressuring, awaits further data for its resolution.

A key factor in producibility in the Piceance Basin is the presence of fractures. The distribution of fractures within the basin is related to the distributions of stress and fluid pressures. An indicator of the former is likely the distributions of structures while the latter 
follows directly from the fluid pressure data. Let $\sigma_{L}(>0)$ be least compressive stress and $p$ be fluid pressure. Then the quantity $\psi$,

$$
\psi=p-\sigma_{L},
$$

indicates the potential for an open fracture network. In particular, the domain $\psi>0$ is the domain of viable fractures. As $\sigma_{L}$ generally exceeds hydrostatic pressure (except in cases of extreme basin extension), the viable fracture zone must lie within the zone of positive overpressure.

At this writing, no least compressive stress $\left(\sigma_{L}\right)$ measurements across the basin were available. For illustrative purposes, assume the typical $\sigma_{L}$ value of 107.8 times overburden. Assuming a constant rock density of $2.2 \mathrm{gm} / \mathrm{cc}, \sigma_{L}$ is roughly 107.8 bars $\times$ depth (kilometers), in contrast with an approximate value of 98.0 bars $\times$ depth (kilometers) for hydrostatic aqueous fluid pressure. The resulting $\psi$ isosurface seen in Fig. D4 lies within the overpressured domain shown in Fig. D2(a). Fractures are thus likely to exist in the zone $\psi>0$ if the above assumptions on $\sigma_{L}$ are valid.

A more accurate description of the compartment structure and, in particular, fracture sweet spots in the Piceance Basin awaits more complete fluid pressure and stress data as well as fracture network mapping. In particular, one would like to correlate these with structures as in Fig. D5 and with gas production data, the latter presumably related to both gas content and fractures. A key practical challenge is to use remote sensing to predict fractured reservoir location and characteristics. Basin evolution and fractured reservoir prediction models are being used to make such predictions.

A key issue in the Piceance Basin is whether observed fractures are from overpressure, as suggested above, or flexure or other "tectonic" origin. If $\sigma_{L}$ is locally sufficiently low, as for flexure, then $\psi$ can be positive even though $p$ is hydrostatic. Thus, predicting fracturing requires a model of stress, fluid pressure and the diagenetics of fracture filling precipitation and cleating or other shrinkage phenomena. 


\section{Pressure Compartmentation According to the TBEG Data Set: Mosaic Compartmentation}

In this section, we review the available pressure data and its implications for the location and characteristics of abnormal pressuring in the Piceance Basin. We conclude that abnormal pressuring and related compartmentation is in the form of a mosaic of overand underpressured zones.

Fig. D6(a) shows the locations of pressure data points in three dimensions used to show the observed distribution of fluid pressures in the Piceance Basin and to calibrate the model; Fig. D6(b) shows a map view of the interpolation grid with latitude and longitude values along the axes. Fifty-six highest quality data points from thirty-one wells were taken from a list of pressure data compiled by the Texas Bureau of Economic Geology (TBEG). In this data set, shut-in times of drill stem tests (DSTs) were used to distinguish data groups of varying confidence levels: high quality data refers to data from DSTs in which shut-in times were greater than one hour; the remainder of the data was classified as moderate quality if the shut-in times were 30 to 60 minutes, or unknown if this information was unavailable (Kaiser and Scott, 1996). In Fig. D6(a), these data points represent the subset of data in which there is the greatest confidence. Most of the data locations, fortysix points, are within the Mesaverde Group, seven are in the overlying Tertiary units, and three are in the Mancos or older groups. The actual pressure values range from $682 \mathrm{psi}$ (about 47 bars) to 5462 psi (about 376 bars). Overpressuring, defined as the fluid pressure minus hydrostatic pressure, ranges from -103 bars to 56 bars.

Using our data interpolation package, this pressure data implies a patchy distribution of fluid pressures. Fig. D7 shows the isosurfaces of overpressure of one bar (a) and 10 bars (b). The greatest concentration of overpressure patches is in the region southeast of the central part of the basin, with fewer in the south central area and north central area. Fig. D7(c) shows the isosurfaces of -7 bars underpressure. Underpressure 
appears as a cluster of patches in the southern part of the basin, as well as a large continuous area in the northern part of the basin. Most of the smaller patches in the southern part of the basin are interspersed with the overpressure patches. In some cases the overpressure zone resides within an underpressured patch. Thus, in these regions overpressuring and underpressuring alternate in a vertical sequence. Likewise, the larger surface of underpressuring in the north encloses smaller patches of overpressuring located there.

This mosaic character may be illustrated by examining the overpressure distribution on isochron surfaces. Figs. D8(c-f) show map views of pressure distribution on isochrons between the 70.1 mya isochron (Fig. 8(a)) and the 72.6 mya isochron (Fig. D8(b)). Figs. D8(c-e) show three small, isolated overpressure compartments: the 70.2 mya isochron, the 70.35 mya isochron, and the 72.6 mya isochron. These overpressure compartments are enclosed within and separated by the ambient underpressure. Fig. D8(f) shows distinct strongly underpressured and normally pressured compartments, enclosed within the ambient underpressure (approximately -10 bars) on the 71.0 mya isochron. In addition, a diffuse zone of underpressure exists in the north central part of the basin, one of the deeper parts of the basin, just west of the deepest part of the basin. This is contrary to intuition, as it might be expected that deeper parts of the basin should tend to exhibit greater fluid pressures because of thermal expansion of fluids and compaction. This figure suggests that the hydrologic system of the Piceance Basin is rather complex.

We believe that the patches of overpressure and underpressure will correlate with structures in the Wolf Creek and Divide Creek Anticlines, as well as block faulting in the Rulison Field area, and structures in the Piceance Creek and Sulphur Creek areas in the northern part of the basin (Fig. D5). This correlation may be the result of their location in or proximity to fields, which usually are developed around major structures, or may reflect a structural control on fluid pressure distribution in the basin. In the next quarter, we will examine the nature of this correlation in more detail. 
The patchy nature of the fluid pressure distribution is not surprising in light of the heterogeneity of the reservoirs and their tight, largely fractured-controlled permeability. Some caution is advised, however, because of the low data density. For example, it is possible that overpressure occurs in a continuous zone of sinuously connected domains, the sinuous connections being missed by the low data density. The lithologic variability of the Mesaverde Group, especially the non-marine units of the Williams Fork Formation and overlying strata, is highly variable, comprising interbedded mudstones and fine grained fluvial channel sandstones, with interspersed coaly deposits. This results in units of complex morphology that are laterally discontinuous and not easily predictable in their subsurface location. Possible sinuous connections between overpressure zones could be through fluvial channel sandstones, although we don't have sufficient data yet to test this conjecture. In addition, the grain size and composition are variable, resulting in typically low permeability sandstones. Permeability and porosity are believed to be largely fracture controlled. Thus, the abnormal fluid pressure distribution will be largely influenced by the geometry, connectivity, and extent of the fracture network system.

These figures suggest that the Piceance reservoir system is highly compartmentalized. A study of the hydrology of the Piceance Basin by the TBEG (Kaiser and Scott, 1996), in which the above mentioned pressure data was used, supports this. They show that it is an unintegrated flow system, divided by permeability contrasts, faults and facies changes, as well as abnormal pressure zones. Thus, even with a greater density distribution of reliable data, we believe the resulting pressure distribution will have the same mosaic character, as shown in the above figures. Figs. D9(a-d) shows the distribution of pressure using an additional 75 points from the TBEG data set, although the confidence in this additional data, as evaluated by TBEG, is lower.

For comparison, we illustrate the distribution of abnormal pressures and compartmentation in the Anadarko Basin. Fig. D10(a) shows the distribution of points for which quality-screened pressure data was available. The quality analysis of this data was 
performed by Al-Shaieb and co-workers at Oklahoma State University. As determined by data points in Fig. D10(a) and our interpolation scheme, Figs. D10(b-d) show isosurfaces of underpressure and overpressure in the Anadarko Basin. In the Anadarko Basin, there are larger, more continuous regions of abnormal pressure, with significant overpressuring predominant in the south central part of the basin, and underpressuring in the northwestern half of the basin and toward the deep eastern margin of the basin. These figures suggest the presence of large abnormal pressure compartments in the basin, as well as clusters of smaller compartments lying outside the larger compartments. The differences in the character of pressure compartments in the Anadarko Basin relative to that of the Piceance Basin may be attributed to two factors, a geologic factor and a data density factor. First, the Anadarko Basin contains lithologies with more conventional intergranular porosity and permeability, which allows much greater fluid communication across larger areas of the basin. This is in contrast to the hydrologically unintegrated Piceance Basin. Secondly, over 2900 pressure data values were used in the Anadarko Basin, allowing a much better resolution of the pressure distribution. This is in contrast to fewer than 200 data points in the above Piceance Basin study.

It is important to note that data availability and selection will affect the interpreted three dimensional character of the fluid pressure distribution. For example, Fig. D1 1 shows the 10 bar overpressure isosurface using only the normal to overpressure values of the high quality TBEG data set. In other words, the high quality data set has been arbitrarily screened by removing all underpressure values, leaving only 16 pressure data points in the normal to overpressure range. In contrast to Fig. D7(b), this isosurface is large and continuous in nature, and does not show the mosaic character. In selecting the data in this way, the fluid pressure profile resembles more closely what is expected to be the compartment style of basins with more conventional intergranular porosity and permeability. From this, we conclude that it may be dangerous to simply extrapolate one's view from experience in other basins by neglecting data inconsistent with this view. 
Using all of the TBEG data, the underpressure and overpressure domains are examined further in Fig. D12. The small spatial scale compartments in Fig. D12(a) (overpressure) and (b) (underpressure show a complex mosaic of abnormally pressured zones. There is a cluster of small spatial scale overpressure compartments in the southern half of the basin (a) which correlate spatially with the more continuous overpressure gradient zone delineated using a more limited data set, shown in Fig. D1. Note that in this zone of concentrated small spatial scale compartments, there are also some small spatial scale underpressure compartments (compare (a) and (b)). The cluster of small spatial scale overpressure compartments of (a) lies within the space avoided by the broader scale underpressure zones delineated in (c) and (d). Thus, there is some relation between the sparser data set prediction of a continuous overpressure compartment and the underpressure zone predicted by the TBEG data. 


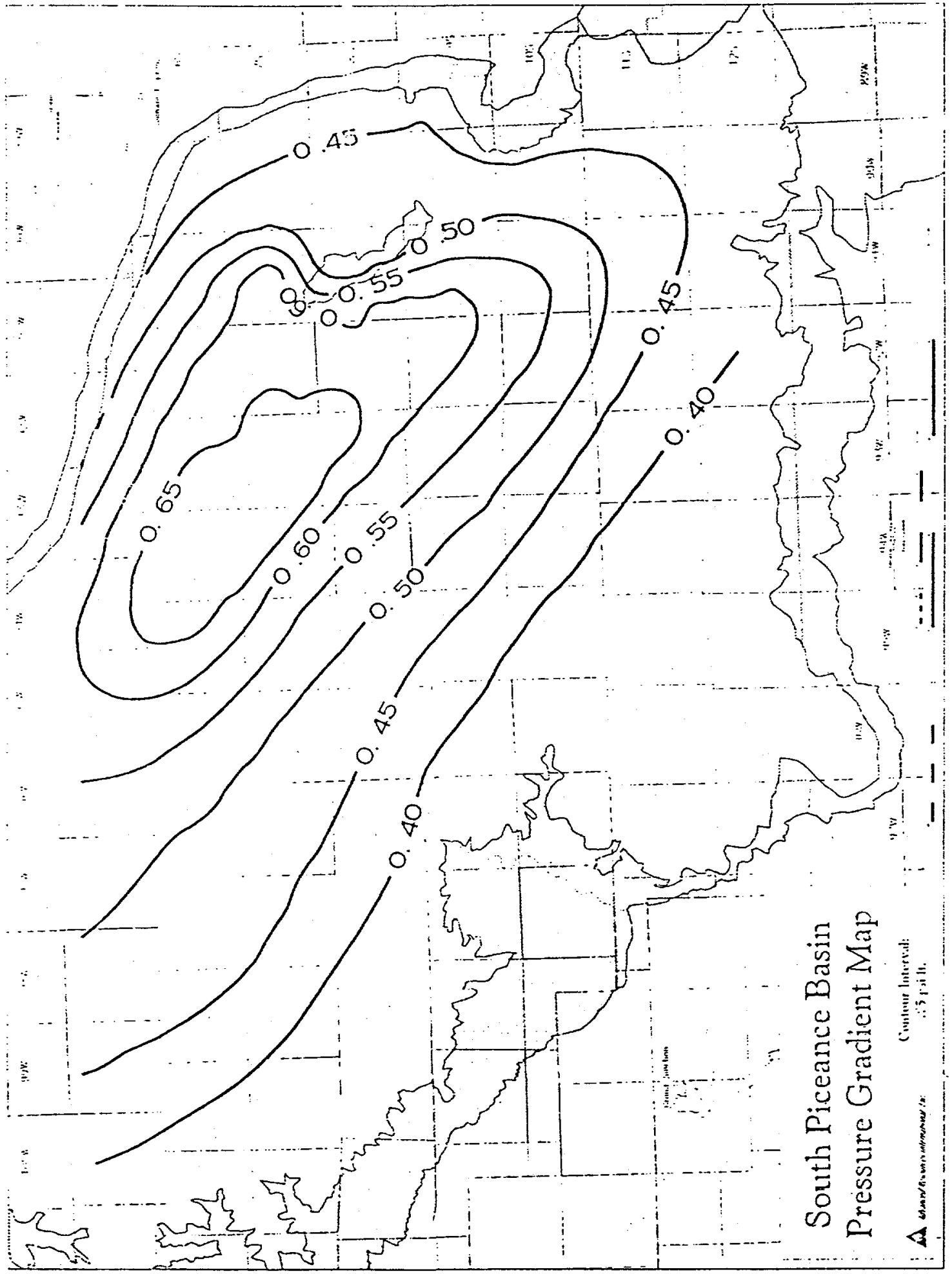

Fig. D1 Pressure gradient (producing formation pressure/depth to producing zone) as a contour map in the southern part of the Piceance Basin. 
(a)

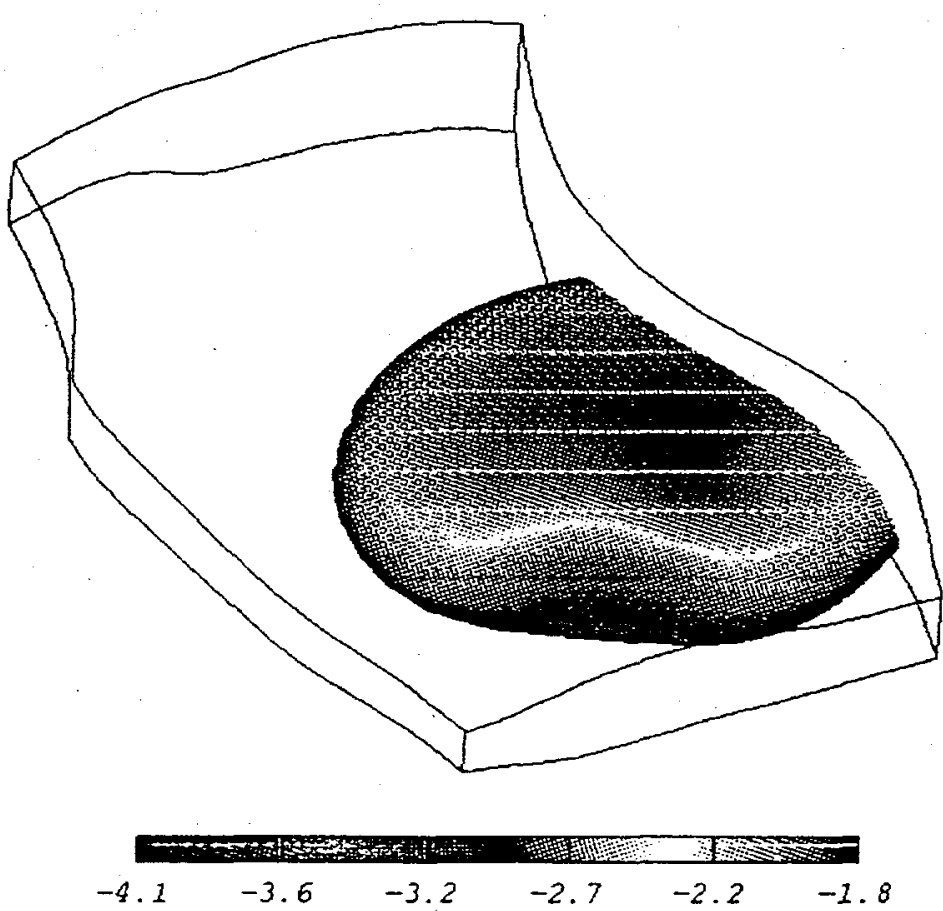

(b)

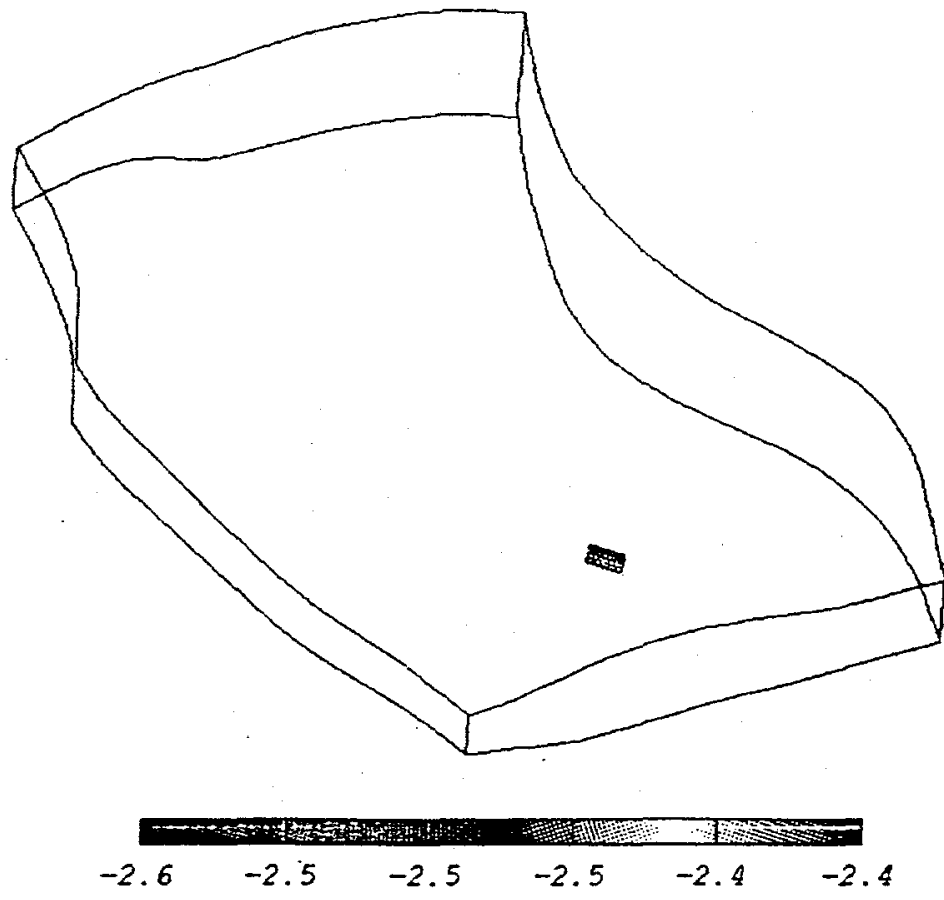

Fig. D2 Three dimensional depictions of pressure isosurfaces in the modeling domain, constructed from well pressure data; (a) 20 bars overpressure isosurface, (b) 1 bar underpressure isosurface, and (c) (next page) map view of 4-bar overpressure isosurface with latitude and longitude coordinates as indicated. Note that the juxtaposed overpressured and underpressured domains suggest that a seal lies between these two zones. 


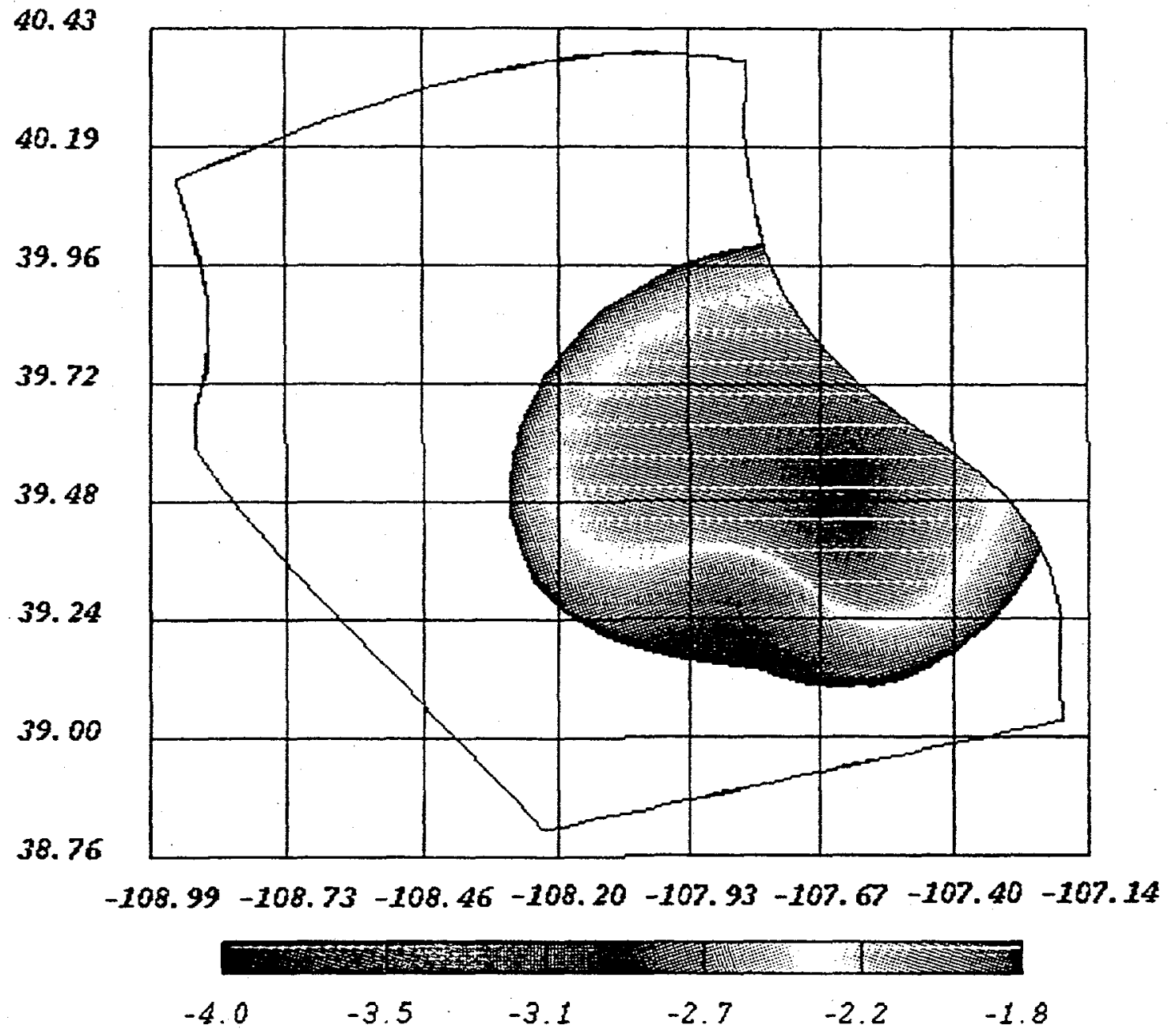

Fig. D2(c) 


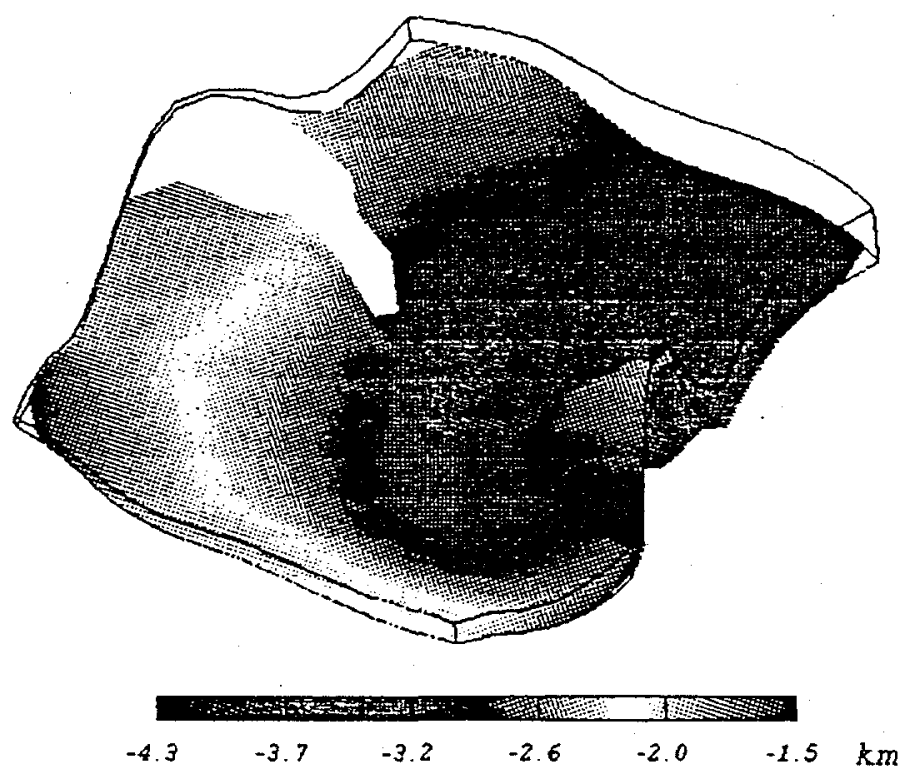

Fig. D3 Configuration of the Mancos Shale. In our pressure interpolation it is assumed to underlie the abnormally pressured zones in the Piceance Basin (see Fig. D2); the domain represents sediments deposited between $72.1 \mathrm{Ma}$ and $72.8 \mathrm{Ma}$ and not the entire stratigraphic column (i.e., about the bottom 15\% of the domain of Fig. D6(a)). Use has been made of the Powley (1990) observation that normal pressure underlies the compartmented zone in many U.S. onshore basins.

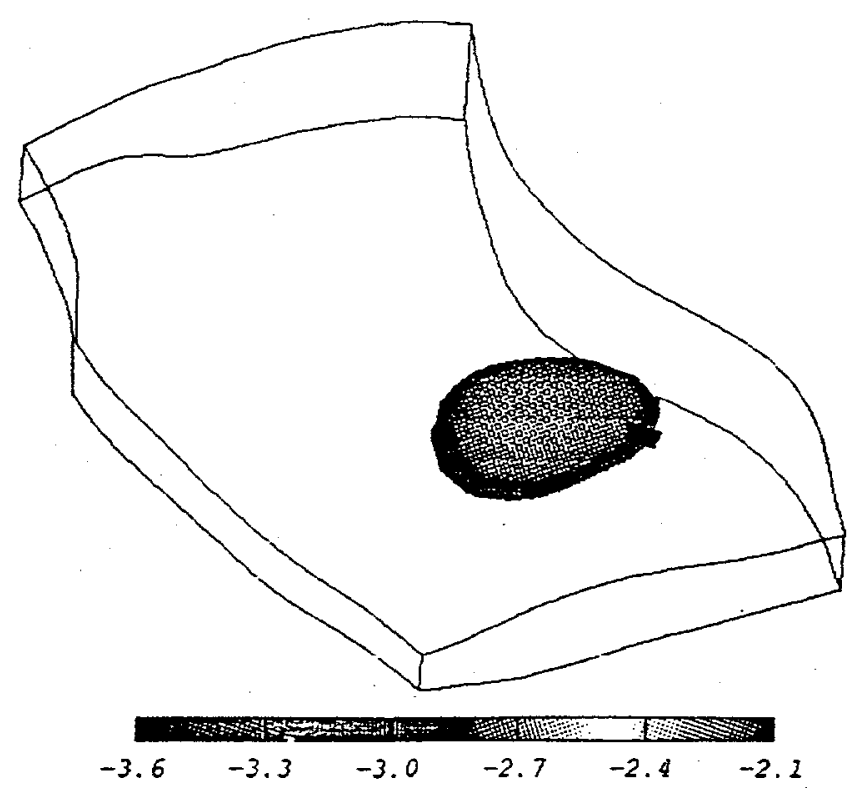

Fig. D4(a) Three dimensional configuration of region perspective for fractures, depicted as a surface within which fluid pressure exceeds least principle stress. 
40.43

40.19

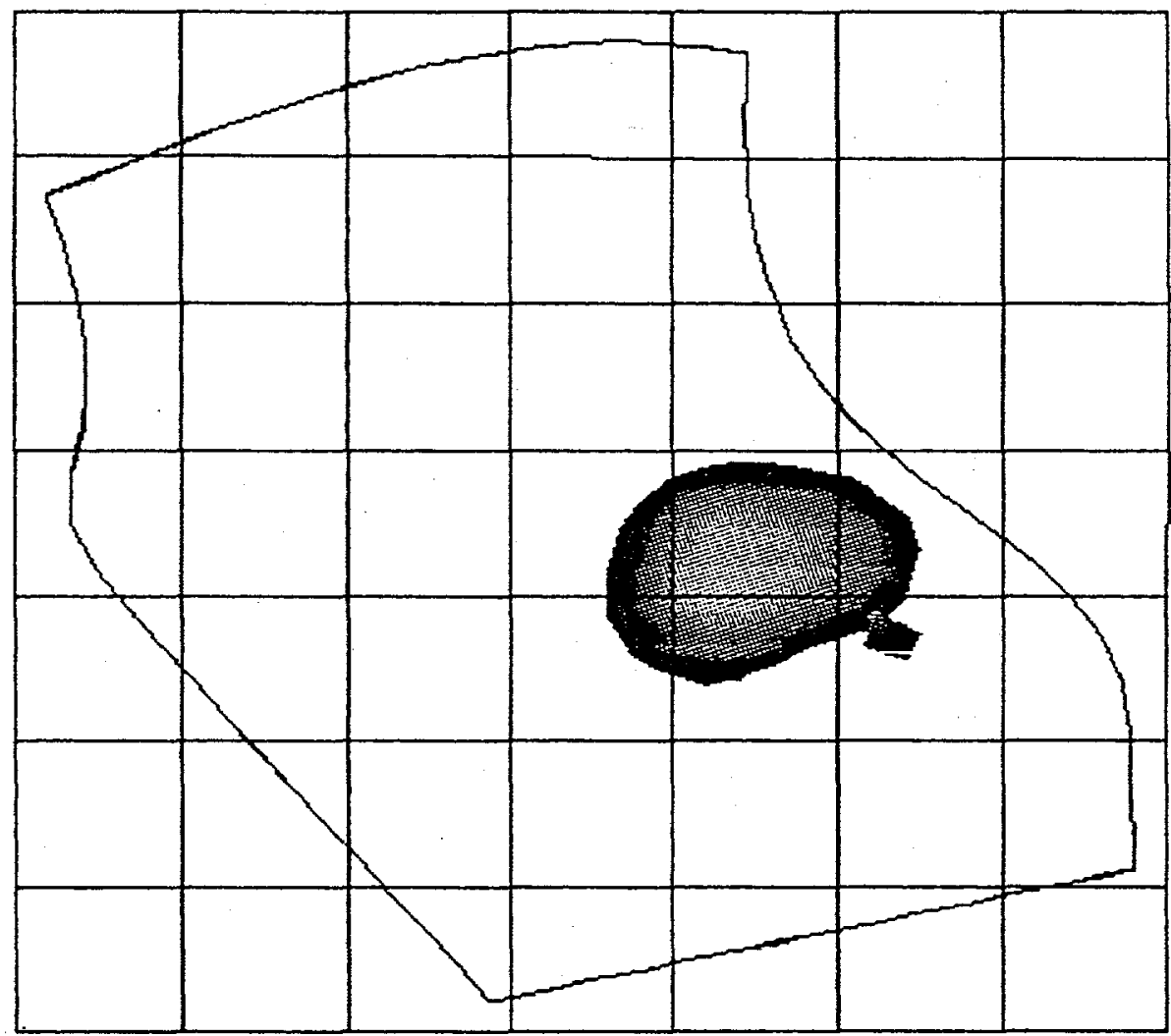

38.76

$-108.99-108.73-108.46-108.20-107.93-107.67-107.40-107.14$

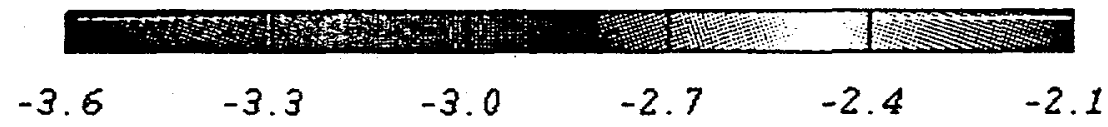

Fig. D4(b) Map view of frame (a) showing perspective longitude/latitude and depth location of prospective hydrofractured zones. Similar maps will be produced based on CIRF.B predictions so that the least principle stress variations in space within the basin can be accounted for. 


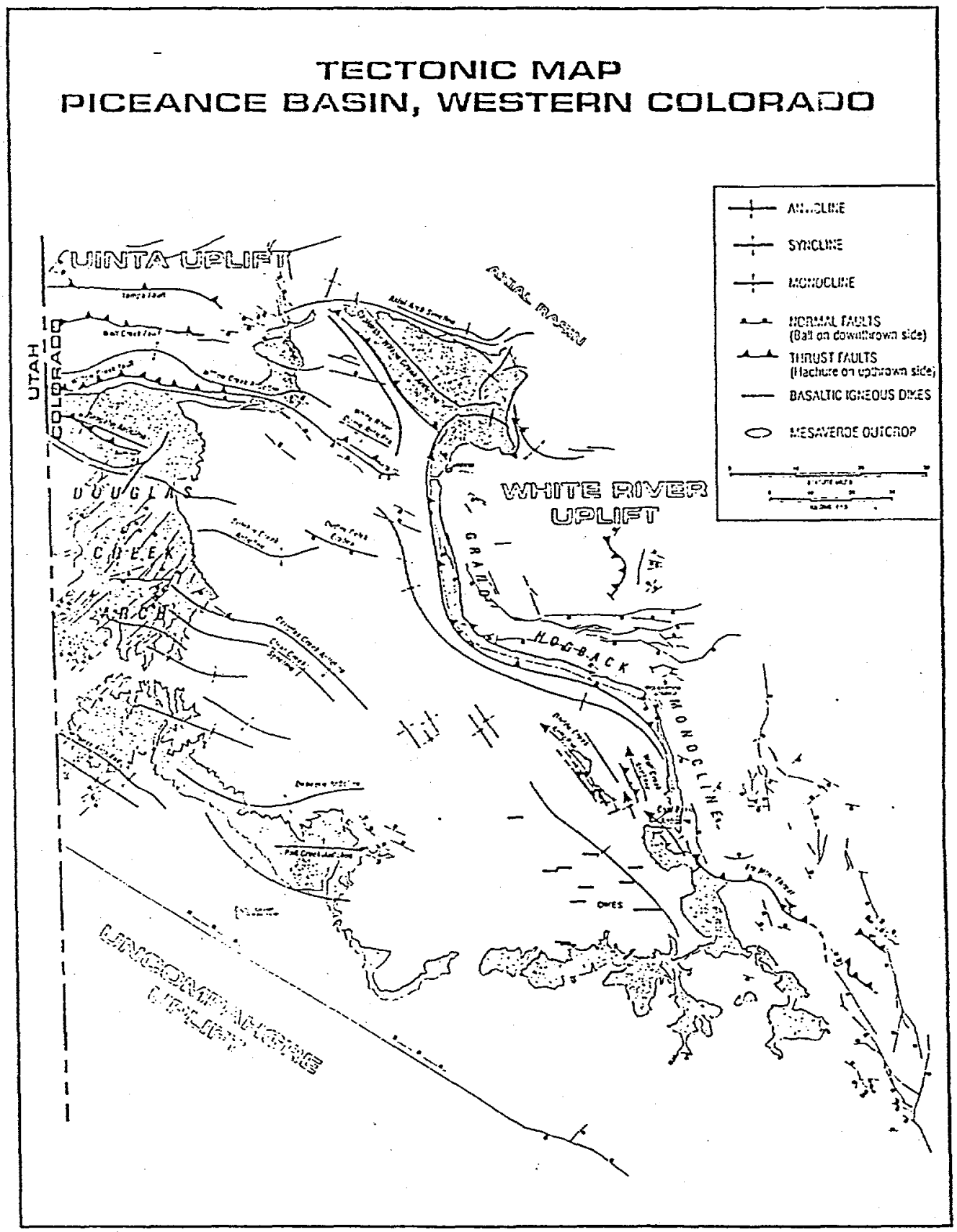

Fig. D5 Major structures in the Piceance Basin area. Note the correlation between distribution of major producing gas fields and some of the structural features, particularly anticlines. 


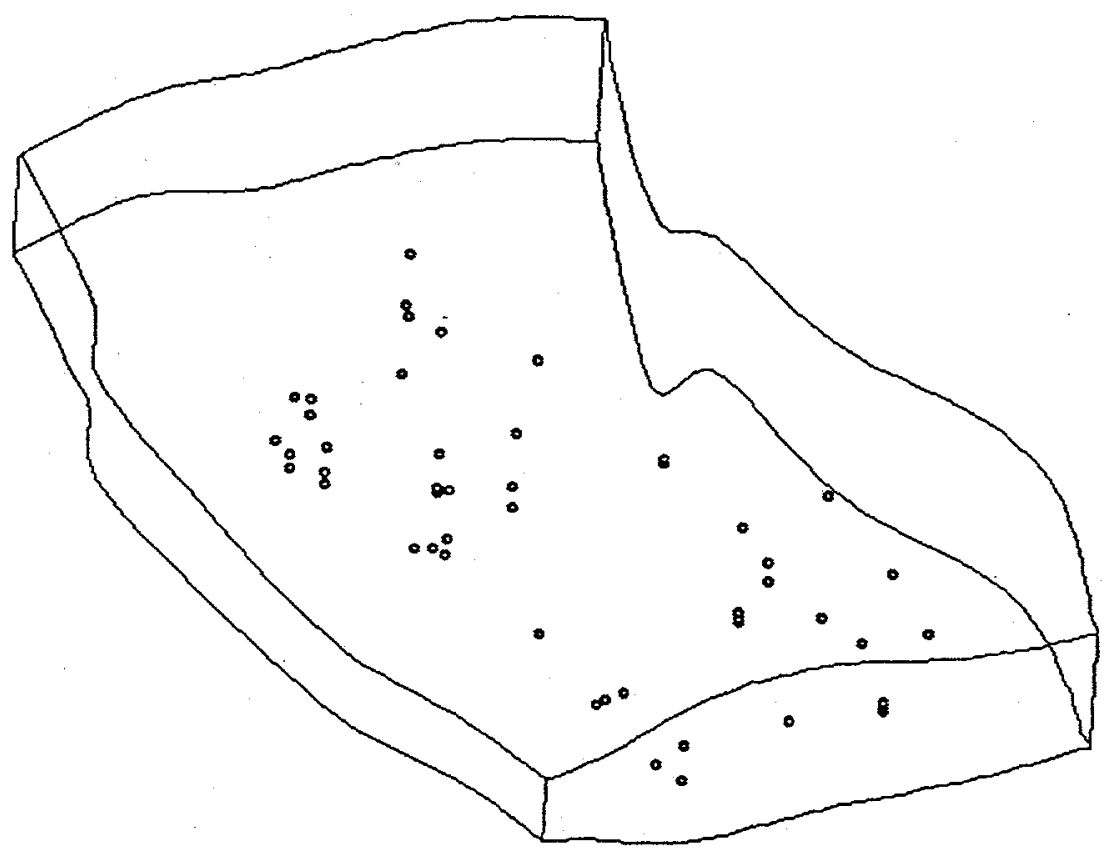

Fig. D6(a) Location of 56 high quality pressure data points, as evaluated by TBEG, in the Piceance Basin. Vertical exaggeration is $20 \mathrm{x}$. 
$\mathrm{Y}$

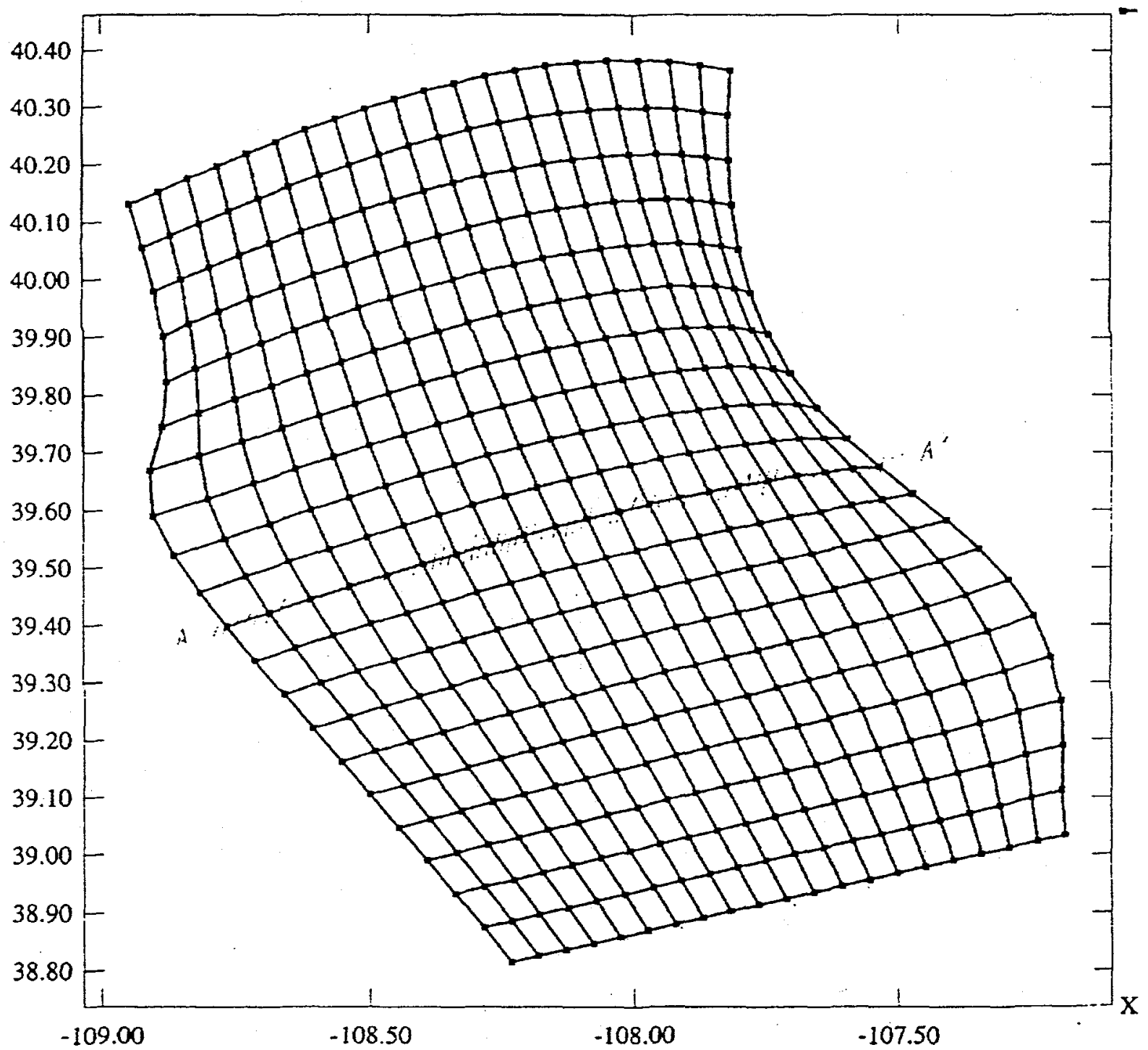

Fig. D6(b) Map view of the interpolation grid, with longitude and latitude values along the $x$ and $y$ axes; $A-A$ ' is location of cross-section illustrated for results of preliminary $3-D$ simulations. 


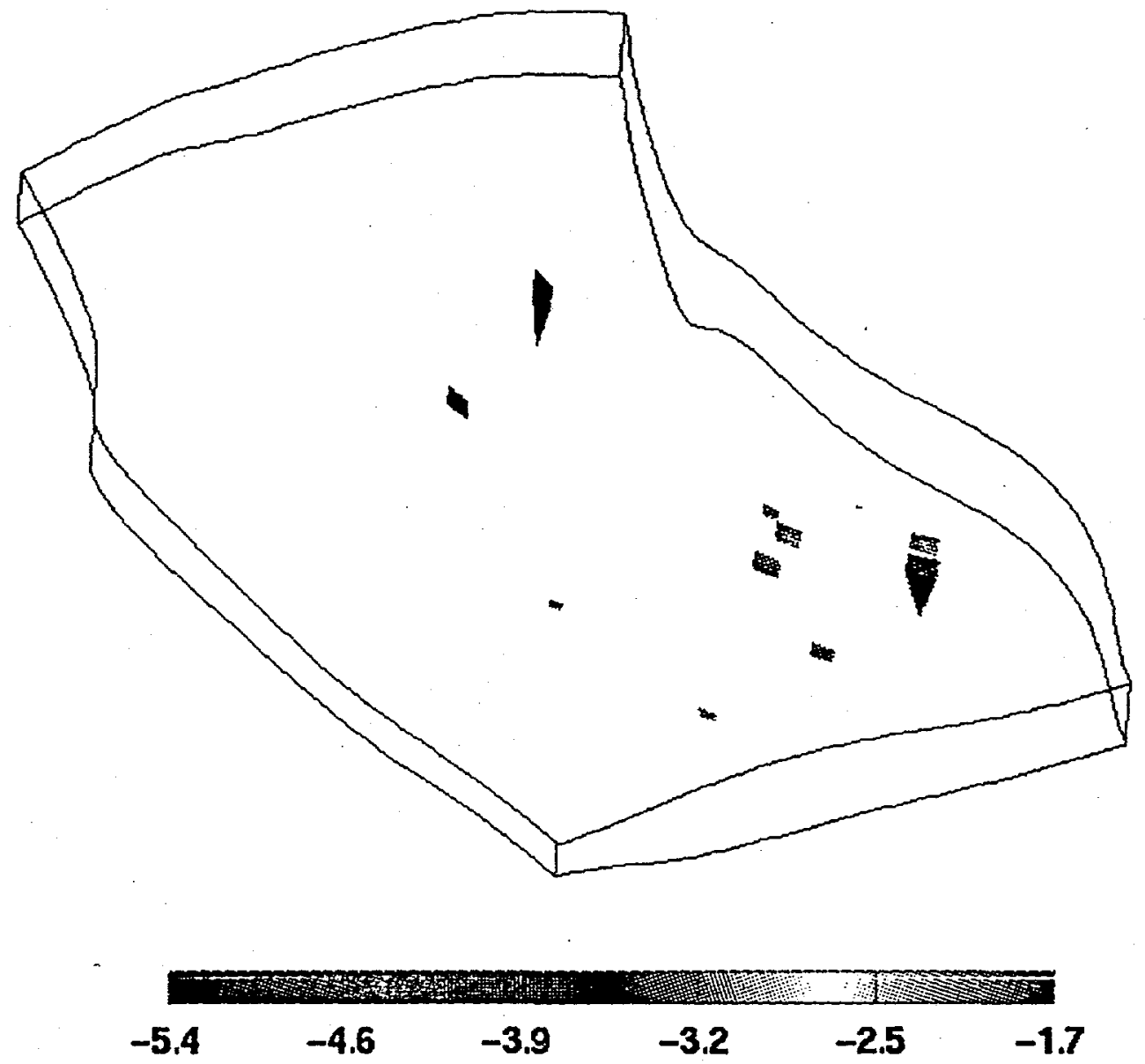

Fig. D7(a) Isosurface of 1 bar overpressure in the Piceance Basin, using highest quality pressure data; vertical exaggeration is $10 \mathrm{x}$. 

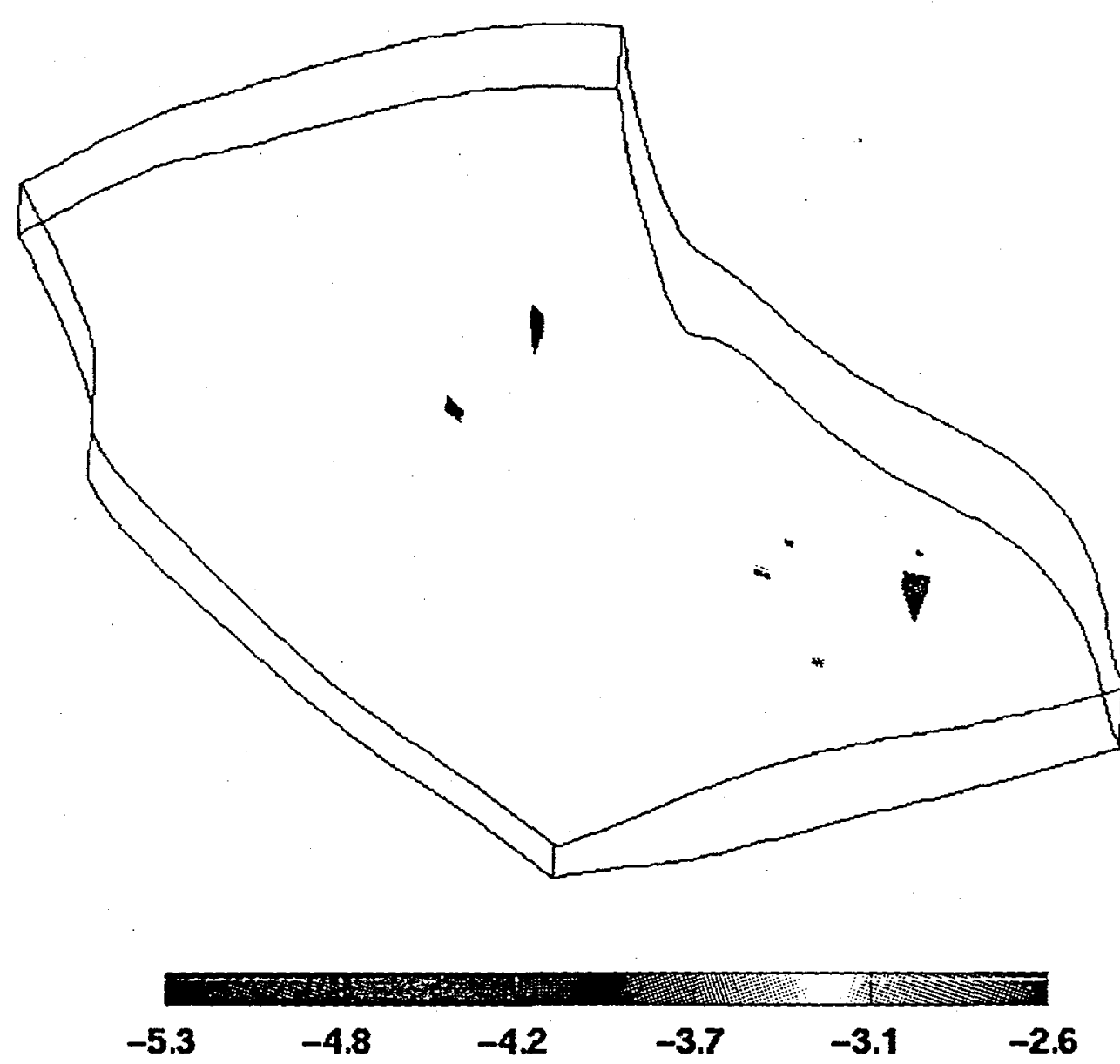

Fig. D7(b) Isosurface of 10 bars overpressure. 

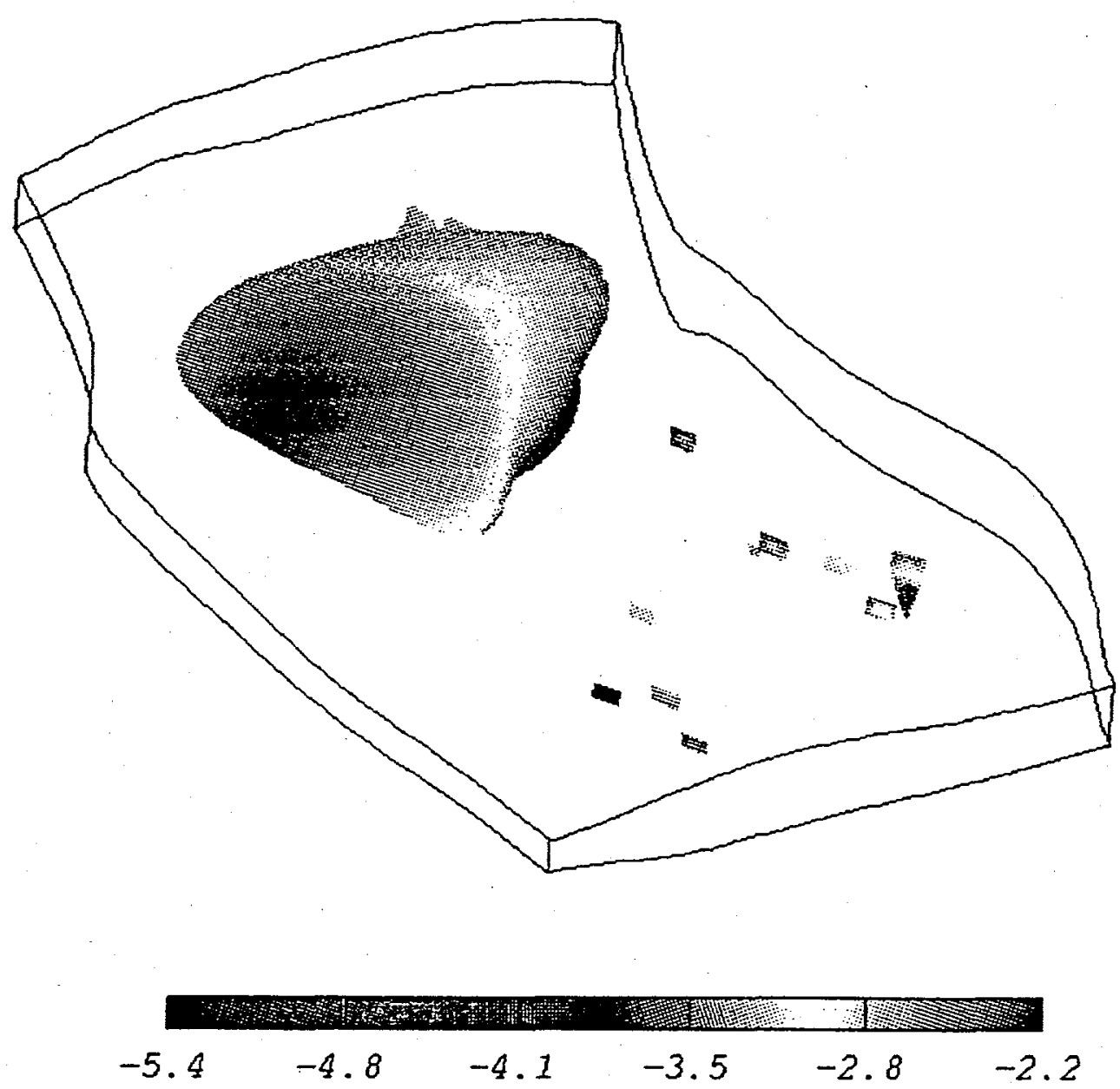

Fig. D7(c) Isosurface of 7 bars underpressure. 


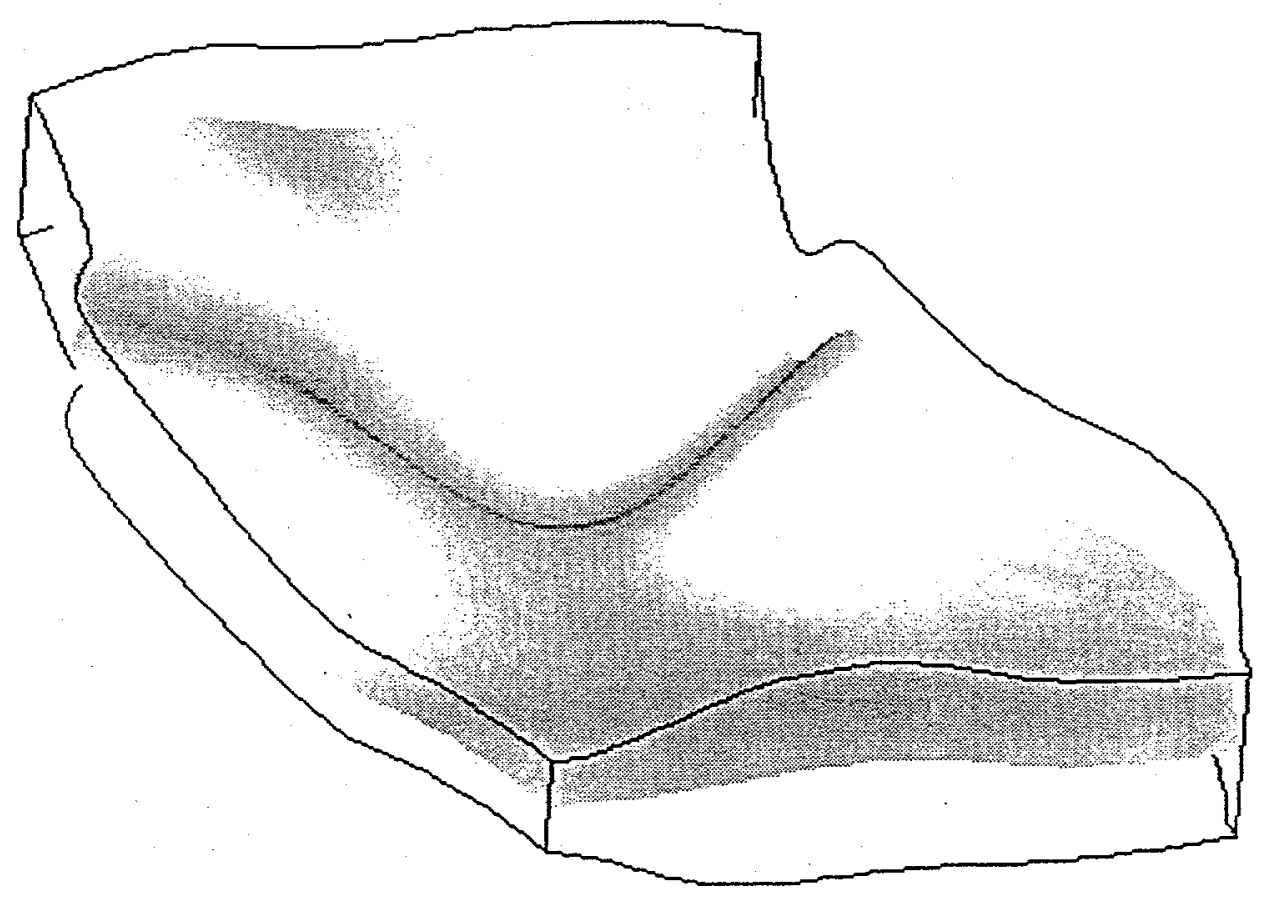

Fig. D8(a) 70.1 my isochron. 


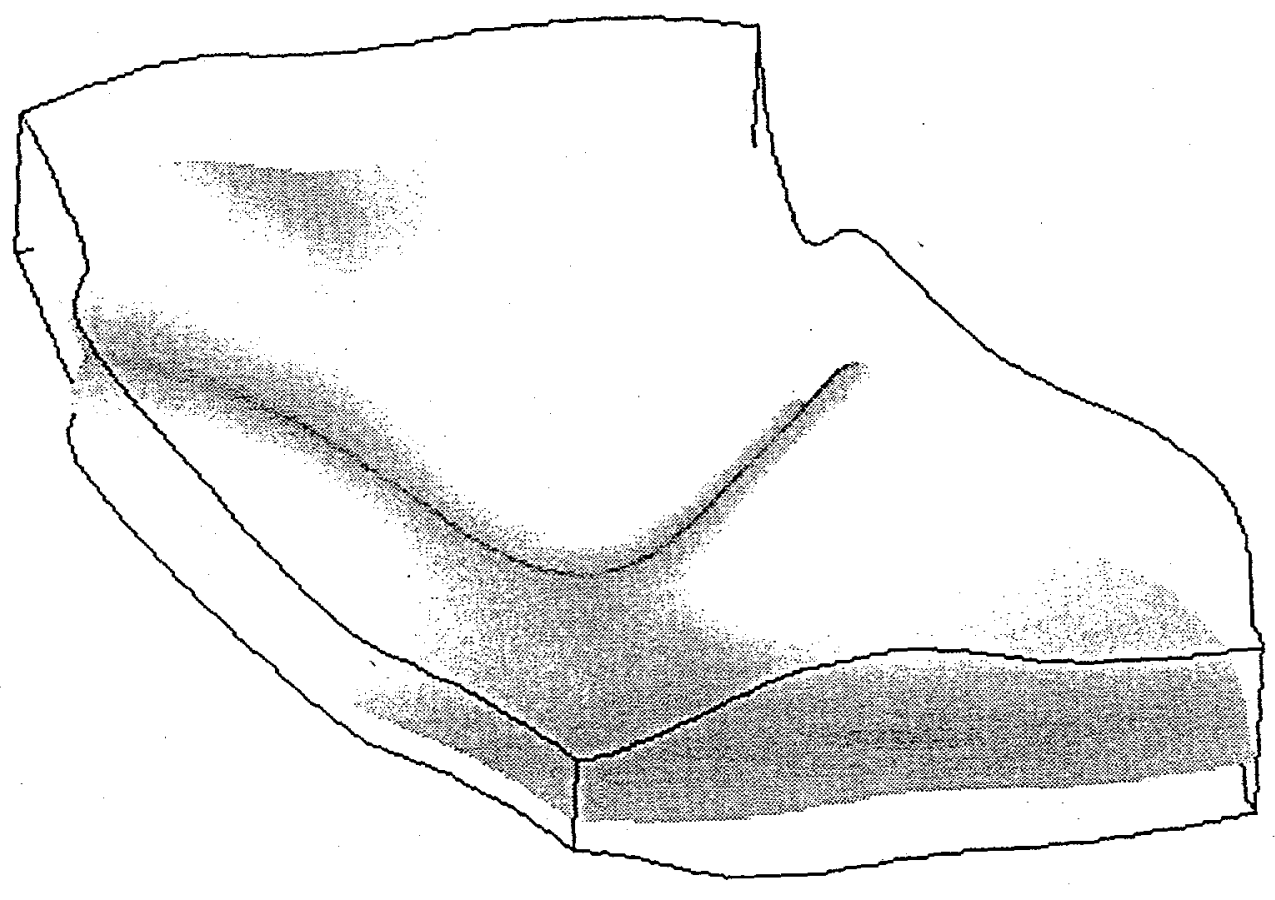

Fig. D8(b) 72.6 my isochron. 


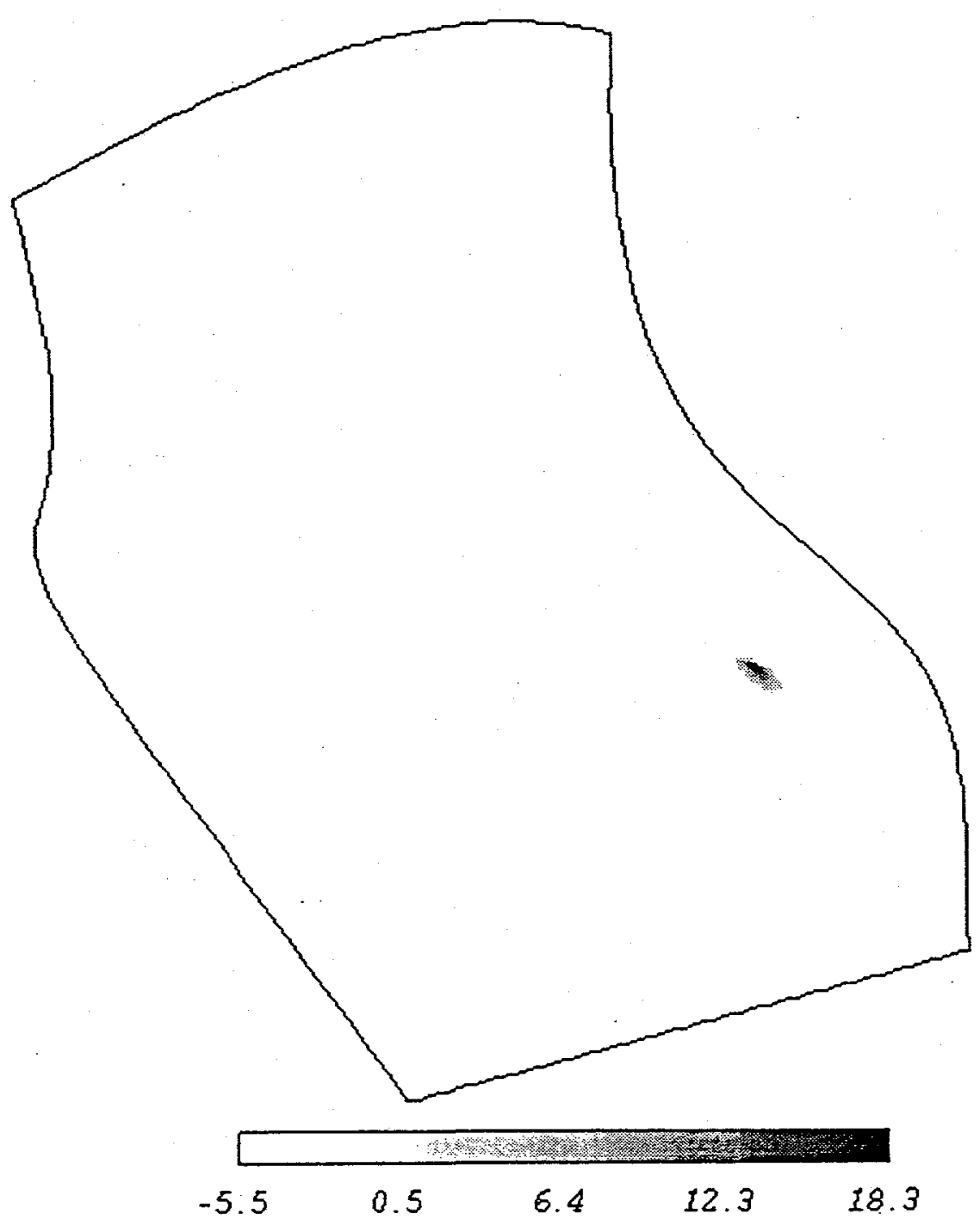

Fig. D8(c) Abnormal pressure distribution on the $70.2 \mathrm{my}$ isochron. 


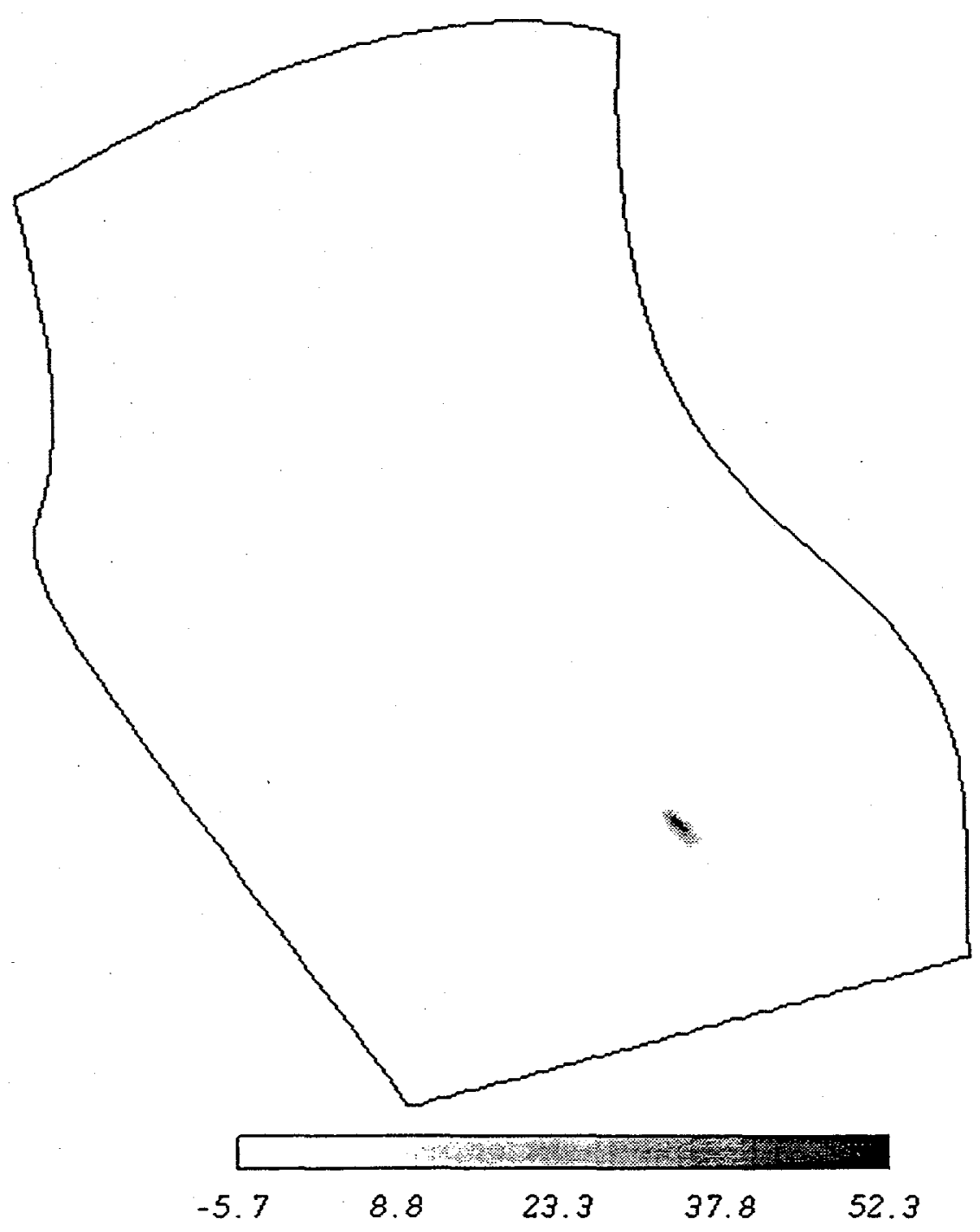

Fig. D8(d) Abnormal pressure distribution on the 70.35 my isochron. 


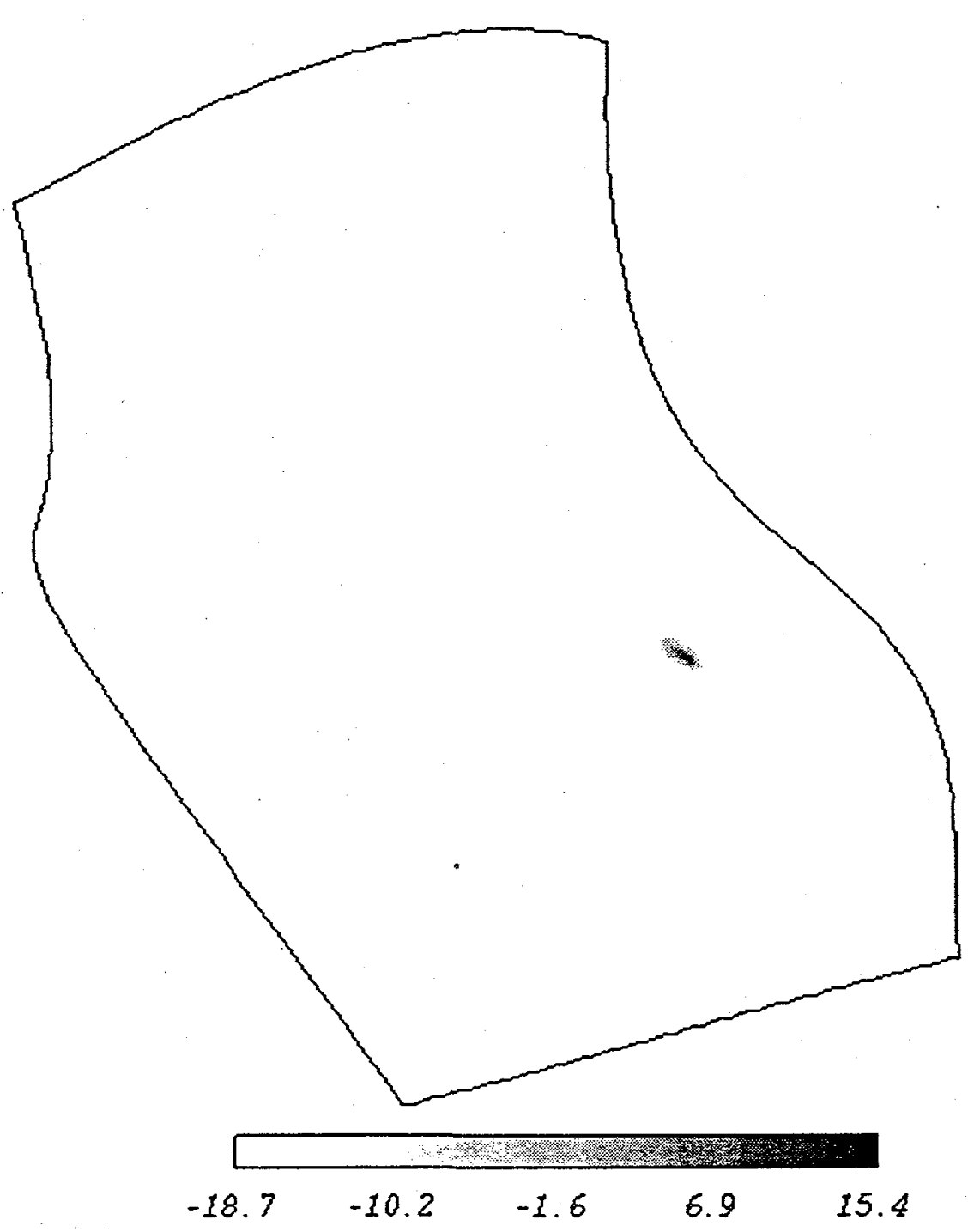

Fig. D8(e) Abnormal pressure distribution on the 72.6 my isochron. 


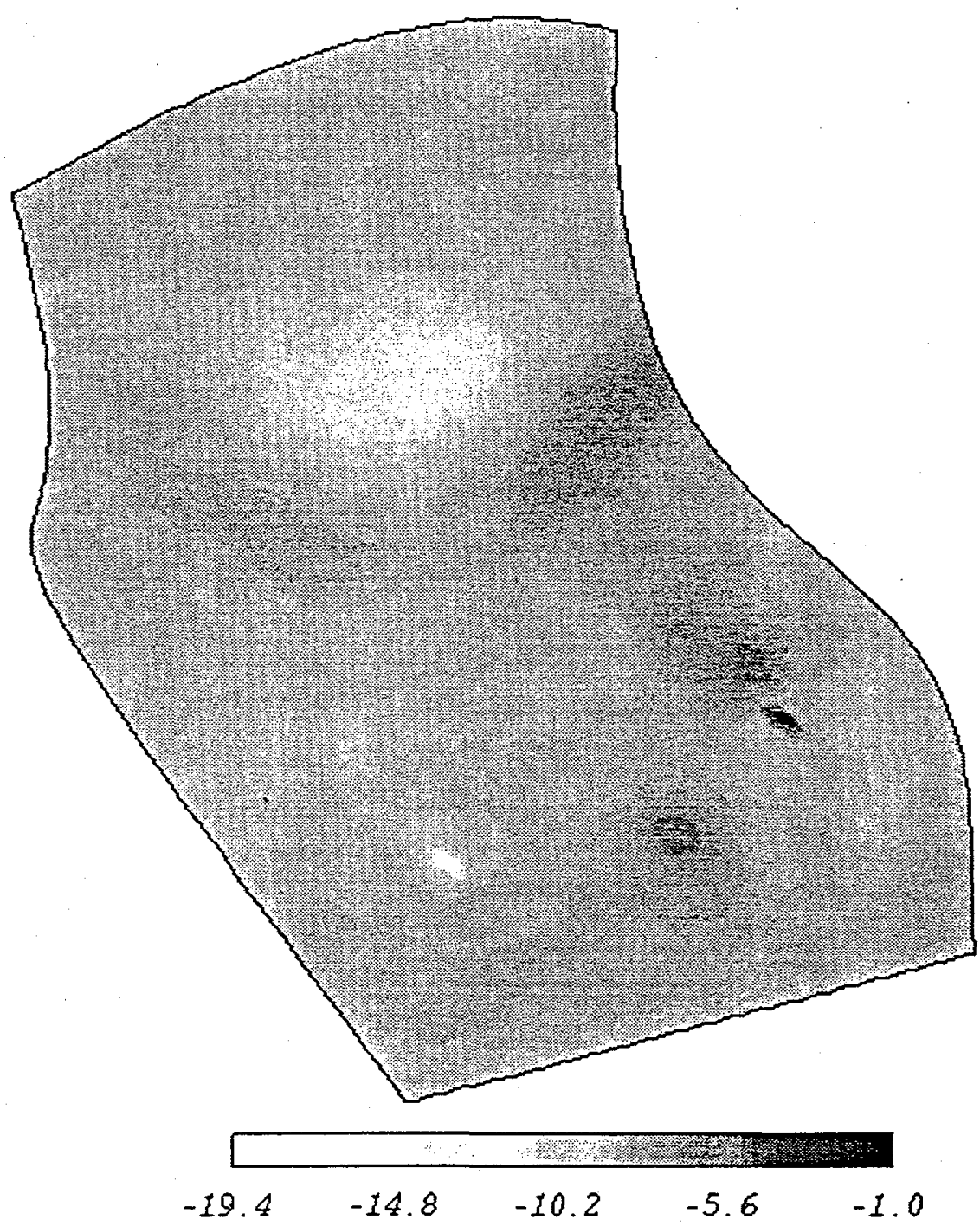

Fig. D8(f) Abnormal pressure distribution on the 71.0 my isochron. 


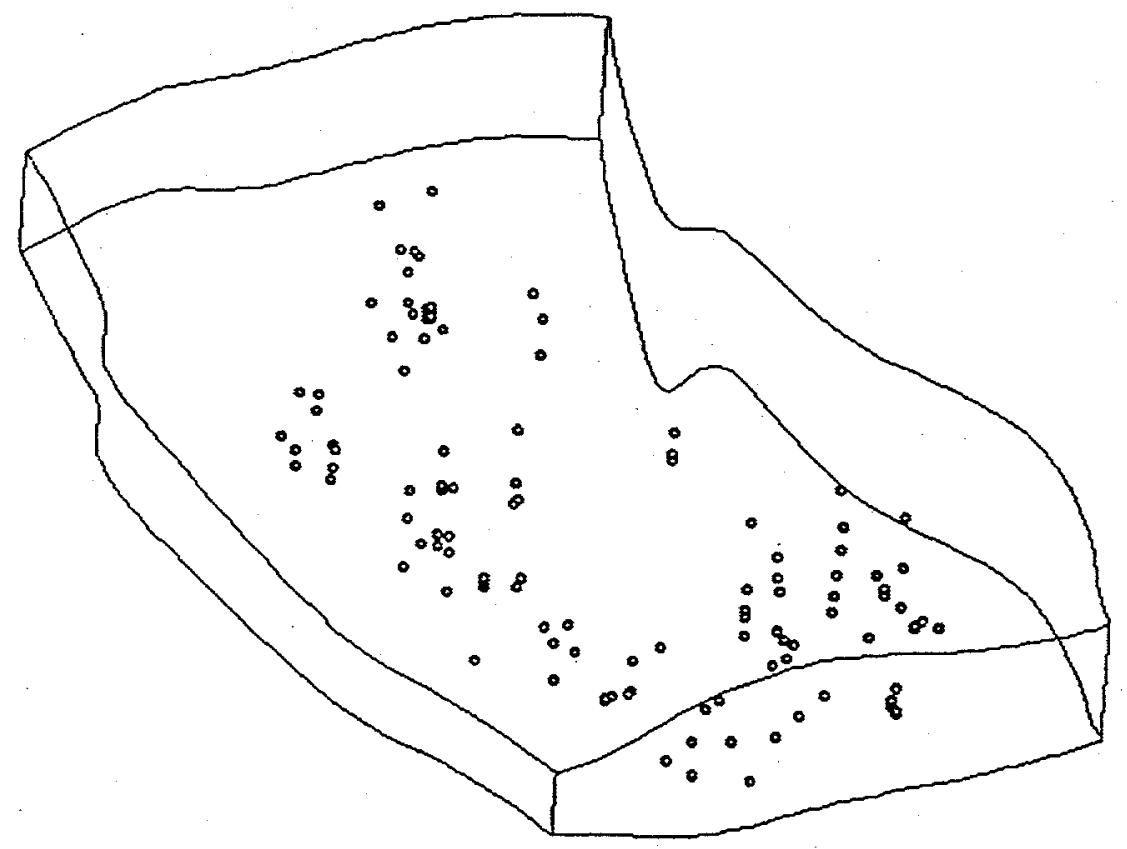

Fig. D9(a) Location of all 129 pressure data points (TBEG) in the Piceance Basin. Vertical exaggeration is $20 x$. 


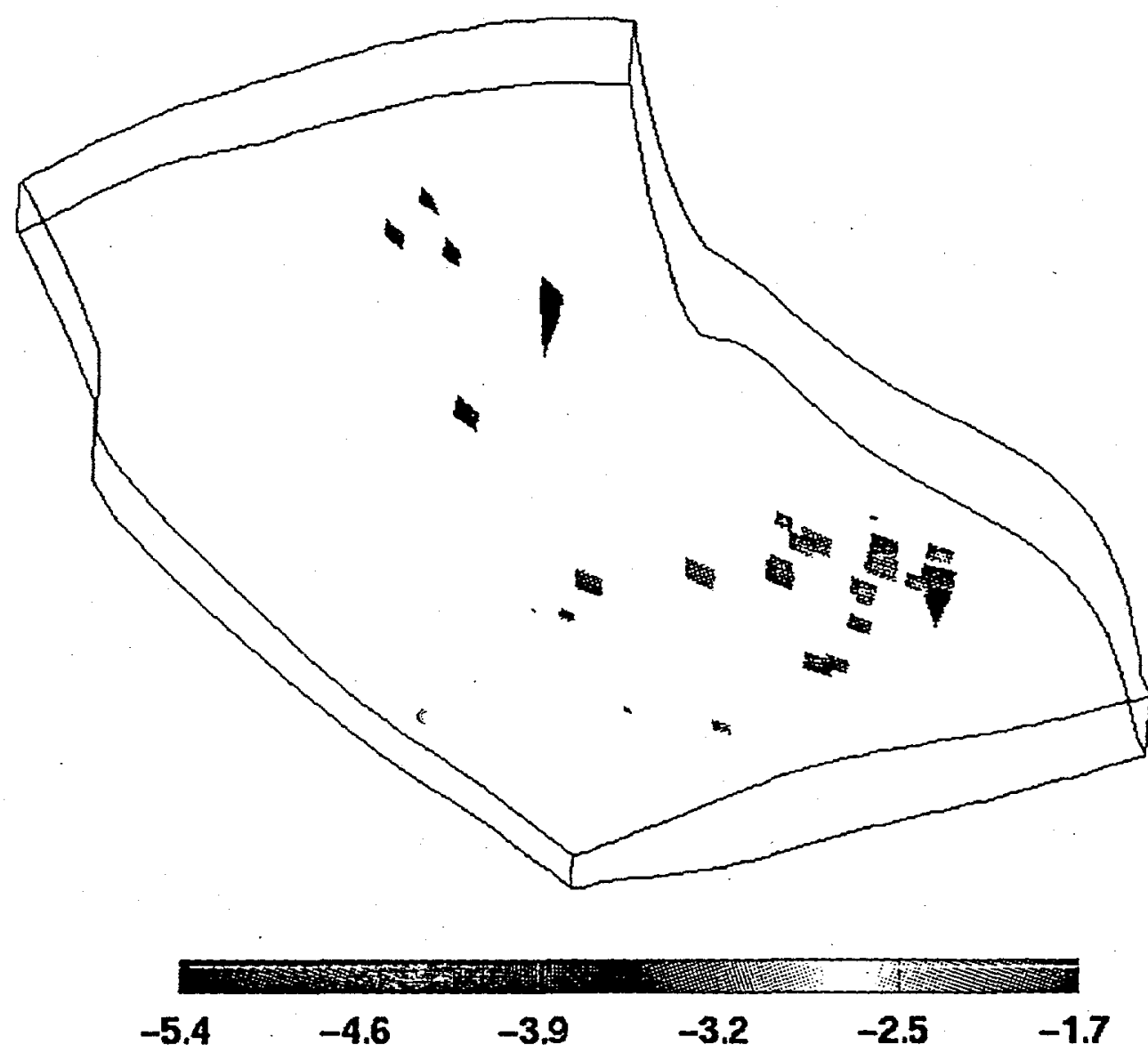

Fig. D9(b) Isosurface of 1 bar overpressure in the Piceance Basin, using high, moderate, and unknown quality data. Vertical exaggeration is $10 \mathrm{x}$. 


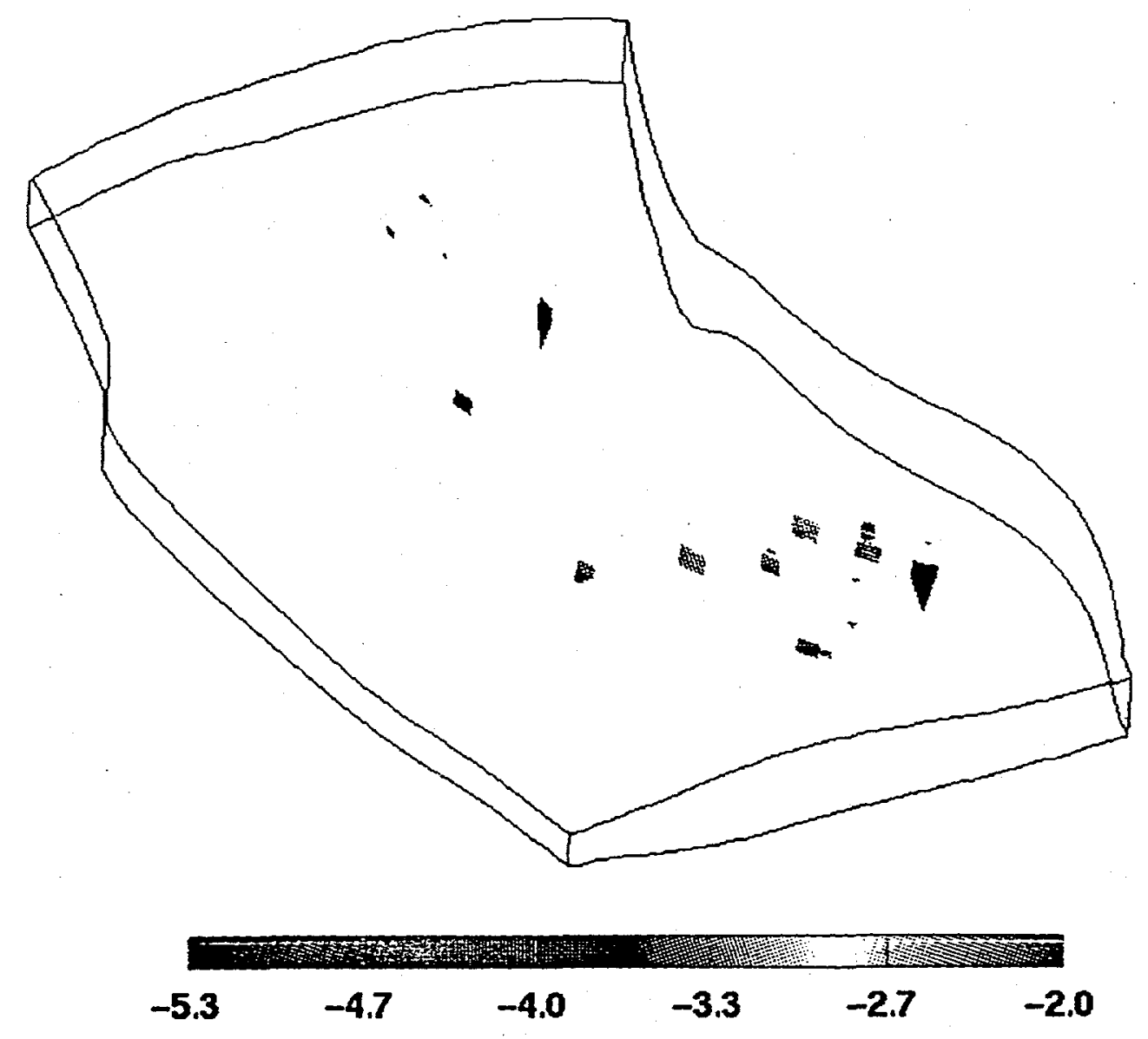

Fig. D9(c) Isosurface of 10 bars overpressure. 


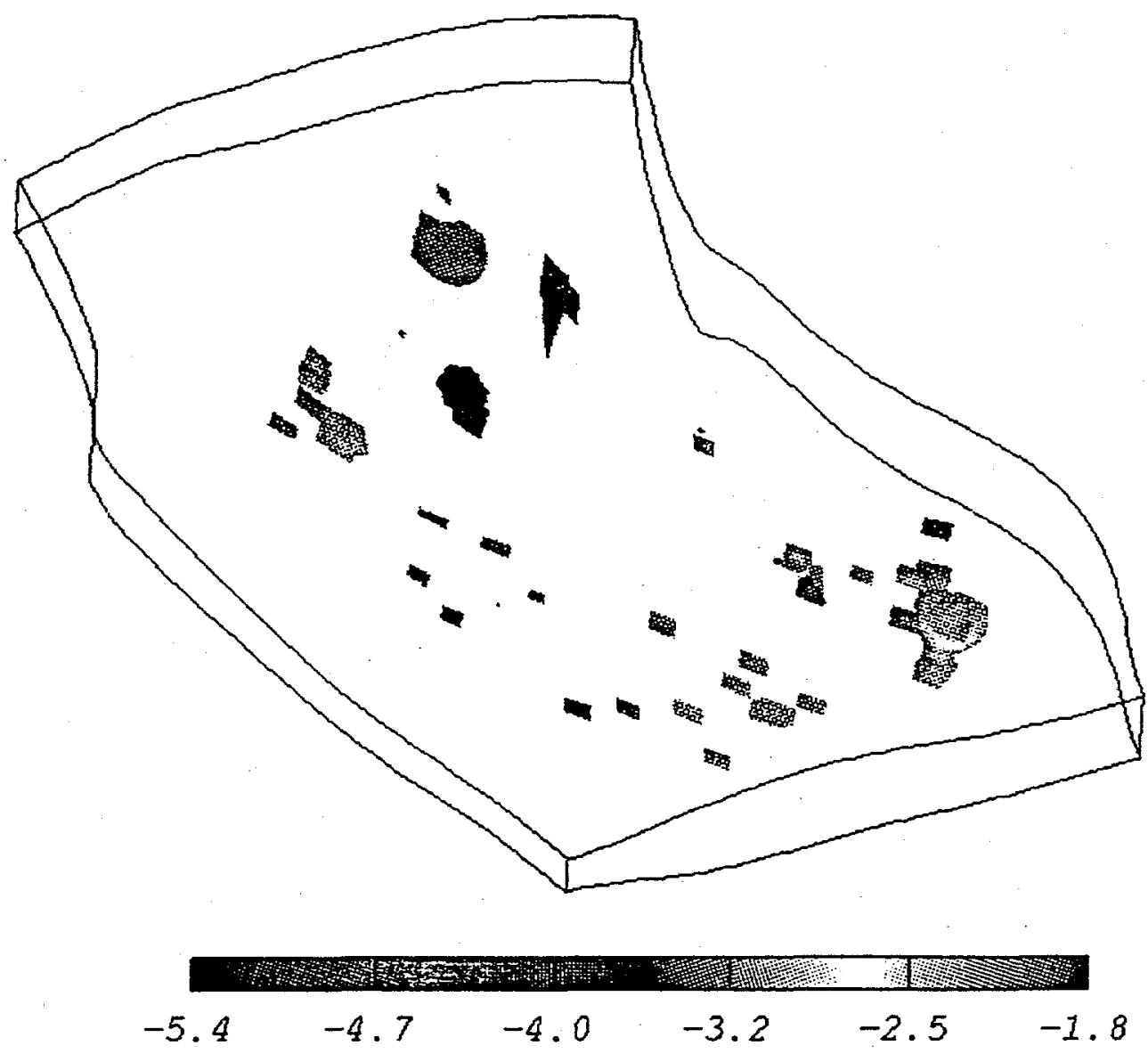

Fig. D9(d) Isosurface of 7 bars underpressure. 


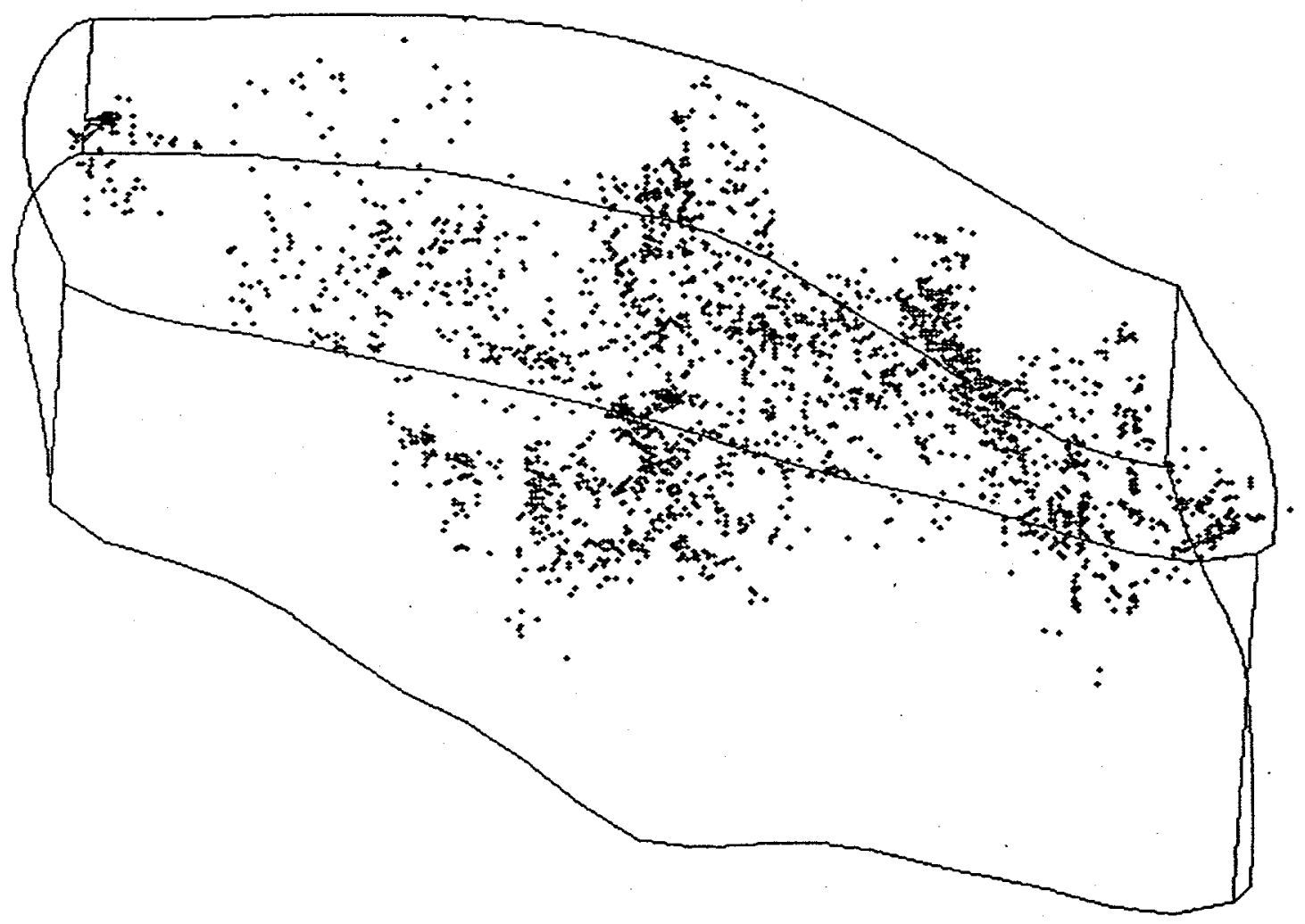

Fig. D10(a) Location of over 2900 pressure data points in the Anadarko Basin. Vertical exaggeration is $20 x$. 


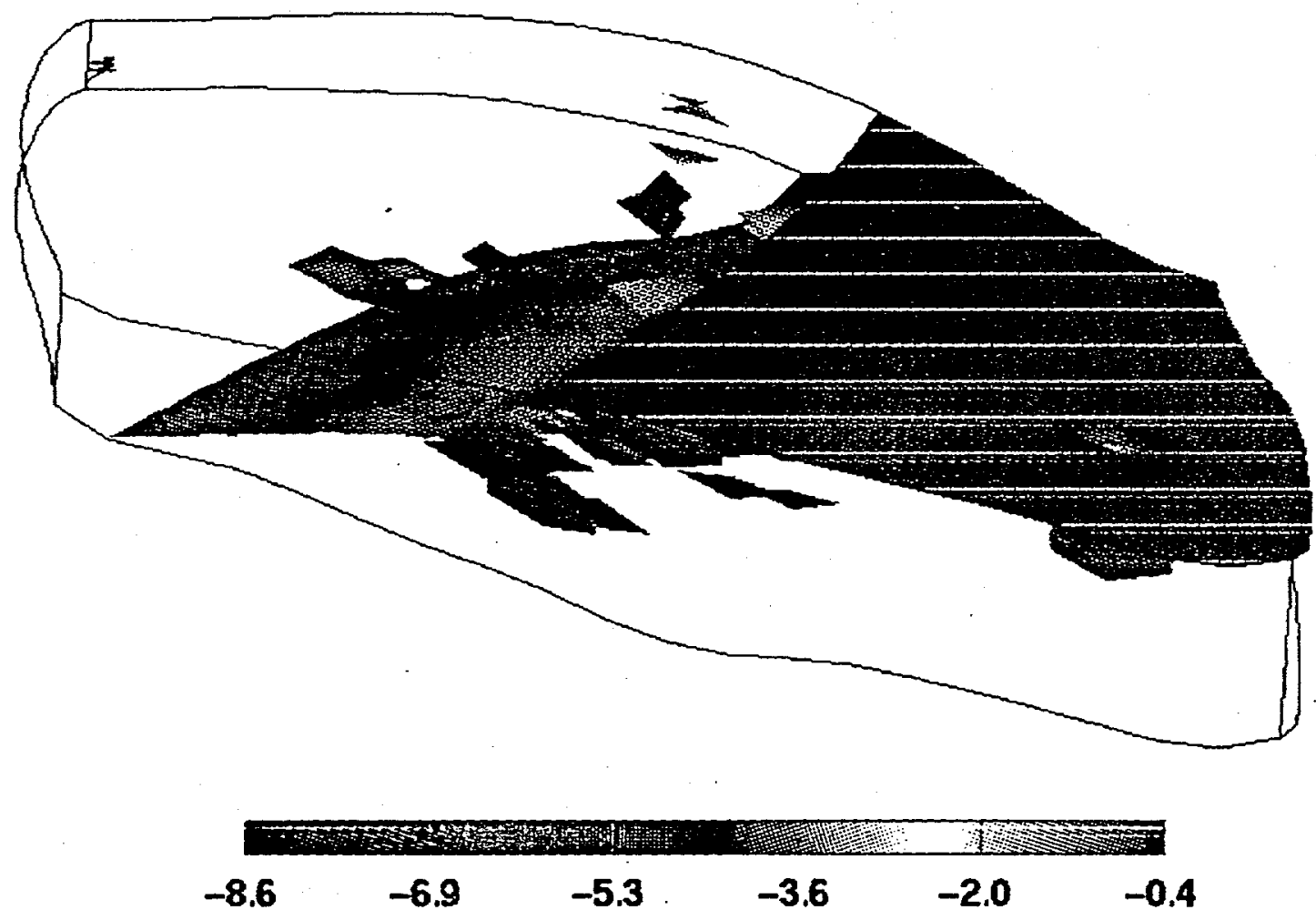

Fig. D10(b) Isosurface of 1 bar overpressure in the Anadarko Basin. Vertical exaggeration is $10 \mathrm{x}$. 

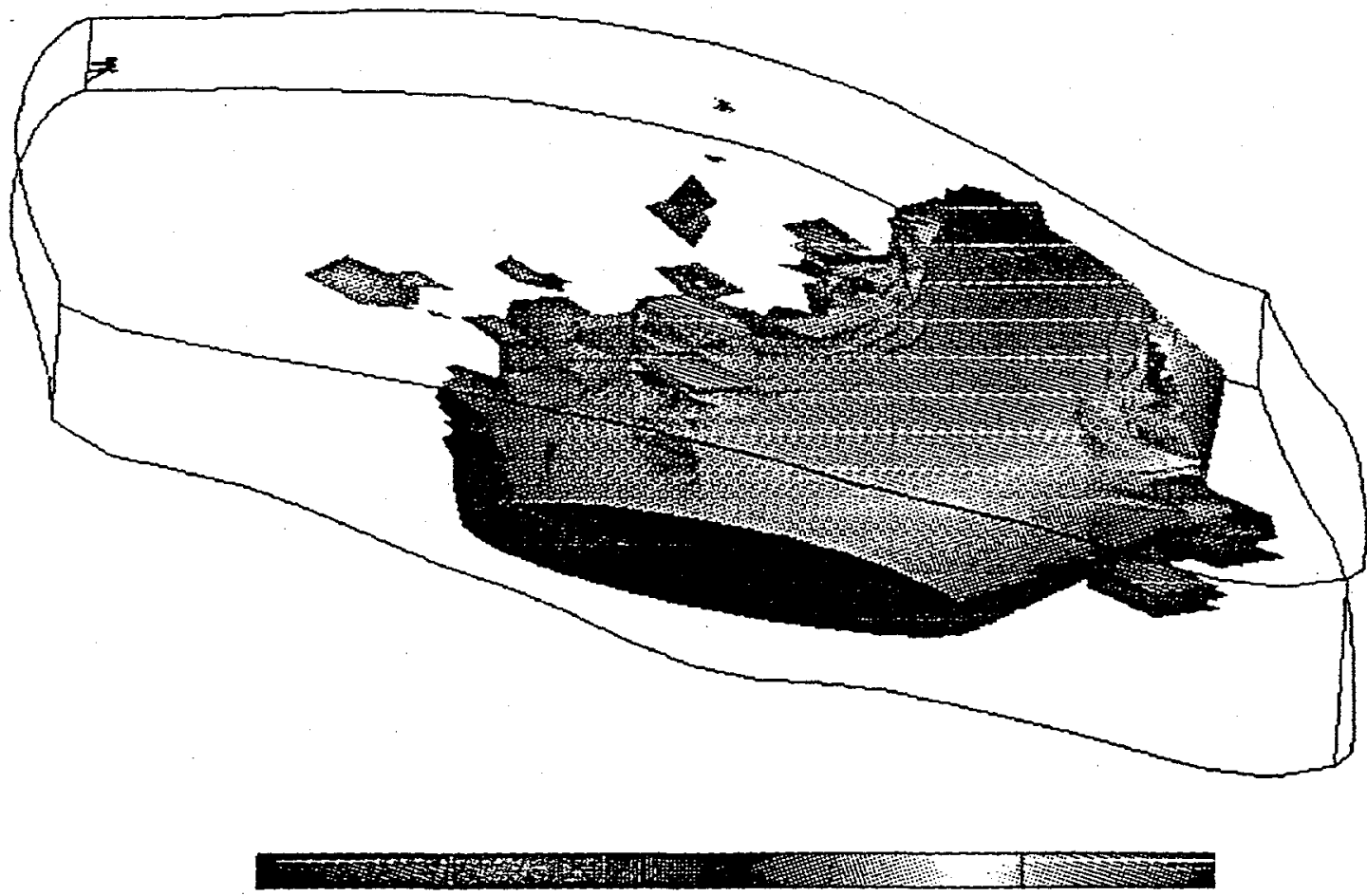

$\begin{array}{llllll}-8.6 & -7.3 & -6.0 & -4.7 & -3.4 & -2.1\end{array}$

Fig. D10(c) Isosurface of 10 bars overpressure. 

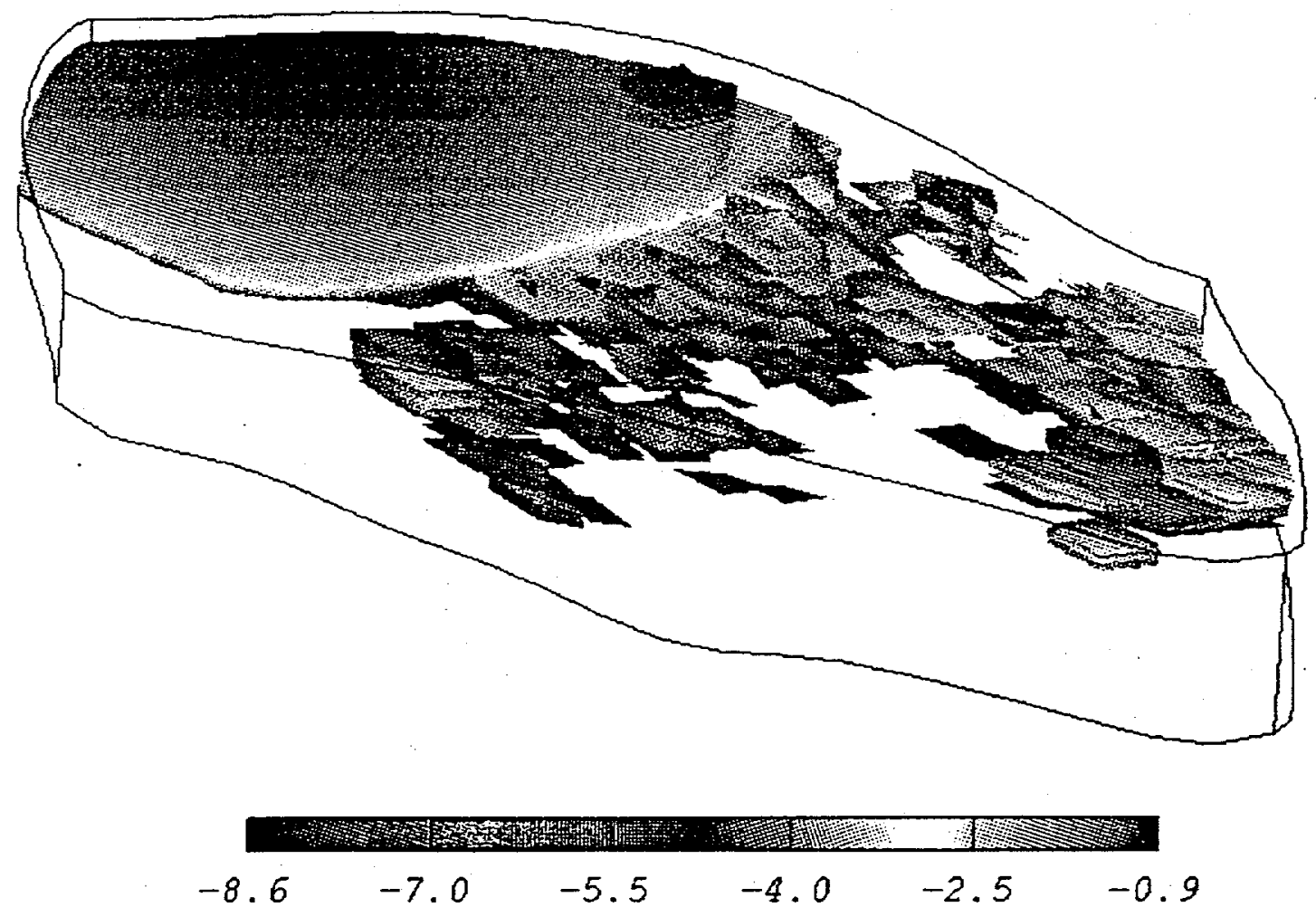

Fig. D10(d) Isosurface of 7 bars underpressure. 


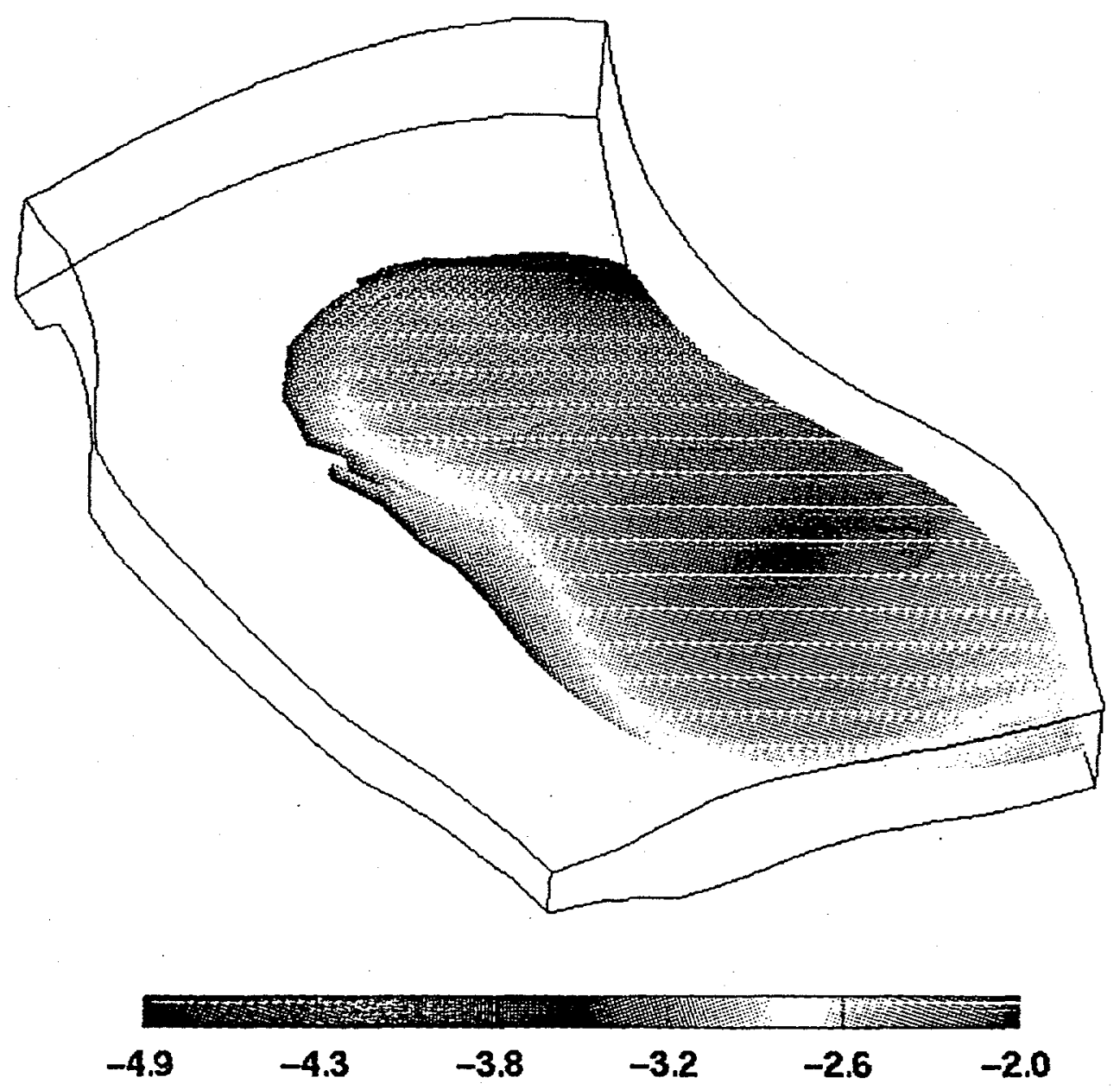

Fig. D11 Isosurface of 10 bars overpressure, using only the normal to overpressured data points of the highest quality data set. 
(a)
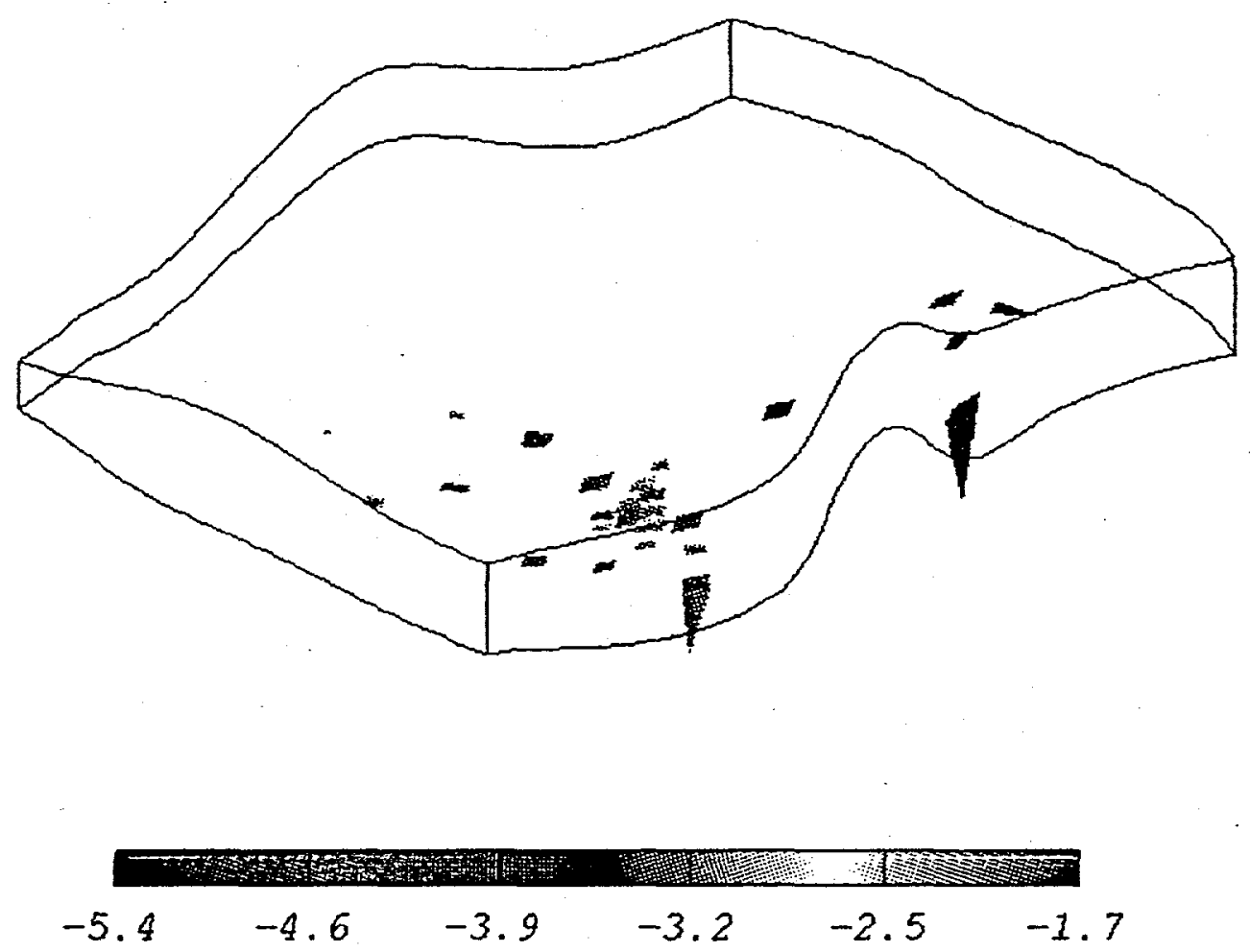

Fig. D12 Overpressure and underpressure isosurfaces, as determined for all TBEG data. (a) Isosurfaces enclosing small compartments of overpressure greater than or equal to $1 \mathrm{bar}$. (b) Isosurfaces enclosing small compartments of underpressure less than or equal to -7.5 bars. (c) and (d) Isosurfaces of greater spatial extent of intermediate values which enclose the small overpressure and underpressure compartments; (c) is -3.8 bars, (d) is -4.8 bars. 
(b)

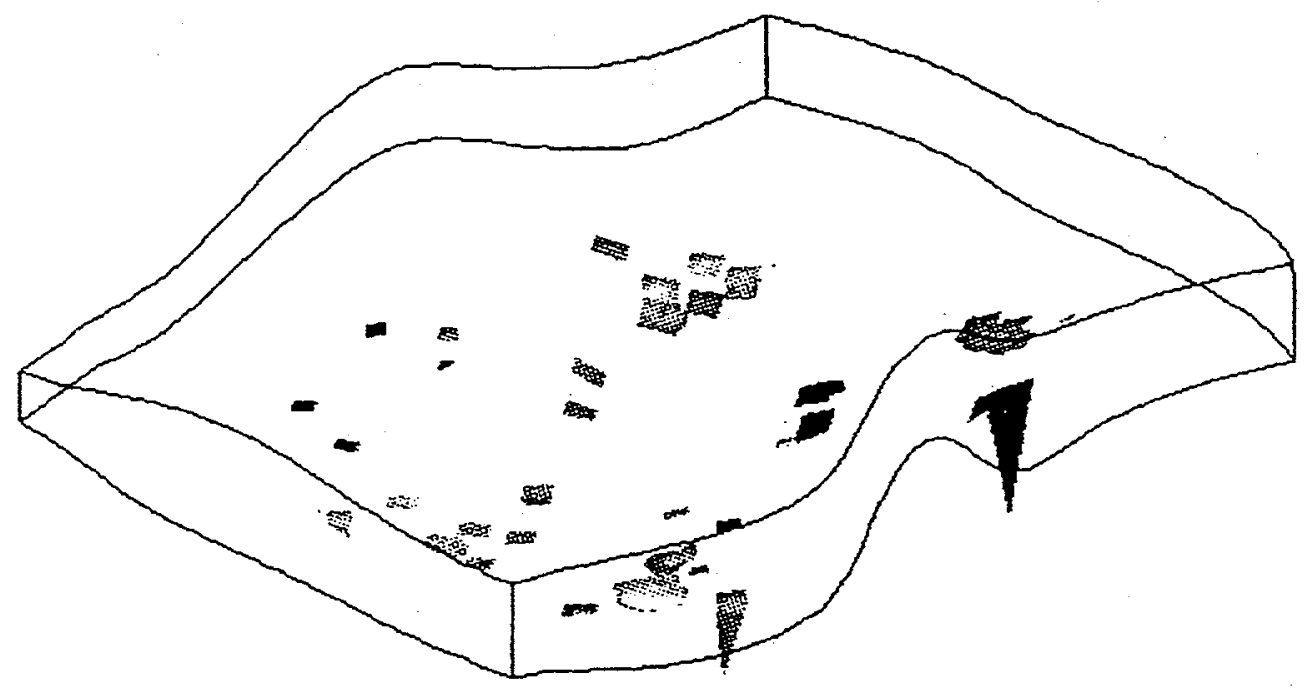

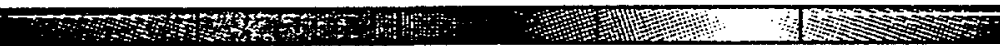

$\begin{array}{lllllll}-5.4 & -4.7 & -4.0 & -3.3 & -2.6 & -1.8\end{array}$


(c)

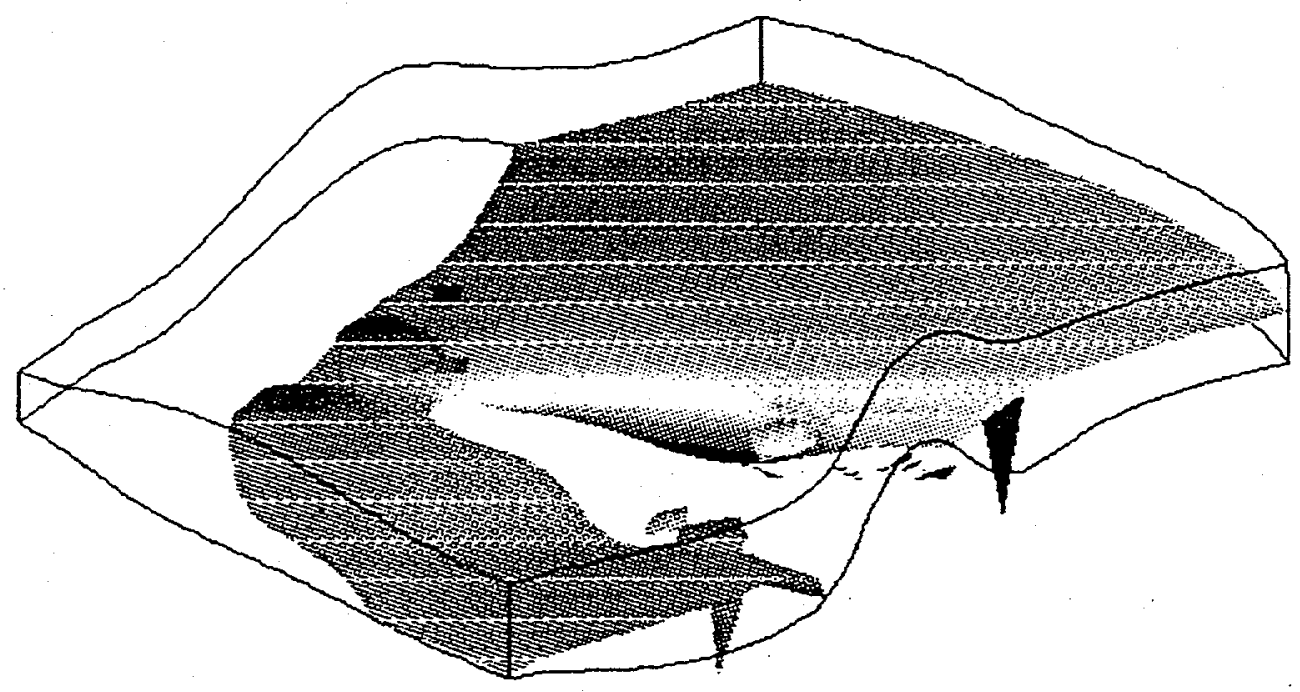

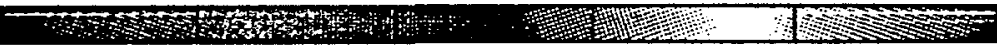

$\begin{array}{llllll}-5.4 & -4.6 & -3.9 & -3.2 & -2.4 & -1.7\end{array}$


(d)

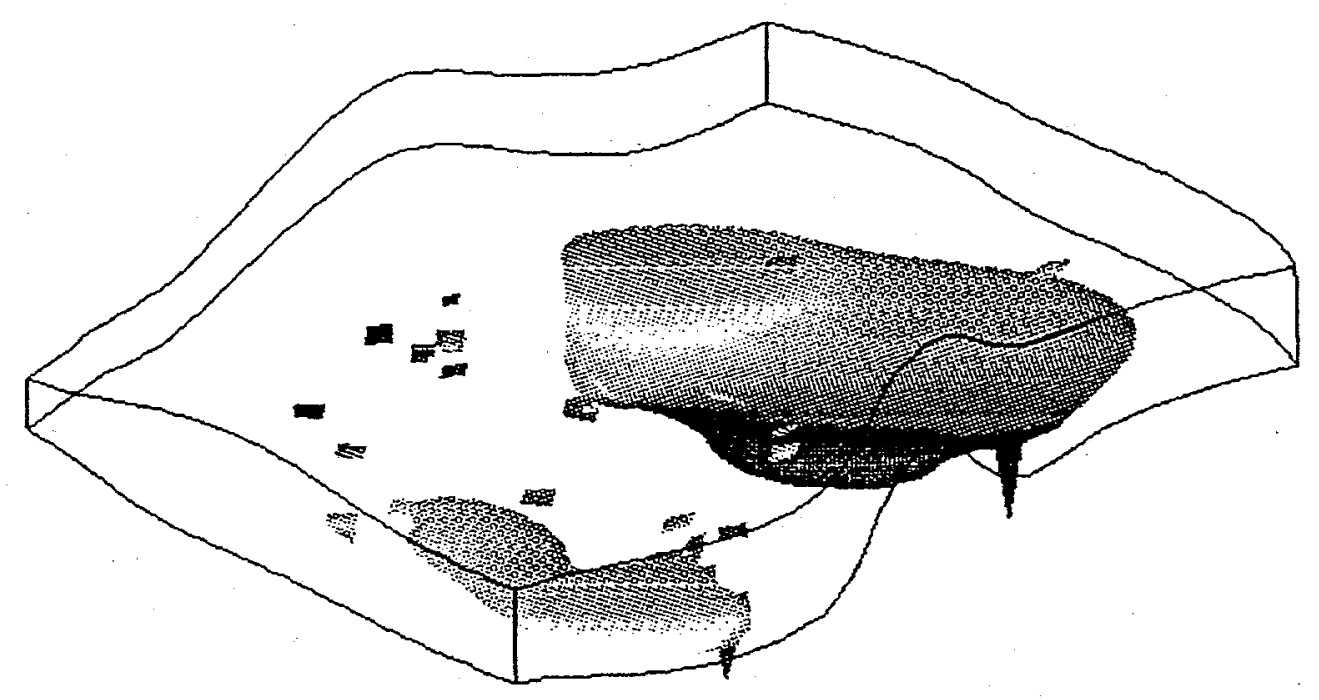

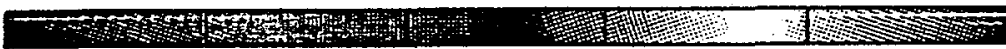
$-5.4$
$-4.7$
$-3.9$
$-3.2$
$-2.5$
$-1.7$ 


\title{
Naturally Fractured
}

Tight Gas Reservoir

Detection Optimization

\author{
Appendix E
}

\author{
Preliminary \\ Piceance Basin \\ Simulation
}

J.M. Maxwell, A. Park, D. Payne and P. Ortoleva Laboratory for Computational Geodynamics Department of Chemistry

Indiana University Bloomington IN 47405 


\section{Overview}

A variety of simulations are being carried out to test various aspects of the CIRF.B basin simulator being used and extended for the present study. These simulations are described briefly below. They are a preparation for the final objective of this project predicted maps of the fracture network distributions in the Piceance Basin.

\section{Preliminary Piceance Basin Simulations}

Simulations of the Piceance Basin using the CIRF.B three dimensional simulator are being conducted. Initial simulations use a simplified quartz and water chemistry, constant grain size, and simplified burial and thermal histories. The three dimensional domain used was designed to capture the shape of the basin as determined from our sediment history reconstruction data set (see earlier quarterly reports for further detail on this data set).

Preliminary results show that grain size affects the development of fluid pressure compartments and hydro-fracturing. Figs. E1(a-b) are cross sections through the threedimensional simulation domain, along an east-west transect in the central part of the basin. Generally, finer-grained systems are more likely to develop abnormal pressure compartments and fracturing (Fig. E1(b)). Furthermore, because of their higher matrix permeability, coarser-grained systems may also develop abnormal pressures, but the pressure gradients are not as steep, making the boundaries between fluid pressure regimes more diffuse (Fig. E1(a)). It is interesting to note that even without grain size variation (i.e. sedimentary features imposed at deposition), overpressuring may develop a patchy distribution, as shown in Fig. E1(b). With more detailed accounting of sedimentary 
features specific to the Piceance Basin, we believe that the model will predict an even more irregular distribution of abnormal pressures, like that demonstrated in the TBEG data.

Fig. E1(b) also shows that in a system bearing fine silt-sized grains such as this simulation, significant permeability may be created as a result of hydro-fracturing. The greatest permeability correlates well with the largest fracture radius. This is significant as permeability and porosity in the Upper Cretaceous units of the Piceance Basin are believed to be fracture controlled.

In the future, work will proceed on making the simulations more realistic by constraining the input with more complete lithologic, burial rate and thermal history data, as developed earlier during this project.

\section{Effect of Lithologic Variation on Compartmentation}

A simulation was cartied out on the monomineralic (quartz) problem using a $\pm 50 \%$ variation in grain size to illustrate the effect of lithologic variation on abnormal pressuring and compartmentation. The most interesting finding is that even in the presence of bedding, compartment geometry can have a strongly autonomous (self-organized) character.

A cross-section of a basin is shown in Fig. E2(a) after 29 my of deposition and diagenesis. Note the variation of overpressure. This double maximum feature has interesting three dimensional implications, as suggested in Fig. E2 (b-c). Map views are seen in Figs. E2(d-e), colored for depth. A similar map shows permeability isosurface of 3 Darcy. These results show the complexity of fracture-defined compartmentation in systems with bedded lithologic variation. 


\section{Cooling and Overpressure Decline/ Underpressuring}

The widespread underpressuring in the Piceance Basin presents another challenge for basin modeling. To test CIRF.B in this context we simulated a case wherein the heat flux at the bottom decreased from an equivalent $45^{\circ} \mathrm{C} / \mathrm{km}$ to $15^{\circ} \mathrm{C} / \mathrm{km}$ in 100 my. During the first 20 my the grain size input was $0.7 \mathrm{~mm}$. From 20 to 30 my this was reduced to $0.05 \mathrm{~mm}$. After 30 my sedimentation was essentially zero.

In Fig. E3(a-e) is shown contour colored maps of permeability, grain height and overpressure. At 30 my a large overpressured zone is observed. The pressuring mechanism here and throughout is by compaction and fluid $\left(\mathrm{H}_{2} \mathrm{O}\right)$ thermal expansion. In late periods (see $30,50,65$ and 100 my) the overpressure declines and ultimately a large spatial scale underpressured zone is created.

\section{Multi-Mineralic Effects on Overpressure}

We have been testing the mineralogy effects on overpressure generation and other aspects of basin dynamics. Fig. E4 shows a set of characteristic variables after 30 my of simulated deposition and subsidence. Frame (a) shows the depth-colored iso-overpressure surface. Frames (b-d) are maps of porosity, quartz mode and muscovite mode on a surface approximately 250 meters from the bottom of the basin. Frames (e-g) show the three dimensional version of frames (b-d).

Variations in mineralogy lead to corresponding variations in porosity and permeability. Thereby the mineral mode variations affect the spatial distribution of overpressure and hence of fracturing. These variations also affect mechanical properties and hence stress. The latter is also affected by fluid pressure and, through fracturing and pressure solution, affects pressure. 

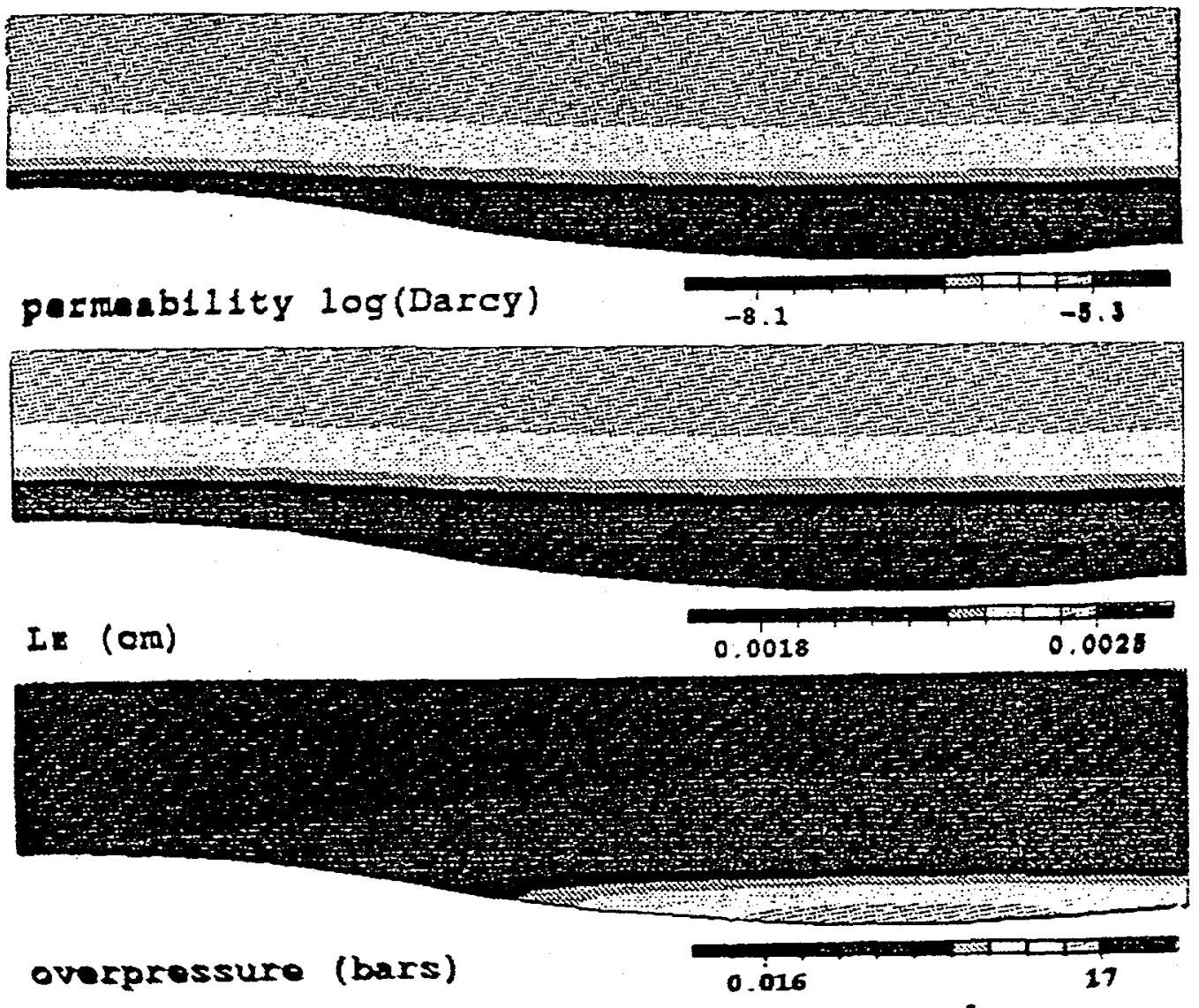

\section{ORX}

Fig. E1(a) Cross section through the three dimensional simulation domain at $50 \mathrm{my}$. Grain size is $.0025 \mathrm{~cm}$. No hydrofractures have developed.

Overpressuring is limited in extent and the maximum value is relatively low. 

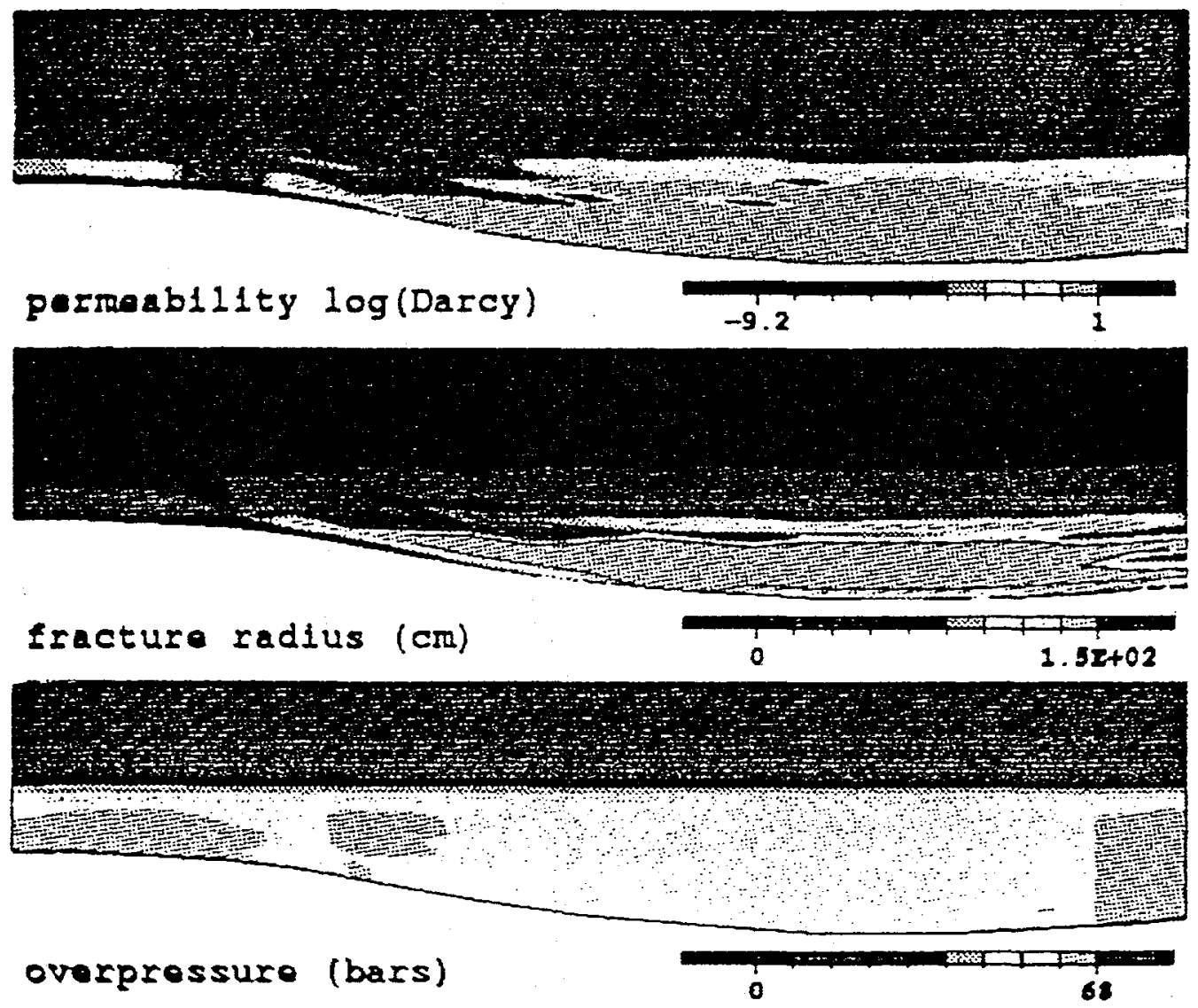

\section{$50 \mathrm{NY}$}

Fig. E1(b) Same as in Fig. E1(a), except that grain size is $.001 \mathrm{~cm}$. Hydro-fracturing has developed, and results in significant increase in permeability. A large overpressured compartment at the bottom of the basin is separated by a high pressure gradient zone. Pressure distribution in this compartment is patchy. The difference between case El(a) and El(b) illustrates the importance of developing an accurate sedimentary history for accurate fractured reservoir prediction. 

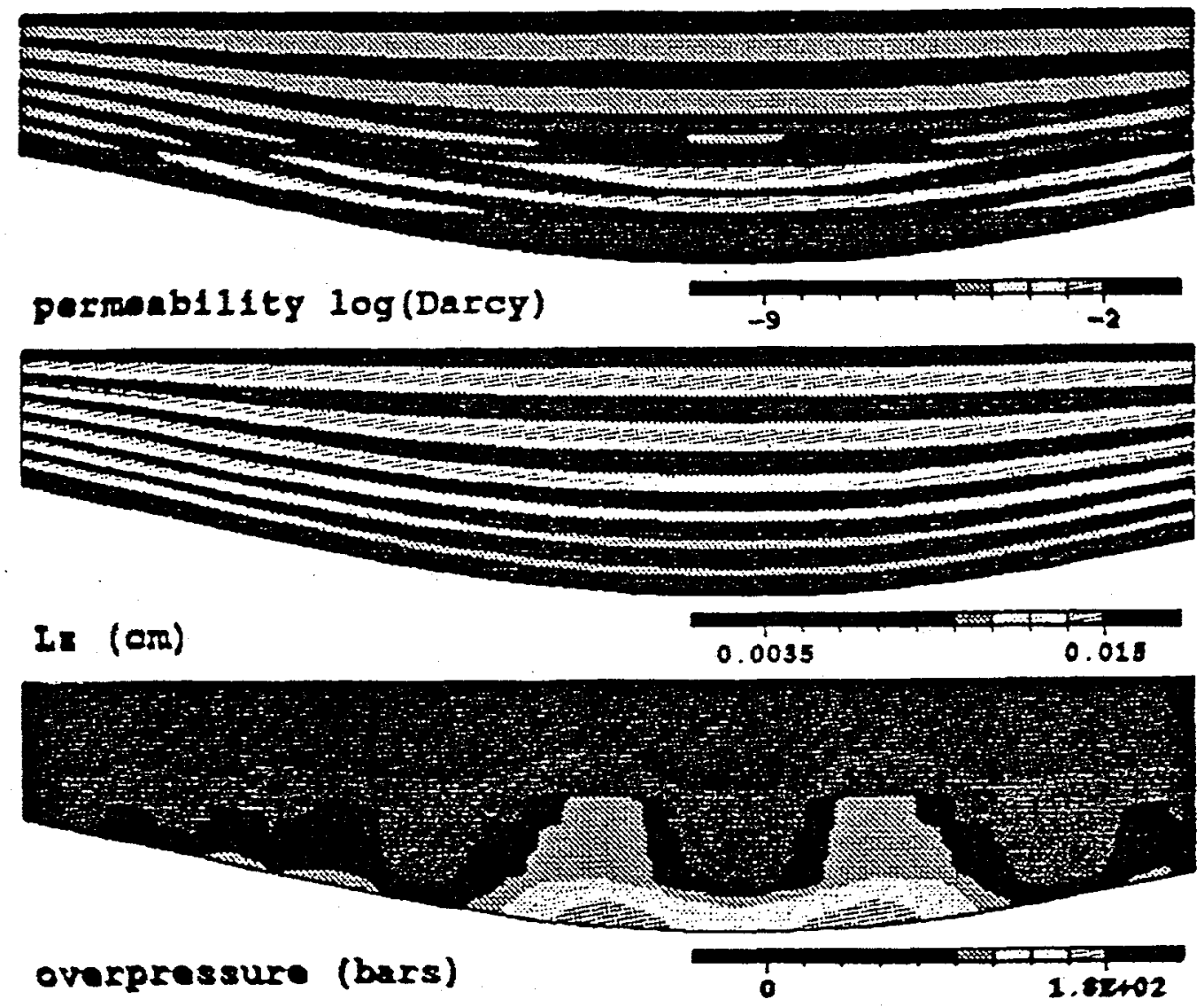

\section{$291 \times$}

Fig. E2(a) 

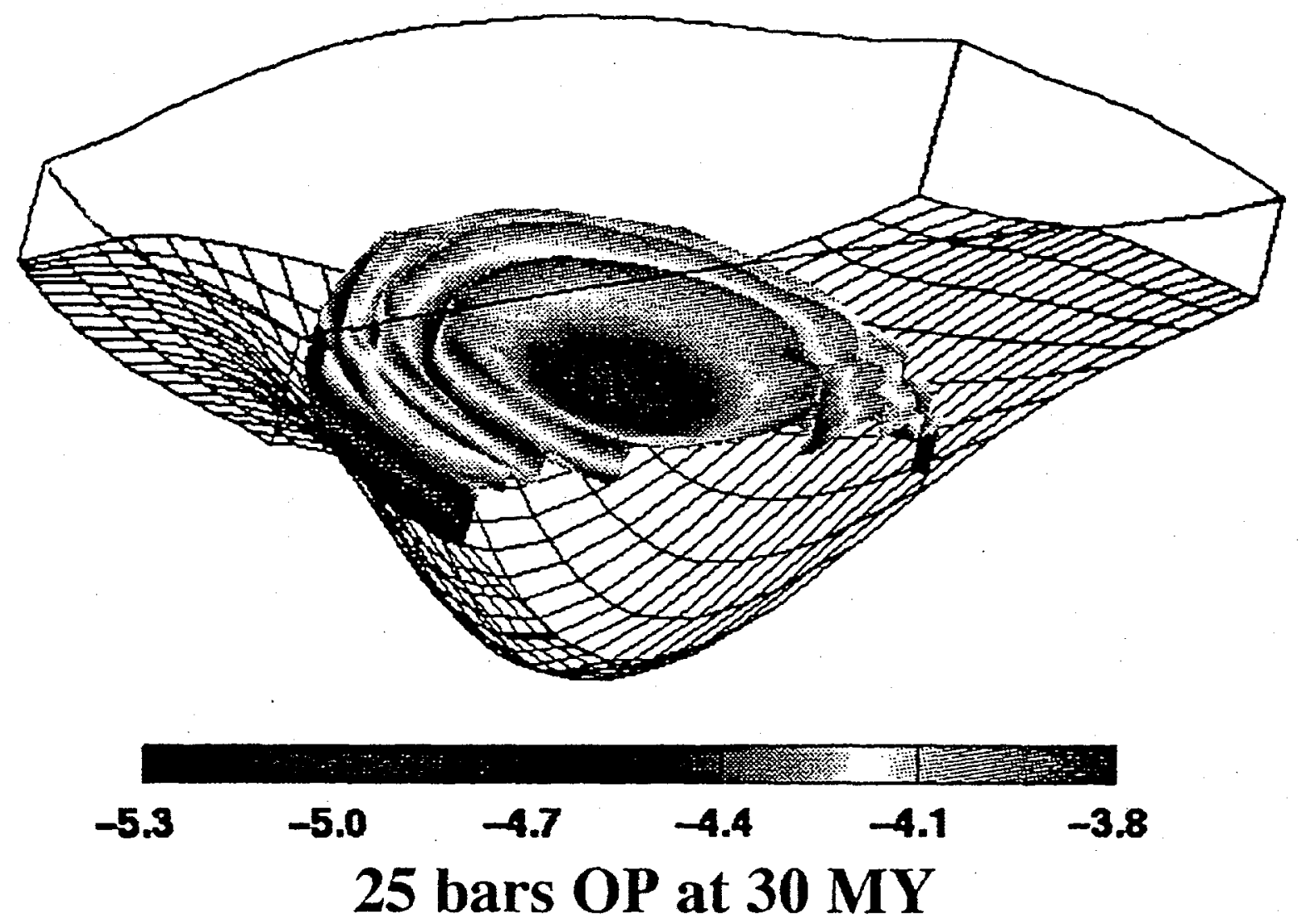

Fig. E2(b) 

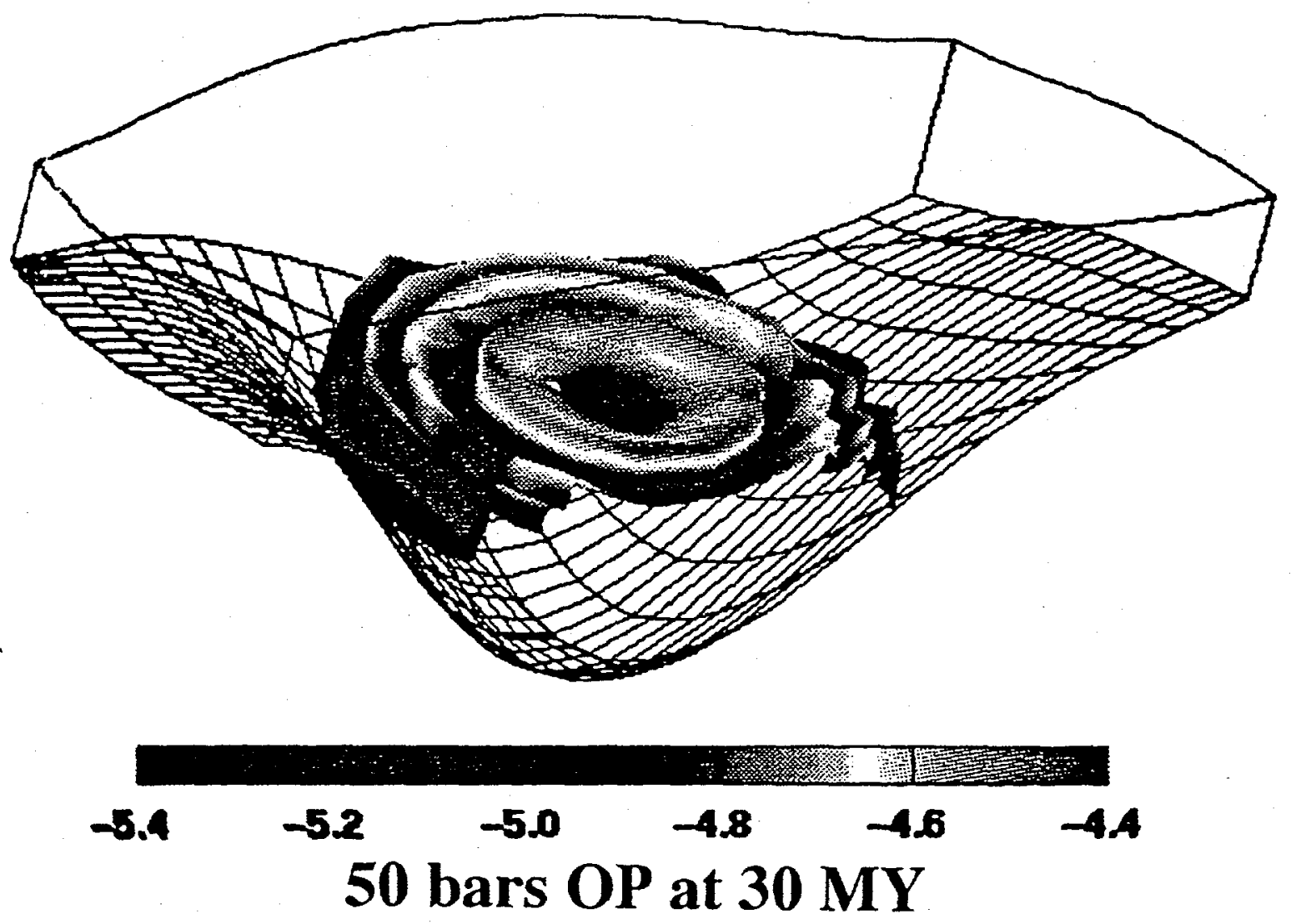

Fig. E2(c) 

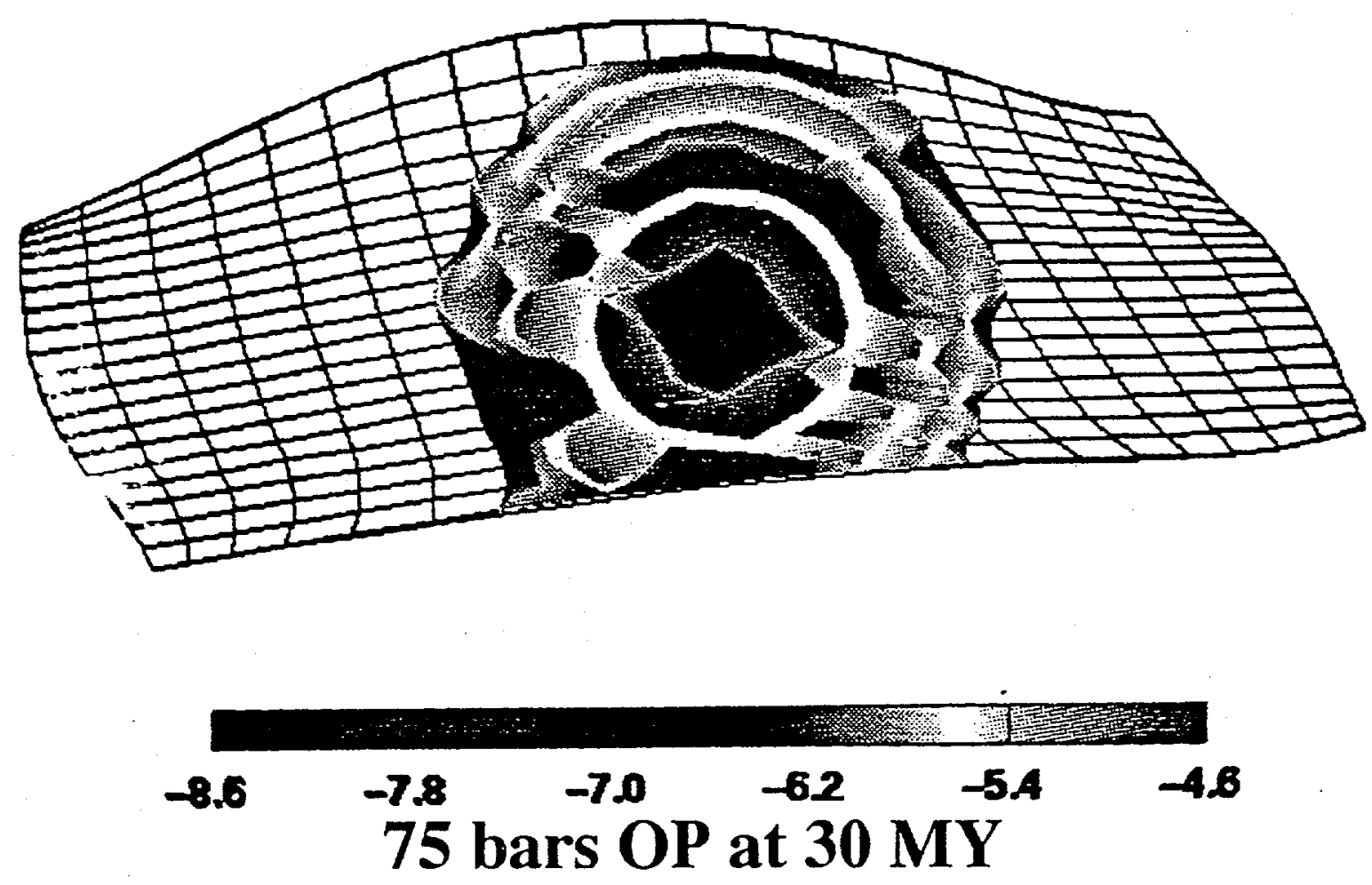

Fig. E2(d) 

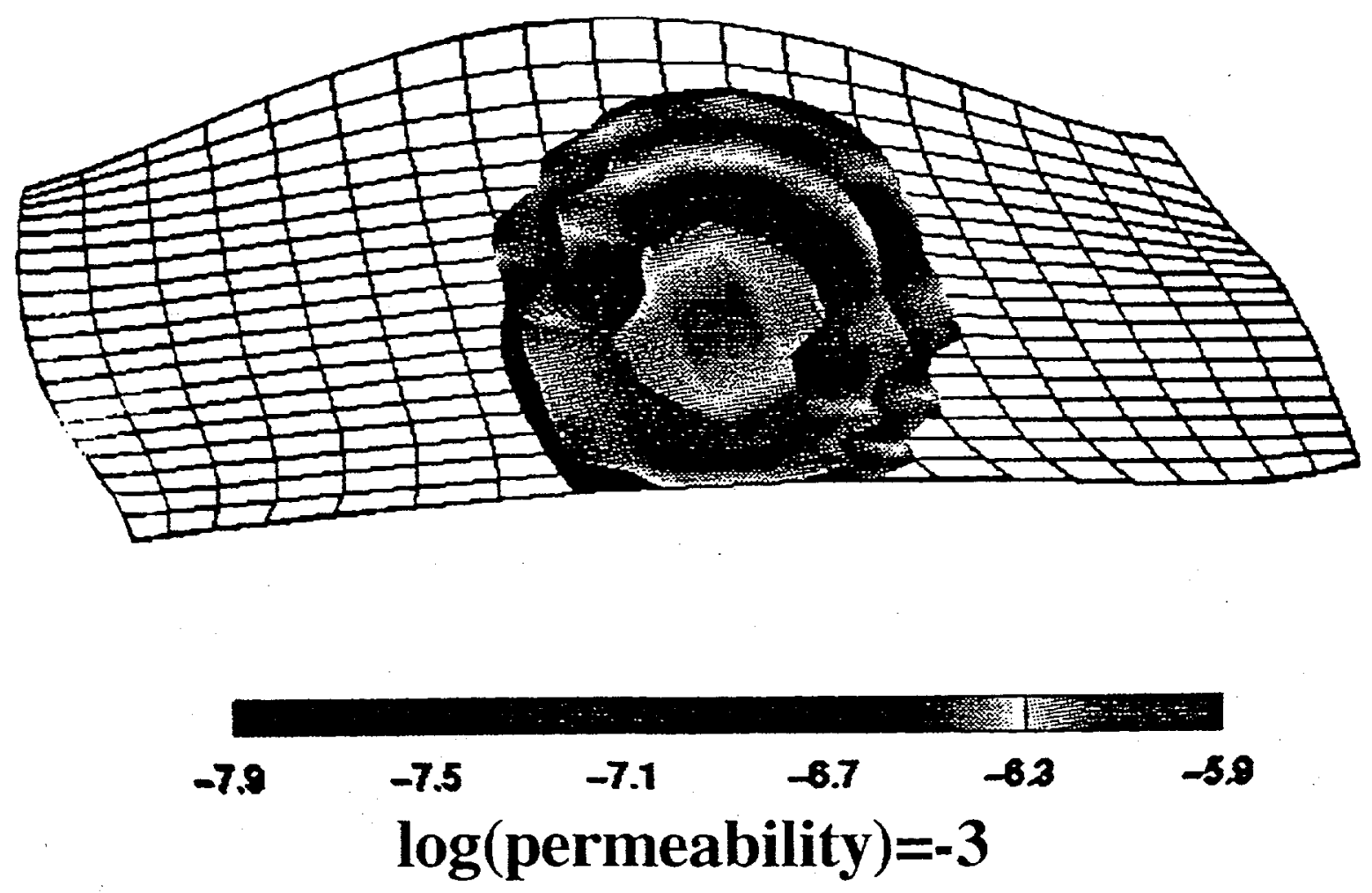

Fig. E2(e) 


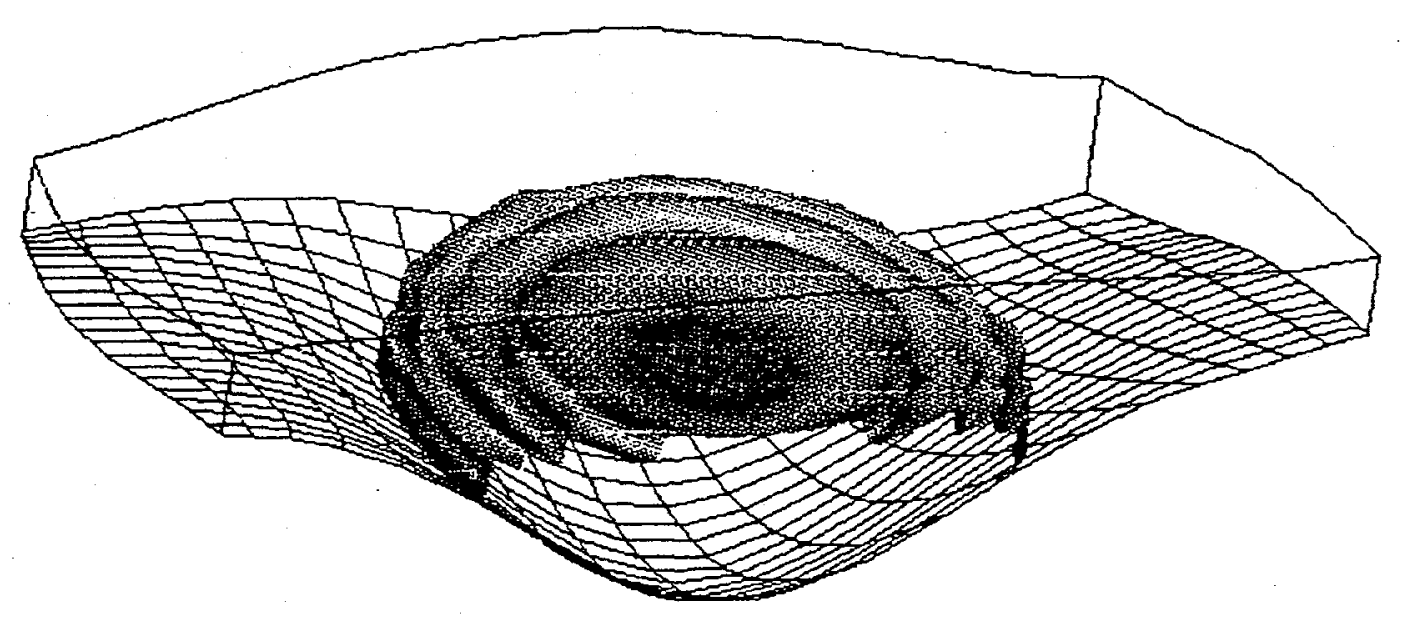

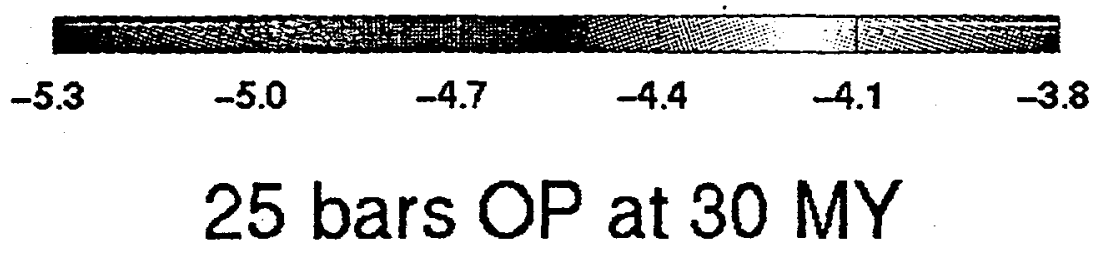

Fig. E3(a) 


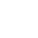

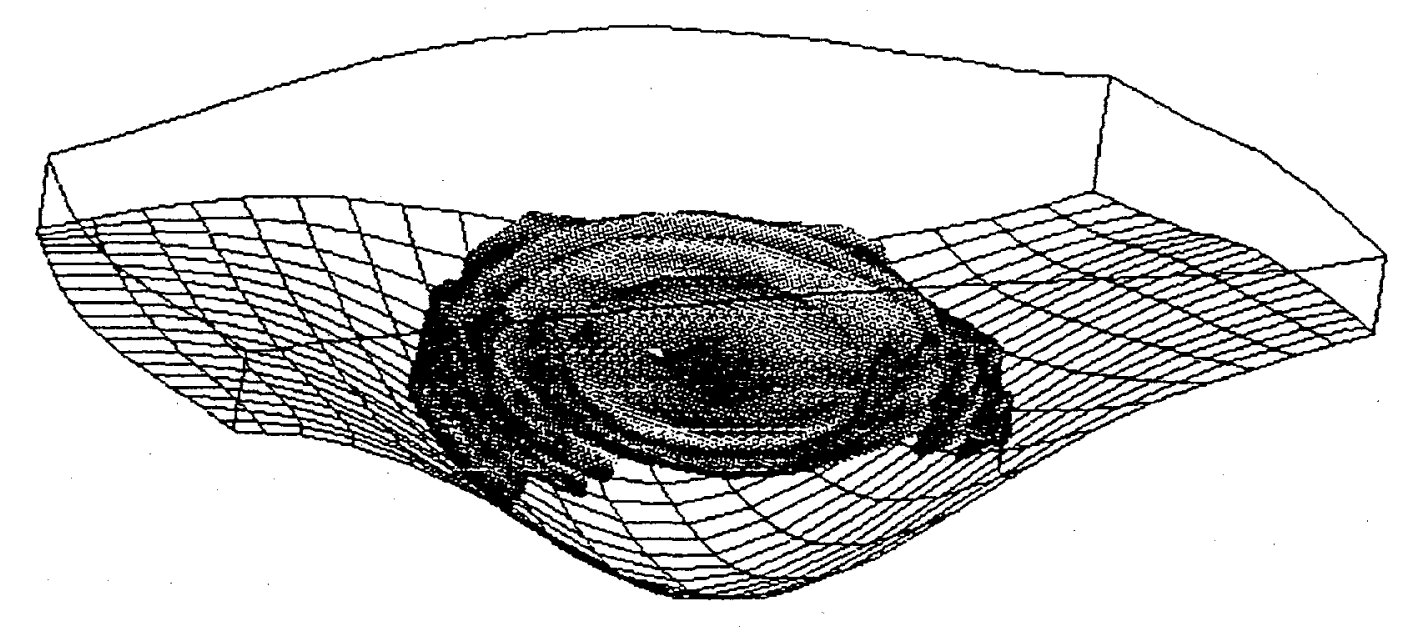

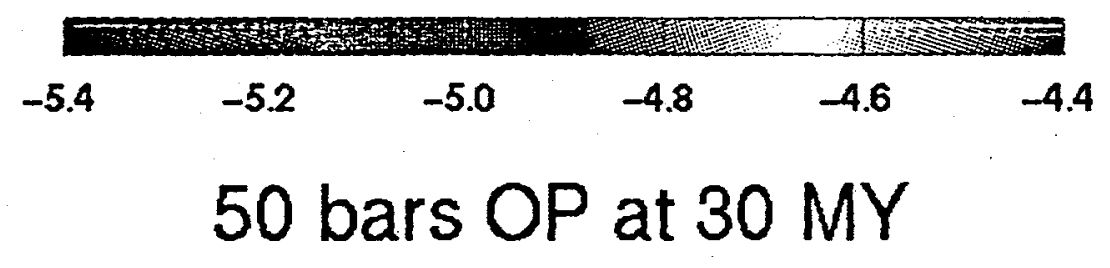

Fig. E3(b) 


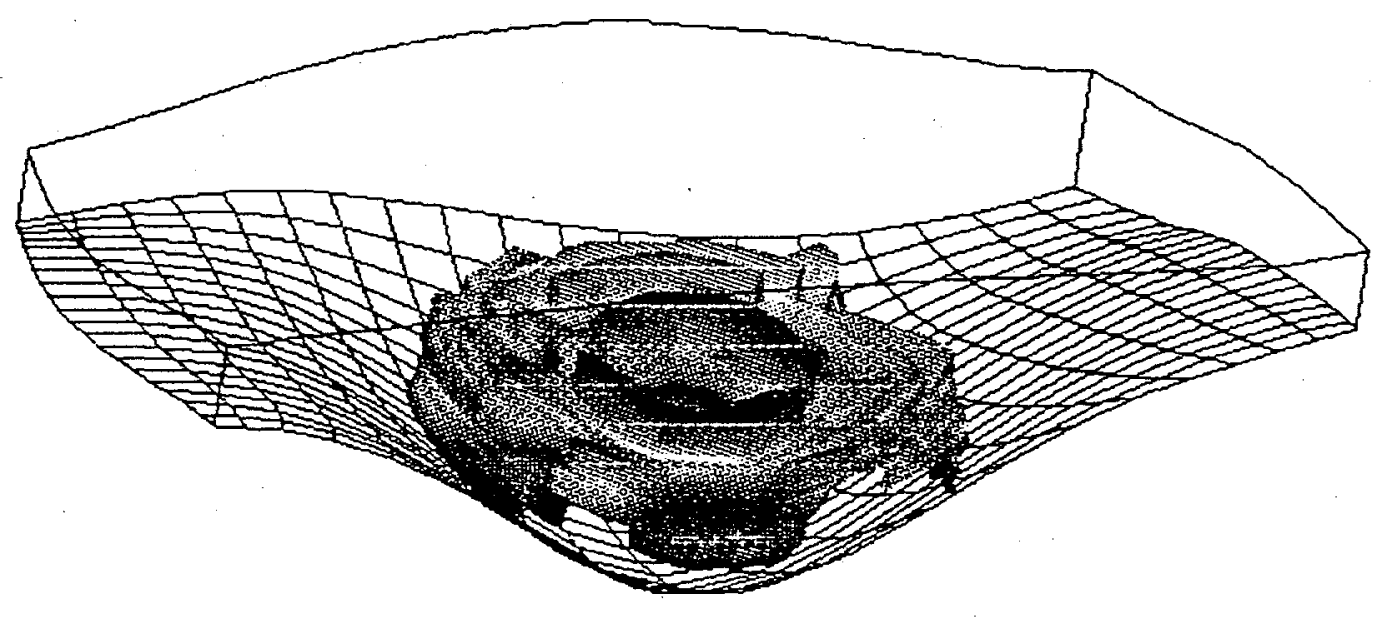

\begin{tabular}{|c|c|c|c|c|c|}
\hline & 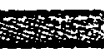 & & 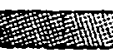 & & \\
\hline-8.6 & -7.8 & -7.0 & -6.2 & -5.4 & \\
\hline
\end{tabular}

Fig. E3(c) 


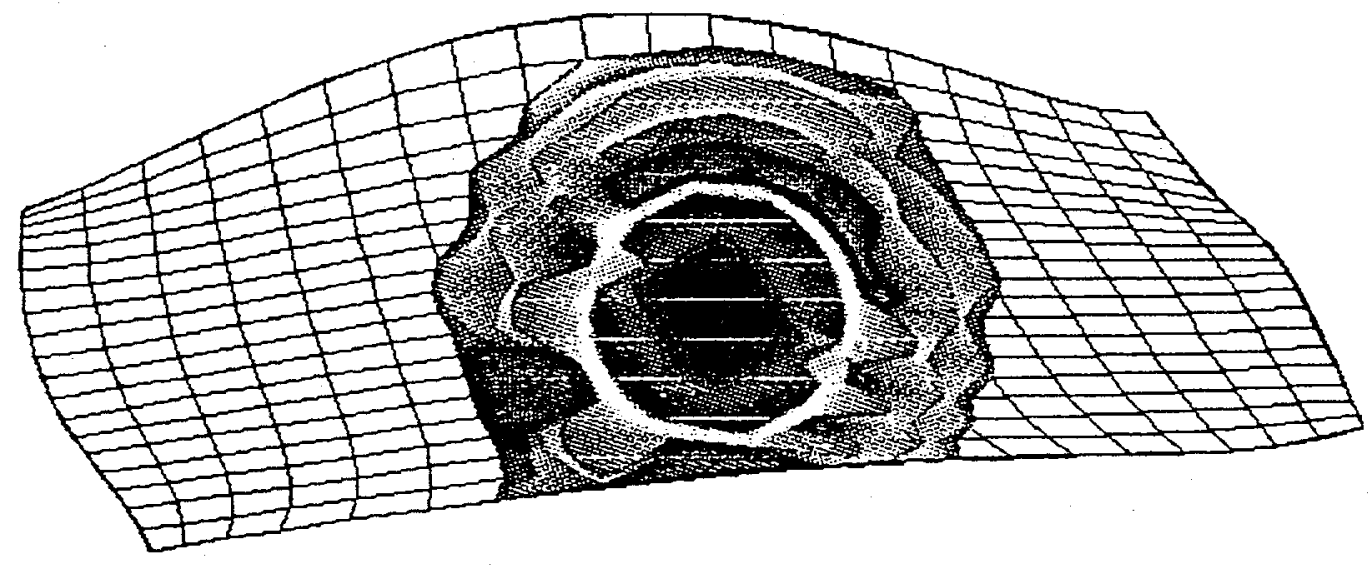

\begin{tabular}{cccccc}
\hline-7.6 & -7.8 & -7.0 & -6.2 & -5.4 & -4.6 \\
-8.6 & 75 & bars OP at $30 \mathrm{MY}$ &
\end{tabular}

Fig. E3(d) 


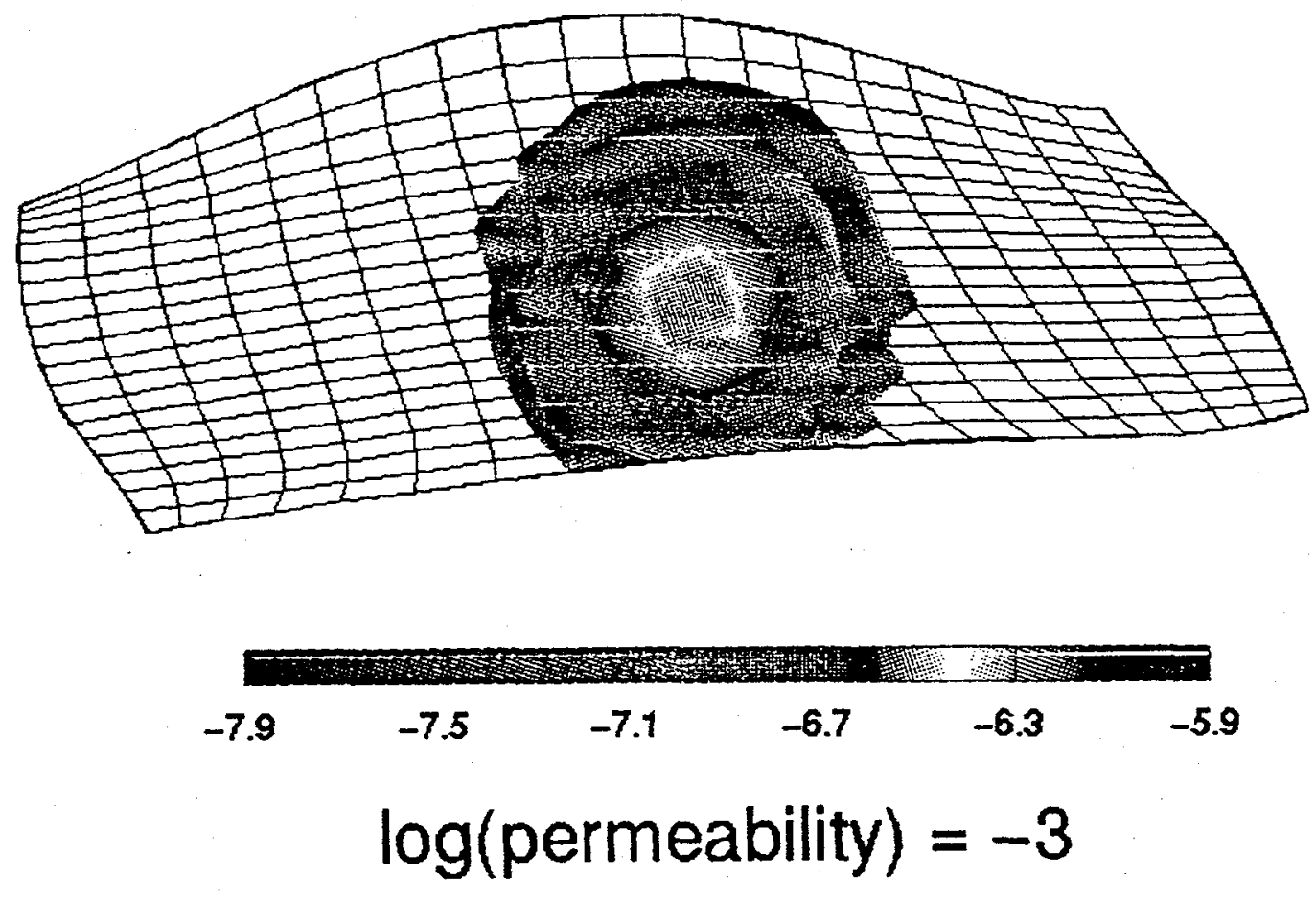

Fig. E3(e) 
(a)

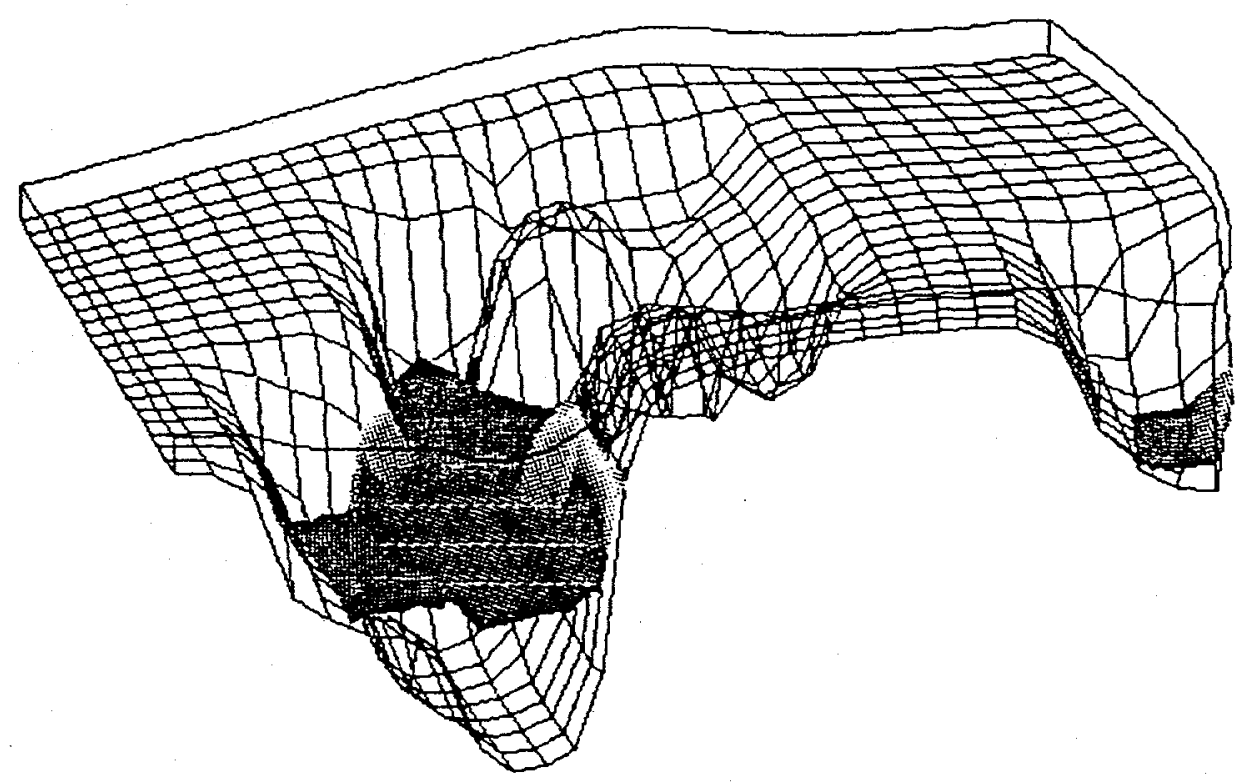

Fig. E4 CIRF.B simulation results at 38 my showing (a) fluid pressure $(b, e)$ porosity, $(c, f)$ modes of quartz, and $(d, g)$ muscovite. In (a) the surface shown represents the isosurface of approximately 50 bars of overpressure, produced from the thermal expansion of water and the chemical compaction of the sediment composed of quartz and muscovite grains of very fine sand grain sizes. The varying color indicates the depth of the isosurface. The map views of porosity (b) and modes of quartz (c) and muscovite (d) are evaluated at the surface of the sediment slightly above the bottom surface of the basin, as can be seen from the three dimensional representations of the same variables in $(e, f, g)$. Except in the deeper basin regions, the differences in the colors of the mineral modes and the porosity reflect the varying sediment types in those regions. The maximum size of the basin is $130 ¥ 150 \mathrm{~km}$, with the maximum depth of the basin at $1.1 \mathrm{~km}$. The vertical exaggeration of 5 is used for the three dimensional figures. 
(b)

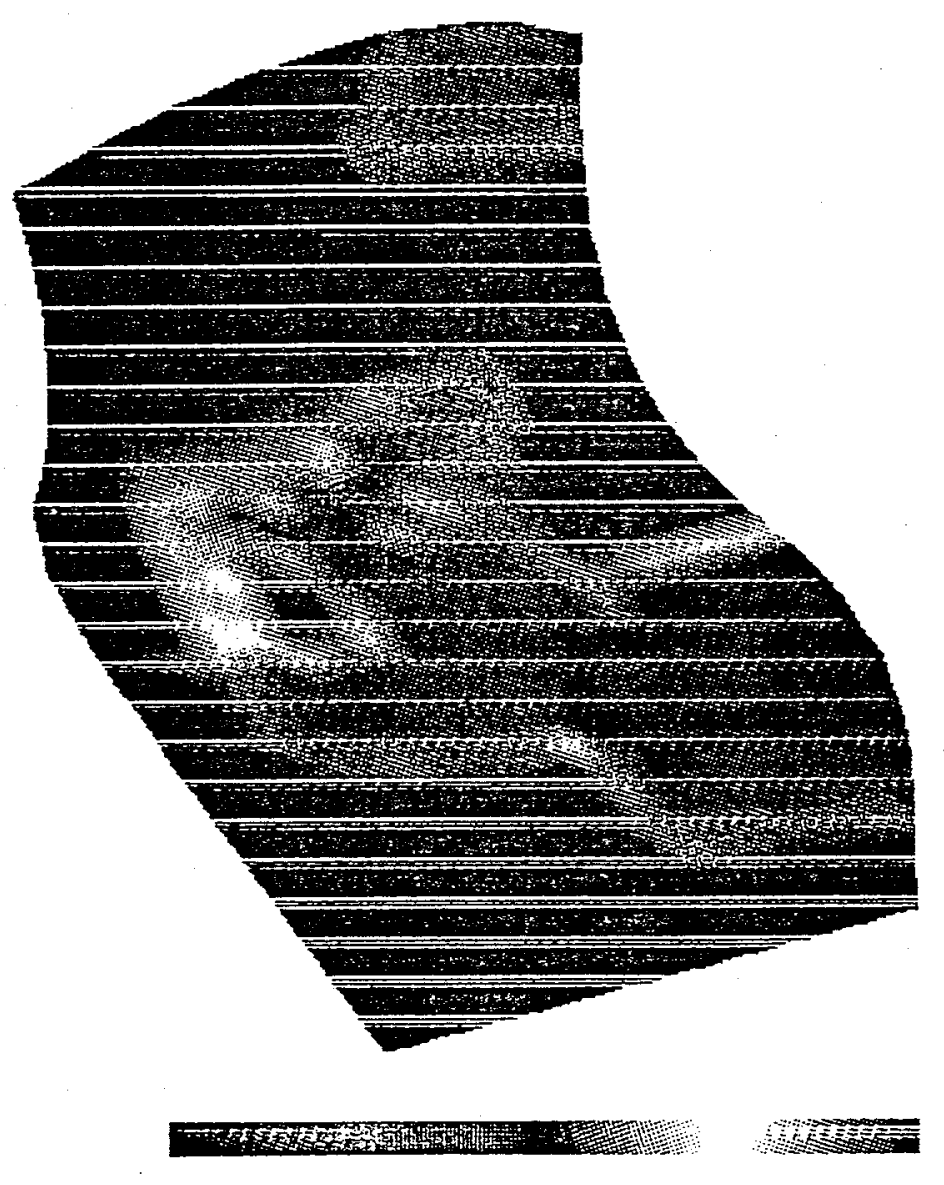

0.05

0.25 
(c)

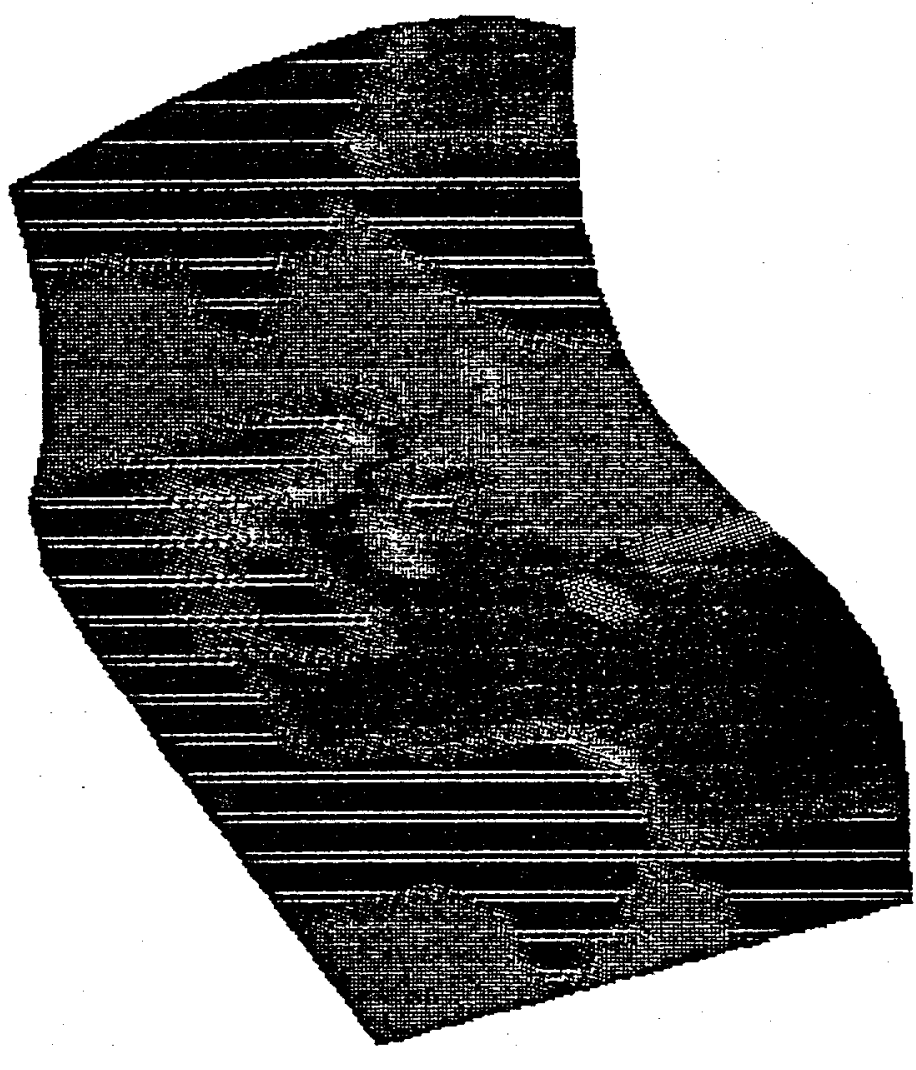

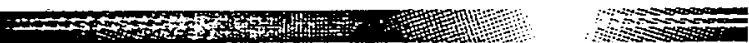

0.61 
(d)

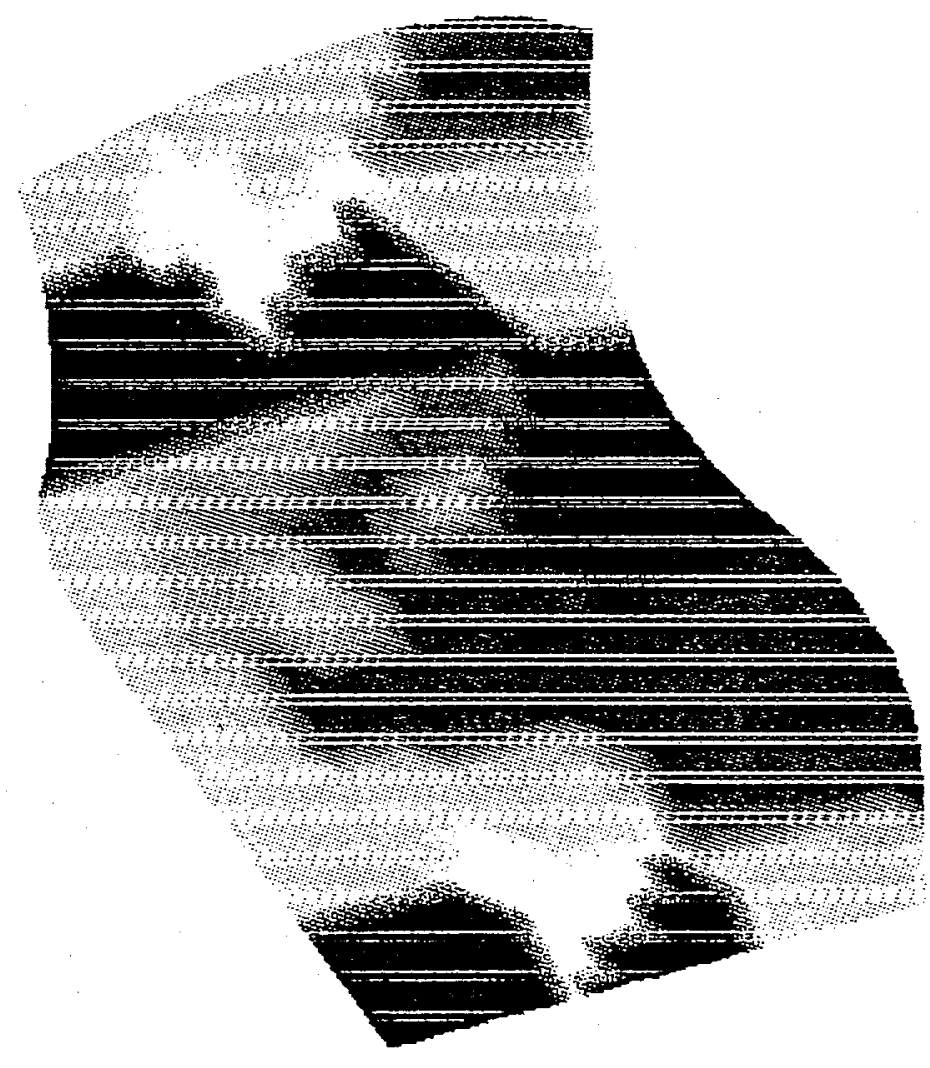

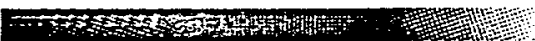

WhES

0.0

0.17 
(e)

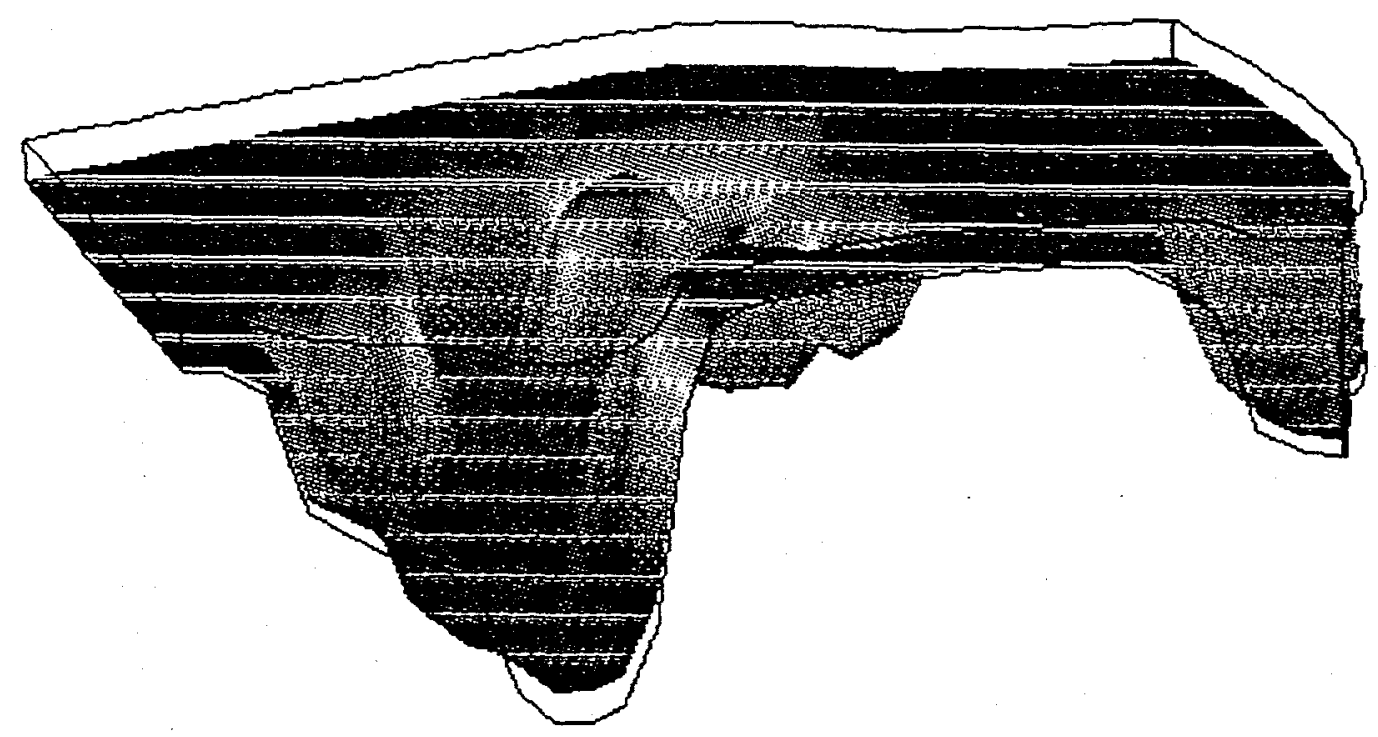

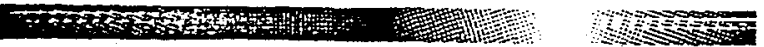

0.05

0.25 
(f)

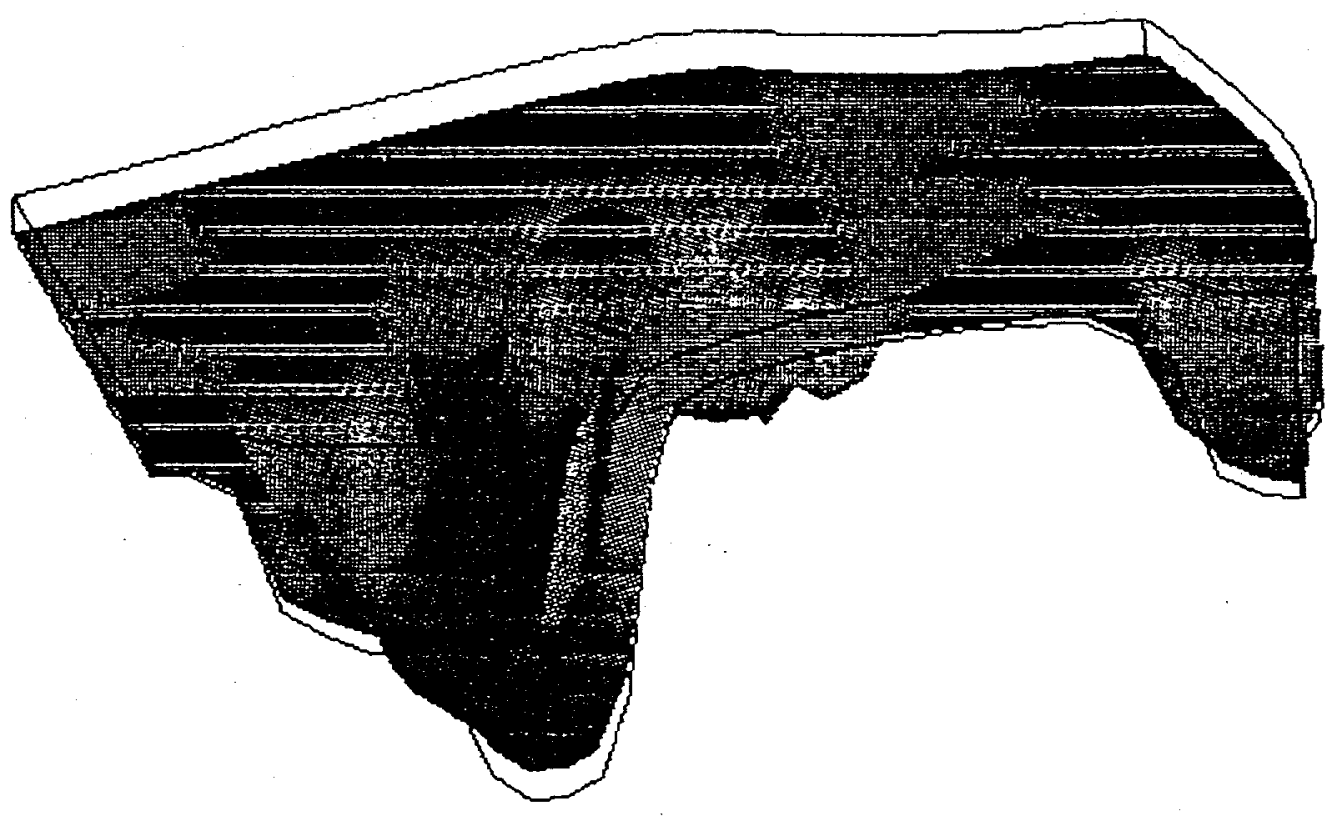

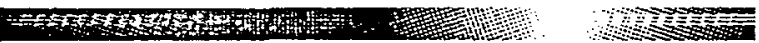


(g)

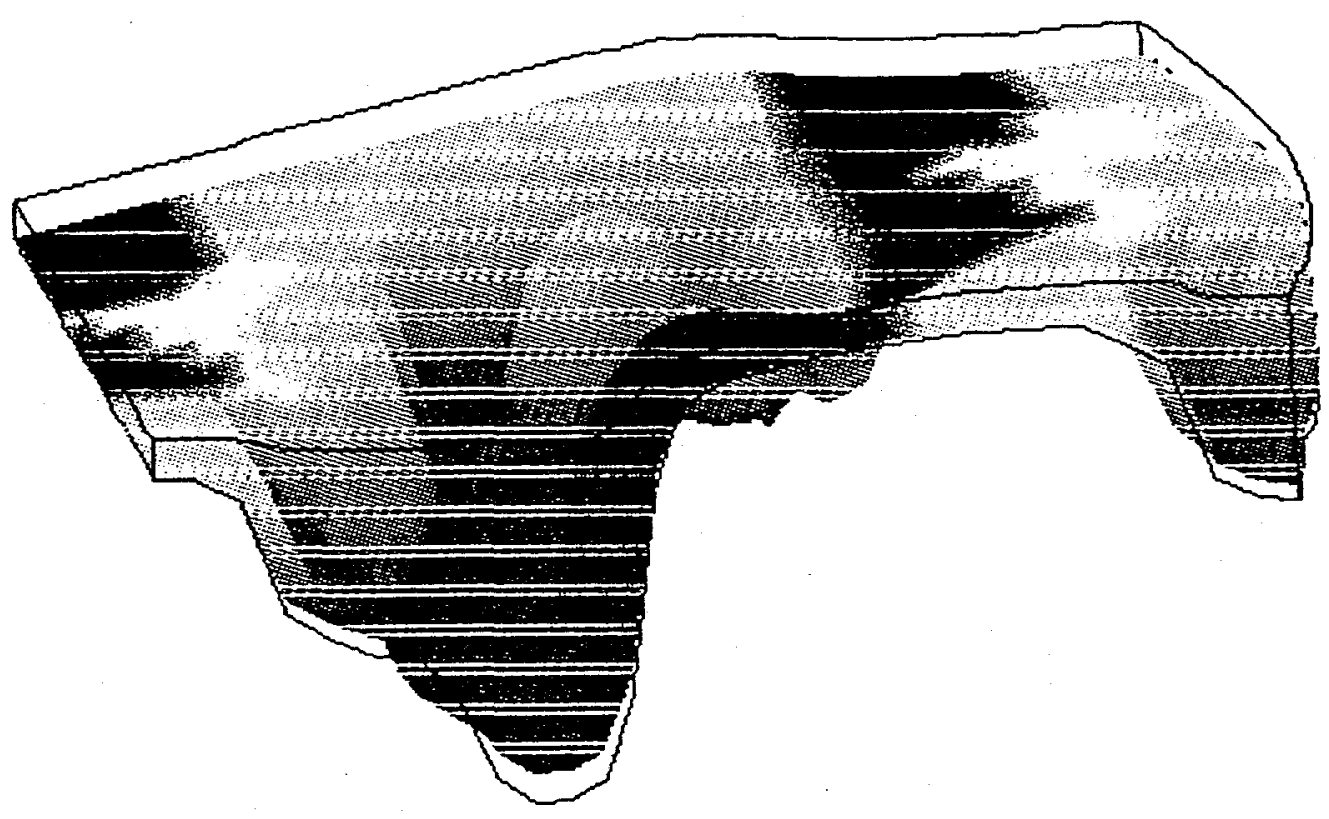

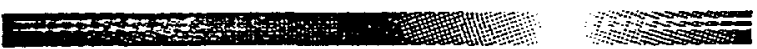

0.0

0.17 


\section{References}

Collins, B.A. (1976) Coal deposits of the Carbondale, Grand Hogback and Southern Danforth Hills coal fields, eastern Piceance Basin, Colorado: Quarterly Report of the Colorado School of Mines 71 (1).

DeLeeuw, J.W. and C. Largeau (1993) A review of macro-molecular organic compounds that comprise living organisms and their role in kerogen, coal and petroleum formation, in Organic Chemistry. Principles and Applications, M.M. Engel and S.A. Macko, eds., New York, Plenum Press, 23-72.

Johnson, R.C. and V.F. Nuccio (1986) Structural and thermal history of the Piceance Creek Basin, western Colorado, in relation to hydrocarbon occurrence in the Mesaverde Group, in C.W. Spencer and R.F. Mast, eds., Geology of Tight Gas Reservoirs, AAPG Studies in Geology 24, 165-205.

Johnson, R.C. and V.F. Nuccio (1989) Surface vitrinite reflectance study of the Uinta and Piceance Basins and adjacent areas, eastem Utah and western Colorado - Implications for the development of Laramide basins and uplifts, U.S. Geological Survey Bulletin 1787-DD.

Kaiser, W.R. and A.R. Scott (1996) Hydrologic setting of the Williams Fork Formation, Piceance Basin, Colorado, in Geologic and Hydrologic Controls Critical to Coalbed Methane Producibility and Resource Assessment: Williams Fork Formation, Piceance Basin. Northwest Colorado, GRI Topical Report, GRI-95/0532.

Law, B.E., V.F. Nuccio and Barker, C.E. (1989) Kinky vitrinite reflectance profiles Evidence of paleopore pressure in low-permeability gas-bearing sequences in Rocky Mountain foreland basins, AAPG Bulletin 73, 999-1010.

Lorenz, J.C. (1985) Tectonic and stress histories of the Piceance Creek Basin and the MWX site, from 75 m.y.a. to present, Sandia National Laboratories report SAND842603,UC-92.

Mason, E. and R. Ehrlich (1995) Automated, quantitative assessment of basin history from a multiwell analysis, AAPG Bulletin 79 (5), 711-724.

Morrow, D.W. and D.R. Issler (1993) Calculation of vitrinite reflectance from thermal histories: A comparison of some methods, AAPG Bulletin 77, 610-624.

Nuccio, V.F. and R.C. Johnson (1989) Variations in vitrinite reflectance values for the Upper Cretaceous Mesaverde Formation, southeastern Piceance Basin, northwestern Colorado - Implications for burial history and potential hydrocarbon generation, U.S. Geological Survey Bulletin 1787-H.

Ortoleva, P. (1994a) Geochemical Self-Organization, New York, Oxford University Press.

Ortoleva, P., ed. (1994b) Basin Compartments and Seals, AAPG Memoir 61.

Ortoleva, P. (1996) Basin Compartments, in preparation. 
Ortoleva, P., J.M. Maxwell, D. Payne, C.Qin, W. Sibo, F. Tounsi and J. Comer (1996) Predicting fractured reservoir location and characteristics: A basin modeling approach, in Fractured Reservoirs: Identification, Characterization and Prediction, Rocky Mountain Association of Geologists, in press.

Powley, D. (1990) Pressures and hydrogeology in petroleum basins, in Self-Organization in Geological Systems: Proceedings of a Workshop held 26-30 June 1988. University of California at Santa Barbara, P. Ortoleva, B. Hallet, A. McBirney, I. Meshri, R. Reeder and P. Williams, eds., Earth Science Reviews 29, 215-226.

Reinecke, K.M., D.D. Rice and R.C. Johnson (1991) Characteristics and development of fluvial sandstone and coalbed reservoirs of Upper Cretaceous Mesaverde Group, Grand Valley Field, Colorado, in Coalbed Methane - 1991, Rocky Mountain Association of Geologists, 209-225.

Rightmire, C.T. and R. Choate (1986) Coal-bed methane and tight gas sands interrelationships, in Geology of Tight Gas Reservoirs, AAPG Studies in Geology 24, 87-110.

Suzuki, N., H. Matsubayashi and D.W. Waples (1993) A simpler kinetic model of vitrinite reflectance, $A A P G$ Bulletin $77,1502-1508$.

Sweeney, J.J. and A.K. Burnham (1990) Evaluation of a simple model of vitrinite reflectance based on chemical kinetics, AAPG Bulletin 74, 1559-1570.

Tyler, R. and R.G. McMurry (1995) Genetic stratigraphy, coal occurrence and regional cross section of the Williams Fork Formation, Mesaverde Group, Piceance Basin, Northwestern Colorado, Colorado Geological Survey Open File Report 95-2.

Tyler, R., W.R. Kaiser, R.G. McMurry, H.S. Nance, A.R. Scott, N. Zhou and C.M. Tremain (1995) Geological characterization and coalbed methane occurrence: Williams Fork Formation, Piceance Basin, northwest Colorado, Gas Research Institute Annual Report GRI-94/0456.

United States Geological Survey (1994) Coal Quality Database, Version 1.3, U.S.G.S. Open File Report \#94-205.

Young, R.G. (1966) Stratigraphy of coal-bearing rocks of the Book Cliffs, UtahColorado, Utah Geological and Mineralogical Survey Bulletin 80, 7-20. 